\title{
PROBLEMAS Y DESAFÍOS DE LA MINERÍA DE ORO ARTESANAL Y EN PEQUEÑA ESCALA EN COLOMBIA*
}

\author{
FREDDY HERNÁN PANTOJA TIMARÁN"* \& SEBASTIÁN DAVID PANTOJA BARRIOS *"* \\ UNIVERSIDAD DE NARIÑO
}

Recibido/Received/ Recebido: 21/05/2015 - Aceptado/ Accepted/ Aprovado: 08/03/2016

\section{Resumen}

\begin{abstract}
El objetivo del presente artículo de reflexión es analizar brevemente las condiciones sociales, políticas, económicas, tecnológicas y ambientales de la minería artesanal y en pequeña escala (MAPE) del oro en Colombia. Este análisis se sustenta en la experiencia de los procesos de planificación, gestión y ejecución de proyectos de intervención minero ambiental, por más de treinta años, en la zona minera de Nariño; así como con el intercambio de experiencias y conocimientos con expertos en otras zonas mineras de Colombia y en distintos países de América Latina donde se desarrolla la MAPE del oro. A partir de lo anterior, se expone un marco para la estructuración de una política pública integral para el desarrollo sostenible y responsable de esta actividad, basada en la implementación de procesos de formalización minera, en el acceso a tecnologías más eficientes y ambientalmente responsables, y en el mejoramiento de las condiciones sociales, de salud pública y de trabajo en las comunidades que ejercen la MAPE del oro tradicional en Colombia.
\end{abstract}

Palabras clave: Minería en Colombia; MAPE; Minería de oro; Formalización minera.

\section{ARTISANAL AND SMALL-SCALE GOLD MINING IN COLOMBIA. PROBLEMS AND CHALLENGES}

\begin{abstract}
The aim of this article is to briefly analyze social, political, economic, technological and environmental conditions of artisanal and small-scale gold mining (ASGM) in Colombia. This analysis is based on the planning, management and implementation experience of environmental mining intervention projects, for over thirty years in the mining area of Nariño; as well as the exchange of experiences and knowledge with experts in other mining areas in Colombia and other Latin American countries where ASGM develops. From the above, a framework for structuring a comprehensive public policy for sustainable and responsible development for this activity, based on the implementation process of mining formalization, access to more efficient and environmentally responsible technologies is exposed, and in improving social, public health and working conditions in communities practicing traditional ASGM in Colombia.

Keywords: Mining in Colombia; ASM; Gold mining; Mining formalization.
\end{abstract}

Artículo de reflexión derivado del proyecto titulado: "Ruta del Oro", el cual fue financiado por la Universidad de Nariño entre los años 2014 y 2016.

* Ingeniero de Minas, Master en Contaminación Ambiental, Doctor en Ciencias Químicas y Profesor Asociado de la Universidad de Nariño, Pasto - Colombia. Dirección postal: Universidad de Nariño, Ciudad Universitaria Torobajo, Cll. 18 Cr. 50, Pasto - Nariño (Colombia). Teléfono: 5727 311449. Correo electrónico: fpantojaudenar.edu.co

Economista y Politólogo, Magister en Economía e Investigador de la Universidad de los Andes, Bogotá - Colombia. Correo electrónico: sd.pantoja431@uniandes.edu.co 


\title{
PROBLEMAS E DESAFIOS DA MINERAÇÃO DE OURO ARTESANAL E EM PEQUENA ESCALA NA COLÔMBIA
}

\begin{abstract}
Resumo
O objetivo do presente artigo de reflexão é analisar brevemente as condições sociais, políticas, econômicas, tecnológicas e ambientais da mineração artesanal e em pequena escala (MAPE) do ouro na Colômbia. Esta análise sustenta-se na experiência dos processos de planejamento, gerenciamento e execução de projetos de intervenção mineiro ambiental, por mais de trinta anos, na zona mineira de Nariño, assim como no intercâmbio de experiências e conhecimentos com peritos em outras zonas mineiras da Colômbia e em diferentes países da América Latina onde se desenvolve a MAPE do ouro. Constrói-se um contexto para a estruturação de uma política pública integral para o desenvolvimento sustentável e responsável desta atividade, baseada na implementação de processos de formalização mineira, no acesso a tecnologias mais eficientes e ambientalmente responsáveis, e na melhoria das condições sociais, de saúde pública e de trabalho nas comunidades onde se exerce a MAPE do ouro tradicional na Colômbia.

Palavras chave: Mineração na Colômbia; MAPE; Mineração de ouro; Formalização mineira.
\end{abstract}

Pantoja, F. \& Pantoja, S. (2016). Problemas y desafíos de la minería de oro artesanal y en pequeña escala en Colombia. En: Revista de la Facultad de Ciencias Económica: Investigación y Reflexión. rev.fac.cienc.econ, XXIV (2), DOI: http://dx.doi.org/10.18359/rfce.2217

JEL: L72, Q01.

\section{Introducción}

Históricamente, la producción minera de oro en Colombia se ha realizado en gran medida a través de la minería artesanal y en pequeña escala (MAPE), entendida en un sentido amplio como toda actividad de explotación minera con escasa tecnificación, uso intensivo de mano de obra no calificada y bajos márgenes de producción por yacimiento (Hentschel et al, 2002; Defensoría del Pueblo, 2010). Según el último censo minero colombiano realizado en 2011 , el $72 \%$ de las minas en el país son pequeñas y el 30\% de la producción de éstas corresponde a minería del oro (Ministerio de Minas y Energía, 2012). Adicionalmente, la MAPE del oro ha tenido un papel fundamental en el desarrollo económico y social de múltiples regiones del país, en especial en zonas con escasa presencia estatal y desligadas de los principales sectores productivos colombianos (Martínez \& Aguilar, 2012).

Sin embargo, en la actualidad existe desconocimiento en diversos sectores políticos y académicos respecto a la importancia económica y social de la MAPE del oro en Colombia, ya que continuamente se la equipara con actividades de explotación minera ilegales, las cuales se han elevado sustancialmente en los últimos años, generando grandes impactos sociales y ambientales. De igual manera, la eliminación de la estratificación por escalas de explotación minera con la promulgación del Código de Minas de 2001 dejó en condiciones de ilegalidad a la mayoría de pequeños mineros (el 66\%, según el censo minero), al no poder cumplir con los requisitos de concesión que desde entonces son idénticos para todo aquel que quiera realizar minería en el país. Además, las políticas de formalización minera emprendidas por el Gobierno han resultado ineficaces por el mismo marco normativo que dificulta la adquisición de títulos mineros, así como por la falta de voluntad de distintos sectores a nivel nacional y regional en torno a la legalización por considerar a la MAPE como una actividad productiva con escaso aporte a la economía nacional (Martínez \& Aguilar, 2012; Güiza, 2014). 
A pesar de ello, la MAPE del oro continúa siendo una actividad rentable y socialmente arraigada en las regiones del país donde se ha llevado a cabo, por lo que no es comprensible que se la desconozca como un motor para el desarrollo de tales regiones y no se busque fomentarla adecuadamente a través de políticas efectivas de formalización y desarrollo sostenible.

Por estas razones, el presente texto pretende describir brevemente las condiciones sociales, políticas, económicas, tecnológicas y ambientales en las que se desarrolla la MAPE del oro en Colombia. Igualmente, destacar otros aspectos relevantes a la naturaleza y potencialidad de la MAPE en su contribución a la economía nacional, la generación de circuitos económicos en ámbitos rurales, creación de fuentes de empleo, capacidad para la supervivencia en entornos de precariedad medioambiental, económica y social, así como creatividad para suplir la ausencia del Estado.

\section{Condiciones sociales, políticas y eco- nómicas de la MAPE en Colombia}

En primer término, es importante mencionar que la MAPE del oro en Colombia se ha desarrollado en contexto, comprendido en tres problemas fundamentales según Pantoja (2015):

- En el contexto social de la población minera. Las condiciones de educación, vivienda, salud y servicios públicos, en general, son modestas en la Zona Andina y precarias en la Costa Pacífica.

- En el proceso de producción. No se dispone de las técnicas adecuadas para un proceso productivo que permita, de manera simultánea, una recuperación óptima del metal precioso y una reducción de los daños y riesgos sobre la salud de los trabajadores y sobre el medio ambiente. Se registra escasa infraestructura minera especializada y vías de acceso a las regiones mineras en mal estado.

- En el proceso de comercialización. Intervienen diferentes intermediarios que prefinancian la producción condicionando a los mineros a vender el oro a precios inferiores al que recibi- ría si se realiza a través de otros mecanismos de mercado y bajo un enfoque de cadena de valor. En general, no se genera valor agregado.

No obstante lo anterior, la principal amenaza que afronta actualmente la MAPE del oro tradicional en Colombia es la estigmatización de la minería y un acelerado y estructural debilitamiento. Al respecto, se evidencian los siguientes aspectos siguiendo a Pantoja (2015):

- Débil apoyo estatal y señalamiento injustificado por parte de algunos estamentos del Estado Colombiano de ser propiciadora de la ilegalidad y la criminalidad.

- Desigualdad en la asignación de responsabilidades sociales y ambientales entre la minería tradicional y otras actividades productivas que también producen impactos sociales y ambientales importantes como la ganadería, la agricultura, el aprovechamiento forestal, entre otros.

- Incorrecta percepción de la población no minera (que son mayoría) hacia la MAPE incrementada por la equivocada difusión de los medios de comunicación sobre la problemática social y ambiental en regiones de minería tradicional del oro.

En segundo término, es importante mencionar que la MAPE del oro en Colombia se ha desarrollado a partir del surgimiento de asentamientos humanos que aparecen espontáneamente, es decir, sin un diseño de planificación previa. Esto ha conducido no solamente la ausencia de un ordenamiento territorial y urbano, sino que además, perenniza las condiciones precarias de vida de esta población en términos de falta de servicios sanitarios (agua potable y alcantarillado), salud, educación y vivienda. Especialmente, en la llanura del Pacífico y en la región selvática oriental colombiana, la explotación de oro ha pasado de ser una labor de carácter ancestral, a una práctica desordenada que con el uso de retroexcavadoras y dragas ha pasado a constituirse en una forma de colonización territorial (Martínez \& Aguilar, 2012; Pantoja, 2015).

Por ello, en estos asentamientos espontáneos, la actividad aurífera ha originado problemas de violencia 
y conflictos sociales que se intensifican por el aislamiento de las regiones mineras con respecto a centros urbanos y por la misma presencia de redes de narcotráfico y grupos armados ilegales. Adicionalmente, las confrontaciones de los pequeños mineros con las comunidades nativas han sido frecuentes en regiones donde se descubre e inicia la explotación de un yacimiento aurífero. De esta manera, el surgimiento de explotaciones de MAPE del oro ha generado a un cambio en el sistema de valores éticos de múltiples comunidades, lo que casi siempre termina en la reducción del control por parte de las entidades, organismos de control estatales y de las mismas fuerzas armadas (CINEP, 2012; Pantoja, 2015).

Respecto a lo anterior, es importante resaltar la compleja relación entre narcotráfico y la MAPE del oro. Durante las décadas de 1990 y 2000 hubo una situación de abandono masivo de los mineros de sus frentes de trabajo para dedicarse a cultivos ilícitos de coca y amapola. Sin embargo, el aumento de los altos precios de oro desde el 2004 ha generado un retorno paulatino de los mineros a su actividad tradicional, pero manteniendo relaciones con actores ligados al narcotráfico. Se ha registrado que en diversas regiones, algunos grupos al margen de la ley se han apropiado de las explotaciones de oro y otros grupos combinan la minería del oro con el narcotráfico (CINEP, 2012; Juárez, 2015; Pantoja, 2015). La mayoría de estos actores están recurriendo a la violencia y al desplazamiento forzado para adueñarse de las minas de oro.

Por otro lado, cabe resaltar la existencia de relaciones de dependencia complejas entre los pequeños mineros y el grupo conformado por intermediarios de la comercialización del oro, propietarios de maquinaría y otras personas que financian su actividad, dada la falta de acceso a crédito formal que obliga a los mineros a contraer créditos y comprometer previamente su producción. Los pequeños mineros, por lo general, no poseen el músculo financiero, la preparación técnica y administrativa necesaria para una participación equitativa con estos actores (Gutiérrez, 2015; Pantoja, 2015). De esta manera, la actividad minera del oro artesanal y en pequeña escala se realiza, en muchos casos, como una economía de subsistencia con muy bajos excedentes que no garantizan la sostenibilidad de la producción ni el bienestar de las comunidades involucradas en dicha actividad. Esto se evidencia en que la gran mayoría de municipios mineros, la pobreza promedio es del 74\%, siendo muy superior al del resto de las regiones rurales (Contraloría General de la República, 2013).

Lo anterior evidencia la necesidad de mencionar el papel de las instituciones estatales en el desarrollo de la MAPE del oro, el cual ha sido en muchos casos contraproducente para éste. Concretamente, la aplicación de Leyes Mineras y Ambientales ha contribuido a mantener y acrecentar la situación de ilegalidad e informalidad de esta actividad. Este fenómeno se debe a múltiples causas, que van desde la obligatoriedad de procedimientos técnicos dispendiosos en tiempo y costo para la obtención de Títulos Mineros y Licencias Ambientales, hasta la existencia de entidades estatales débiles que manejan una normatividad ambigua y complicada y una gran discrecionalidad de sus funcionarios en el manejo y control de legalización y formalización de la MAPE en el país (Suárez et al., 2012; Güiza, 2014; Pantoja, 2015).

Además, la capacidad técnica, administrativa, financiera y logística de tales instituciones, entre las que se encuentran la Agencia Nacional de Minería, las Corporaciones Autónomas Regionales, las Oficinas Departamentales y las dependencias del Ministerio de Minas y Energía y el Ministerio de Ambiente y Desarrollo son insuficientes, y en algunos casos, impiden el funcionamiento legal y organizado de la MAPE. En particular, la falta de instrumentos $e$ información ambiental y minera apropiadas, así como la ausencia de una normatividad consistente frente a la MAPE genera que las entidades estatales no cumplan a cabalidad sus funciones, no concedan o retiran Títulos Mineros y las Licencias Ambientales a los pequeños mineros, sin que existan motivos claros y basados en la normatividad (Suárez et al., 2012; Güiza, 2014; Pantoja, 2015).

Adicionalmente, un hecho que empeora la situación es que los órganos de gestión, administración y control de las entidades mineras y ambientales es que han sido organizados en forma centralizada y no 
están en capacidad de controlar a la gran cantidad de pequeñas explotaciones mineras en el país (cuyo número asciende a 10.384 según el censo minero de 2011), al estar diseminadas en su gran mayoría en regiones de difícil acceso y comunicación precaria. Por ejemplo, en Nariño la Subsecretaria Departamental de Minas y las Oficinas Municipales de Asuntos Mineros cuentan con un solo funcionario de nivel técnico y sus presupuestos son muy bajos (Pantoja, 2015).

De igual manera, la debilidad en algunos casos, y en otros la ineficiencia en tales entidades estatales y de las mismas Fuerzas Armadas se refleja en la demora de los trámites gubernamentales de los procesos de Títulos Mineros, obtención de Licencias Ambientales y compra de explosivos, lo cual dificulta el desarrollo normal de los trabajos de explotación de minería tradicional incluso para los mineros que han tenido la capacidad de legalizarse (Suárez et al, 2012; Pantoja, 2015).

La Subsecretaria Departamental de Minas y las Oficinas Municipales de Asuntos Mineros cuentan con poco personal (tienen un solo funcionario de nivel técnico) y bajo presupuesto.

Otras amenazas y debilidades que según Pantoja (2015) se presentan en torno a la MAPE tradicional del oro son las siguientes:

- Gran dificultad en la adquisición de explosivos e insumos mineros químicos que están restringidos por el gobierno y el Ejercito Colombiano.

- Falta de créditos e incentivos tributarios favorables.

- Incipiente desarrollo del Programa de Formalización Minera en Nariño que ejecuta, de manera descentralizada y con poco presupuesto, el Ministerio de Minas y Energía y sus entidades vinculadas y adscritas.

A lo anterior, es posible mencionar que un aspecto que ha agravado los conflictos en las áreas mineras es la aplicación de la ley $2^{\text {a }}$ de 1959 (creación de Reservas Forestales en Colombia) por parte de las autoridades ambientales. Esto se debe a que la aplicación intransigente, en la actualidad, de esta normativa ha generado un serio "cuello de botella" en la obtención y renovación de múltiples títulos de concesión minera en áreas donde los pequeños mineros han invertido todos sus recursos e incluso habitan con sus familias desde hace muchos años sin tener ningún conocimiento de que en tales áreas se sitúan Reservas Forestales delimitadas en 1959 (Pantoja, 2015).

Por tanto, es posible afirmar que además de las condiciones sociales y económicas adversas que enfrenta hoy la MAPE del oro, existe graves debilidades en la institucionalidad colombiana y de normatividad adecuada y coherente para su desarrollo. Esta situación parte del mismo hecho de que las entidades mineras y ambientales se rigen por términos de referencia para la legalización, control y fiscalización que no reconocen entre empresas mineras grandes y pequeñas, lo cual se estableció a partir de la promulgación del actual Código Minero en el 2001 (Pantoja, 2015).

Este mismo Código Minero eliminó las escalas de minería (grande, mediana y pequeña), por lo que se suprimió la posibilidad de fijar las condiciones legales bajo las cuales se pueda adelantar la pequeña minería (CINEP, 2012).

En línea con lo anterior, es importante mencionar que las circunstancias que han incidido negativamente en el control y formalización de la MAPE pasan por la limitación presupuestal desde el nivel central y la escasa destinación de recursos del Sistema General de Regalías (SGR) a otros proyectos dirigido a la MAPE, lo cual ha impedido concentrar esfuerzos en el programa de legalización y formalización minera. Además, la transición de autoridad minera delegada de Ingeominas (hoy Servicio Geológico Colombiano-SGC) a la Agencia Nacional de Minería-ANM ha dificultado la realización de convenios con la autoridad ambiental para la visita técnica conjunta y la comunicación entre las gobernaciones delegadas y la ANM, para la consulta del Registro Minero Nacional (Contraloría General de la República, 2014; Pantoja, 2015).

Así, pues, un acuerdo sobre minería responsable para la MAPE, en la actualidad, podría resultar 
prácticamente inviable, puesto que los pequeños mineros tradicionales tienen una profunda desconfianza hacia el Estado Colombiano, existe una gran descoordinación institucional tanto a nivel regional como nacional y no débiles condiciones institucionales y de política pública minera y ambiental mínimas para legalizar y formalizar la MAPE que cumpla con un adecuado desempeño social, ambiental y tecnológico.

En relación a las regalías, existe un bajo control de éstas y una débil inversión en el desarrollo de la MAPE tradicional del oro en Colombia, por ejemplo, en Nariño el sector minero es el único que aporta regalías de todos los actividades productivas pero, también, es el único que no ha recibido apoyo financiero de dineros provenientes del Sistema $\mathrm{Ge}^{-}$ neral de Regalías (Pantoja, 2015).

Para aquellos lugares que reciben regalías, "la calidad de vida de la población no sólo no mejoró, sino que, en la mayoría de los casos, vio consolidar su franco retraso en contraste con otras regiones del país" (El Espectador, 2014b). De esta manera, en Colombia se favorece grandes proyectos a cargo de empresas multinacionales que tienden a poseer un alto grado de "lobby" político y económico. En los últimos años se han multiplicado los títulos mineros a favor de estas multinacionales mientras que la MAPE del oro continua desarrollándose prácticamente sola, con grandes limitaciones al margen del sector formal y por las recientes medidas tomadas por el gobierno que tienden a confundir a la MAPE del oro con una minería criminal. El fenómeno de la "puerta giratoria" de funcionarios que salen de entidades estales mineras y ambientales a transnacionales mineras y viceversa, ha contribuido a mantener este carácter privilegiado de las empresas multinacionales en detrimento de la MAPE (Suárez et al., 2012).

Otro problema grave, es la existencia de una corrupción socialmente aceptada en algunas instancias gubernamentales, y cabe aquí citar por ejemplo, el caso de las retroexcavadoras y dragas que atraviesan buena parte del territorio colombiano, ingresan a Nariño y explotan los recursos mineros a lo largo de varios años y a la vista de las autoridades departamentales y municipales, policía y ejército y de las instituciones gubernamentales mineras y ambientales del orden regional y nacional. Así mismo, se han detectado casos de extorsión a los pequeños mineros tradicionales del oro por parte de las bacrim, de los grupos paramilitares, de la guerrilla y de las mismas fuerzas militares de policía y ejército.

\section{Condiciones tecnológicas y ambien- tales de la MAPE en Colombia}

Una vez establecidas de manera general las condiciones sociales y políticas en las cuales se ha desarrollado la MAPE del oro, es necesario abordar cuál es el grado de desarrollo tecnológico en el cual se está llevando a cabo esta actividad en el país, lo cual está íntimamente ligado a sus impactos ambientales. La importancia de esta sección radica en que tal relación entre lo tecnológico y lo ambiental en la MAPE del oro ha sido constantemente dejada a un lado dentro de la institucionalidad y la legislación minera, lo cual se configura como una de las principales razones del desconocimiento de esta actividad y con ello, de su consideración como minería ilegal, sin capacidad de desarrollar una producción ambientalmente sostenible (Pantoja, 2015).

Dentro de las limitantes importantes para el desarrollo de la MAPE, están la falta de tecnología para el proceso de beneficio mineral, así como una baja capacitación a nivel técnico y tecnológico de los mineros, ya que en muchos casos los conocimientos de la actividad se trasmiten de padres a hijos. Como resultado, la gran mayoría de minas son artesanales y pequeñas, las recuperaciones de los procesos de beneficio de minerales no sobrepasan el 60\%. Por estas razones también, los costos de producción son elevados y la rentabilidad es mínima.

Adicionalmente, los gases, el polvo, el ruido, los residuos tóxicos y la incorrecta utilización de explosivos, sustancias químicas y residuos afectan directamente la salud de los mineros y sus familias y deterioran el aire, las aguas y los suelos. Los efectos y riesgos sanitarios y ambientales derivados de las explotaciones a pequeña escala son particularmente altos en las zonas circundantes a las minas. El hecho de que la misma actividad minera, en buena 
parte de los casos, se desarrolla en medio de las viviendas de los mineros genera altos riesgos para la vida de las personas por la presencia de grandes volúmenes de escombreras y huecos que ocasionan inestabilidad de los terrenos que originan deslizamientos y represamiento de las fuentes de agua (Pantoja, 2015). Un ejemplo reciente de ello es el deslizamiento que ocurrió en Sanabria, Santa Bárbara-Iscuandé, (Nariño) durante el mes de febrero de 2014 (El Espectador, 2014c).

Por otra parte, en la MAPE existen condiciones de trabajo muy precarias caracterizadas por graves deficiencias de seguridad e higiene laboral, lo cual tiende a producir altos riesgos de intoxicaciones químicas y accidentes. Las alteraciones ambientales de una pequeña mina debido a su pequeña escala son menores que las de una explotación de mediana o gran minería, mas sin embargo, el problema radica en el gran número de minas y en que están diseminados en grandes extensiones de difícil acceso (Güiza, 2014).

En términos generales, según los principales estudios sobre la MAPE del oro (Pantoja, 2000, 2002, 2003, 2004, 2015; Molano et al., 2012), los principales riesgos $e$ impactos negativos sanitarios $y$ ambientales que se presentan en esta actividad son:

- Contaminación con sustancias tóxicas y peligrosas, especialmente por mercurio, ácidos y bases que se utilizan en la explotación minera del oro;

- Formación de grandes huecos, en la minería aluvial, que generan lagunas de aguas estancadas y subsidencia de los terrenos por las galerías subterráneas;

- Destrucción de la capa vegetal, suelo y subsuelo en las minas y terrenos circundantes, por la continua perforación y levantamiento del terreno, y en consecuencia, deterioro de la flora y fauna circundante;

- Enlodamiento de las fuentes de agua circundantes, por la emisión de residuos sólidos y líquidos de la explotación sin un plan de manejo ambiental adecuado;

- Contaminación con grasas, aceites y combustibles de las máquinas mineras utilizadas (retroe- xcavadoras, motobombas, dragas de succión, molinos de pisones, barriles amalgamadores, etc.).

De esta manera, los investigadores consideran que las actividades mineras relacionadas con la extracción del metal precioso terminarían degradando parte de los ecosistemas encargados de la regulación hídrica del país (Molano et al., 2012; Correa, 2015). Un caso especialmente constituye la problemática del mercurio, reactivo de alto poder contaminante que es utilizado ampliamente por la MAPE del oro, muchas veces sin las precauciones necesarias, causando un gran efecto negativo tanto en aguas, suelos y aire como en la salud humana. La exposición a esta sustancia no se limita a los trabajadores, sino que se extiende a sus familiares, ya que los mineros y los comerciantes del oro procesan la amalgama (aleación de oro y mercurio) en la cocina y en el patio de sus casas (Pantoja, 1999, 2001, 2015; Casas et al., 2015).

La contaminación con mercurio que sufren algunas regiones del país también se ha intensificado con el avance de la actividad minera desarrollada por grupos armados ilegales, convirtiéndose así en una problemática con grandes implicaciones políticas y sociales al orden del día. El mismo presidente Juan Manuel Santos expresó: "Miren lo que está pasando por ejemplo con el mercurio. Colombia ya se volvió uno de los países -imagínense, qué vergüenza-, somos el país con la contaminación per cápita más alta del mundo. Y ya estamos viendo las consecuencias en muchas comunidades" (El Espectador, 2014a)

No obstante, la no existencia de políticas coherentes de formalización minera y ordenamiento minero ambiental a largo plazo han sido una característica constante en la institucionalidad colombiana (Suárez et al., 2012; Güiza, 2014; Pantoja, 2015). Esto ha generado un marcado divorcio entre lo tecnológico, lo ambiental y lo social en la MAPE del oro, reflejado en los siguientes aspectos que describe Pantoja (2015):

- Falta de articulación de los programas ejecutados por el Estado, las ONG y otros actores 
privados frente a los impactos ambientales de la MAPE en Colombia;

- Falta de continuidad en las políticas minero ambientales, especialmente de programas de formalización para la MAPE que comprendan integralmente aspectos sociales, ambientales y tecnológicos. Cada cambio de funcionarios en los Ministerios de Minas y Energía y de Ambiente, hay cambios de políticas, programas $y$ proyectos sin conservar las visiones y estrategias de largo plazo;

- La escasa asignación de presupuesto para los programas de formalización minera y proyectos minero ambientales en las instancias central y regionales;

- Impactos en el tejido social de la población minera por el conflicto armado y cultivos de uso ilícito;

- Dificultades para consolidar las organizaciones mineras comunitarias e influencia política inadecuada en las mismas;

- Altos riesgos laborales en las explotaciones subterráneas y a cielo abierto y baja cobertura en seguridad social;

- Carencia de programas de salud ocupacional y seguridad industrial a mediano y largo plazo.

- Falta de investigación y transferencia tecnológica para mejorar las técnicas minero ambientales;

- No se cuenta con un estudio actualizado sobre las condiciones socioeconómicas, ambientales, sanitarias y tecnológicas de la MAPE tradicional del oro, lo que ha limitado la "toma de decisiones" por los Gobiernos Nacional, Departamental y Municipales sobre la planificación y gestión de la MAPE;

- Ausencia de investigaciones que cuantifiquen los pasivos ambientales generados por la MAPE del oro;

- Carencia de programas de educación minero ambiental formales y no formales, situación que incide en una débil conciencia en las comunidades sobre estos asuntos;

- Desigualdad en la asignación de responsabilidades frente a otras actividades productivas como la ganadería, agricultura, explotación forestal, entre otras, que también producen impactos ambientales importantes;
- No hay programas de cierre de minas, requeridos en aquellas zonas mineras con siglos de tradición minera.

En resumen, el análisis y reconocimiento detallado de las condiciones sociales y políticas, por una parte, y tecnológicas y ambientales, por otra parte, de la MAPE del oro en Colombia, permite establecer una metodología para la conformación de una propuesta para el desarrollo de una MAPE del oro sostenible y responsable, tanto en términos económicos como ambientales. Esta propuesta se resume a continuación.

\section{Hacia una MAPE tradicional del oro sostenible y responsable en Colombia}

Ante el anterior panorama y por el hecho de ser la MAPE del oro una realidad presente y futura en Colombia, el Gobierno nacional y todas las instituciones ligadas a esta actividad deben proponer medidas políticas, normas y acciones a fin de incluir plenamente este sector en el sistema económico, en un marco de desarrollo regional sostenible. Así, una solución a la problemática social y ambiental de la minería en pequeña escala del oro en Colombia es una labor ardua que requiere del concurso activo y coordinado del gobierno, las comunidades, las ONGs, el gremio privado, las universidades e instituciones de investigación. Por tanto, las instituciones y comunidades ligadas la MAPE del oro deben conformar una alianza en pro de una minería en pequeña escala sostenible y responsable, basadas en los siguientes ejes planteados por Pantoja (2015):

- Del orden internacional: Los metales preciosos representan actualmente una demanda importante en los grandes mercados mundiales como reserva monetaria, joyería, medicina, industria, etc., por lo tanto, la minería de metales preciosos es una actividad dinámica y rentable que debe incorporarse a la producción nacional.

- Del orden nacional: La competitividad y sostenibilidad del sector de la minería de los metales preciosos son prioridades del actual gobierno nacional. En las estrategias denominadas "Estrategia para el Crecimiento del Sector" y "Estra- 
tegia para el Desarrollo de las Regiones Mineras" del Plan de Desarrollo Minero Nacional se privilegian las siguientes líneas de acción:

- Adoptar agendas de productividad y competitividad para promover entre la minería local de pequeña escala proyectos de desarrollo sostenible empresarial, modernización tecnológica, producción más limpia y agregación de valor, entre otros.

- Promover acuerdos de cooperación entre empresas mineras, Colciencias, SENA, universidades e institutos tecnológicos, para el desarrollo de proyectos de innovación tecnológica y de capacitación de recurso humano.

- Es imperativo incorporar programas estratégicos minero ambientales que involucren componentes de sostenibilidad social y ambiental como nuevas alternativas de producción más limpia, minería responsable, turismo sostenible geológico-minero, comercialización justa del oro, entre otros.

- Del orden local:

- Es pertinente crear nuevas empresas alrededor de las oportunidades que brinda la minería de los metales preciosos, particularmente en el procesamiento del oro de veta y la explotación aluvial, a partir de las potencialidades, las fortalezas de la comunidad minera, así como las posibles ventajas competitivas a construir a través de un recurso humano capacitado con bases y fundamentos tecnológicos de producción, capaz de gestar nuevos procesos industriales.

- Se necesita suplir las demandas laborales de este sector productivo reconocidas en diferentes diagnósticos realizados por diferentes instituciones estatales. Las localidades identificadas tienen una alta vocación minera y con altas potencialidades en metales preciosos que representan una oportunidad valiosa para gestar procesos de agregación de valor a partir del conocimiento tecnológico de la producción minera.

- Se hace necesario visibilizar y fortalecer la minería de los metales preciosos con una visión integradora de la cadena de valor, a través de la cual se logra mejorar los beneficios para los diferentes eslabones que intervienen desde los proveedores, productores, comercializadores, hasta el consumidor final y que resuelva los factores críticos de esta actividad.

- Es importante llegar a los mineros pequeños ya que en la MAPE están involucradas miles de familias colombianas que generan una gran cantidad de empleo y desarrollo en diferentes zonas del país.

- Del orden local, en el departamento de Nariño:

- La MAPE tradicional del oro genera riqueza, trabajo estable y digno y oportunidades, en por lo menos, 15 municipios de Nariño, donde aproximadamente el 10\% de la población nariñense depende directa $e$ indirectamente de la minería del oro según datos de CORPONARIÑO. De acuerdo con el Servicio Geológico Colombiano-SGC (antes INGEOMINAS), los yacimientos auroargentíferos de Nariño tienen un gran potencial que pueden ser explotados por varias generaciones de mineros tradicionales.

- Existen comunidades mineras sensibilizadas, informadas y dispuestas a trabajar con el gobierno nacional, regional y local, y con las entidades gubernamentales mineras $y$ ambientales, y también con instituciones privadas del orden nacional e internacional.

- Se cuenta con una organización sombrilla denominada "Asociación por la Minería Responsable y Comercio Justo del Suroccidente de Colombia-ASOMIRCOL" que congrega a diferentes Grupos Asociativos de Pequeños Mineros y Mineros Individuales. Igualmente, en los últimos años, la MAPE de Nariño ha contado con el apoyo técnico, académico y científico de la Universidad de Nariño y CORPONARIÑO. Cabe destacar la exitosa la gestión del Centro Ambiental MineroCAM de CORPONARIÑO en Sotomayor.

- Desde los años noventa, se han aplicado diferentes intervenciones para disminuir y 
eliminar el uso del mercurio por parte de la Universidad de Nariño y CORPONARIÑO con la participación activa de municipios mineros, Asociaciones y Cooperativas de pequeños mineros. En este sentido, la más significativa intervención de tipo técnico y científico con exitosos resultados es la investigación doctoral denominada "Optimización del Proceso de la Amalgamación en la MAPE: Mejora de la Recuperación de Oro y Disminución de las Pérdidas de Mercurio" cuyos resultados se están extrapolando a diferentes minas de Colombia, Ecuador, Perú, Bolivia y algunos países de Asia y África.

- Se ha contado con el apoyo de cooperaciones técnicas internacionales de GTZ, CIM/ Frankfurt/GTZ, SINA-GTZ, Convenio Canadá-Colombia, CYTED, UNESCO, OIM, CASM/Banco Mundial, NOVIB-OXFAM, SOLIDARIDAD, CHOPARD BID/ARM, entre las más importantes. Igualmente, se ha interactuado, a nivel horizontal, con diferentes países latinoamericanos, por ejemplo con CETEM del Brasil, organizaciones mineras comunitarias, ONGs y universidades latinoamericanas, españolas y canadienses (Pantoja, 2015).

- Así mismo, en Nariño, se ha avanzado con algunos países latinoamericanos, especialmente con el Ecuador y con el apoyo de CYTED y UNESCO, en la adopción de tecnologías apropiadas que no emplean mercurio como es el molino tipo chileno con canalones de concentración gravimétrica y la técnica de cianuración por agitación.

- Se ha trabajado intensamente en las certificaciones internacionales de minería responsable "Fairtrade y Fairmined" lideradas por ARM y con el apoyo de ASOMIRCOL, Universidad de Nariño, CORPONARIÑO y diferentes cooperaciones internacionales. A la fecha, se han certificado cuatro pequeñas minas de La Llanada y prontamente, seguirán este ejemplo, otras seis minas de los Andes-Sotomayor, Nariño.
- Se ha puesto en marcha el Proyecto integral "Ruta del Oro" de Nariño a través de un Convenio Interinstitucional Universidad de Nariño-Universidad Politécnica de Cataluña-CORPONARIÑO y la iniciativa internacional "Rutas de Minerales de Iberoamérica - RUMYS del Programa Iberoamericano de Ciencia y Tecnología para el Desarrollo-CYTED.

- Se cuenta con Registros Calificados de dos Programas Académicos en la Universidad de Nariño: Técnico y Tecnológico en Minería Sostenible por ciclos propedéuticos y competencias.

- CORPONARIÑO y la Universidad de Nariño han formado parte de diversas Redes y Proyectos Internacionales de investigación y han sido sedes de importantes eventos mineros nacionales e internacionales. Asimismo, se ha participado en eventos en Colombia y el exterior y se han publicado diferentes artículos y productos técnicos y científicos.

Así las cosas, se debe formular una agenda nacional de trabajo y ejecutar acciones prontas y eficaces, articuladas a través de programas coherentes de cooperación comunidad-gobierno, ya que la solución de los problemas sociales y ambientales depende, en buena parte, de la libre voluntad de los mineros de participar o no en la adopción de diferentes medidas. Por lo tanto, los programas de formalización y minero ambientales a ejecutarse entre la comunidad y el gobierno deben comprender aspectos socioeconómicos, culturales y técnicos de manera integral y sobre todo involucrar directamente a la población objeto para contar con su confianza y colaboración.

Un aspecto clave durante la puesta en marcha y desarrollo de programas de formalización minera y proyectos minero ambientales es la concertación de intereses entre los pequeños mineros y el gobierno. Cabe aquí destacar que, cuando se logra una fusión de los diferentes propósitos, se obtienen mejores resultados positivos y sostenibles. La estrategia de emprender, primero, "proyectos piloto" ha dado buenos resultados por lo que se han generado valiosas experiencias para replicarlas en otras zonas. 
Asimismo, se debe partir del reconocimiento de que existen logros y avances en materia social, ambiental y tecnológica de la MAPE en diferentes países latinoamericanos que pueden ser replicados a través de una cooperación horizontal y las universidades e institutos de investigación se pueden constituir en instancias articuladoras para este fin. Igualmente, estas instituciones pueden promover espacios de diálogo sobre estándares y normas tecnológicas y ambientales y abanderar procesos de intercambio de experiencias.

Es importante resaltar la iniciativa de Ministerio de Minas y Energía de establecer Áreas Especiales de Formalización Minera. Son áreas que se podrán delimitar y declarar, por motivos de orden social o económico determinados en cada caso, por el Ministerio de Minas y Energía, o la ANM o de oficio o por solicitud expresa de comunidades que se dediquen a las actividades de minería tradicional, con el objeto de adelantar dentro de los dos años siguientes estudios geológico-mineros, destinados a determinar las clases e proyectos mineros especiales y la realización de un ordenamiento minero que garantice el ejercicio eficiente de la minería. La nueva ley del mercurio (Ley 1658 de 2013) también es una oportunidad para los pequeños mineros del oro colombianos.

De esta manera, se debe propender por la formalización total de la actividad de los pequeños mineros, tanto en su componente minero como ambiental, no desde una posición puramente autoritaria y coactiva. Es decir, se debe generar campañas de sensibilización, difusión y convencimiento, unidas a una clara decisión política de otorgar Títulos Mineros y Licencias Ambientales, proporcionar asistencia técnica apropiada y financiación crediticia en condiciones favorables, otorgar capacitación no formal y establecer programas técnicos y tecnológicos especiales para la MAPE, entre otros.

Lo anterior, evidentemente, no puede quedarse en una acción unilateral de la institucionalidad. Las comunidades mineras deben comprometerse a cumplir con unos estándares de desempeño apropiados para la MAPE, a contar con unos planes de contingencia para emergencias y accidentes, a utilizar la tecnología que permita el aprovechamiento óptimo de los recursos con un mínimo impacto ambiental, $y$ en general, a mantener buenas relaciones con la comunidad no minera y el Gobierno nacional.

Seguido al desarrollo de los procesos de formalización minera, es necesario aprovechar espacios de importancia estratégica y experiencias y herramientas piloto exitosas desarrolladas para la MAPE como APELL, ARAMA, MUNOAIS, Empresa nacional Chilena de Minería-ENAMI, la Ley de Minería Artesanal Peruana, Alianza por Minería Responsable-ARM, Asociación por una Minería Responsable y Comercio Justo del Suroccidente Colombiano-ASOMIRCOL con sede en Pasto, el proyecto GMP-2 de ONUDI en Antioquia, los proyectos que se ejecutan en el Sur de Bolívar por la Gobernación de ese departamento con recursos del Sistema General de Regalías, la estrategia de gestión denominada "Centro Ambiental Minero-CAM" de CORPONARIÑO (Pantoja, 2015).

Por otra parte, entre los primeros pasos que se deben dar están la conformación de un Organismo de Mineros de MAPE a nivel nacional con capacidad negociadora que permita incidir en la adopción de políticas públicas a diferentes niveles. Es necesario elaborar, al comienzo de la ejecución de diferentes Programas, líneas de base en las áreas de trabajo, para posteriormente, establecer indicadores que permitan realizar un análisis cualitativo y cuantitativo de los progresos alcanzados. Por otra parte, es importante establecer un sistema de información para compartir datos sobre medios y recursos de cooperación internacional.

A los gobiernos extranjeros, a través de sus organizaciones de Cooperación Internacional, les corresponden importantes tareas para el mejoramiento de la MAPE en Colombia, entre las cuales se encuentran el apoyo financiero y técnico en la elaboración de leyes, pautas, estándares, normas y valores límite y ejecución de proyectos de formación y fortalecimiento de instituciones para estructurar órganos ejecutivos apropiados para el desarrollo, seguimiento y control de esta actividad.

Es importante instalar en los departamentos mineros regiones "Mesas Permanentes de Diálogo Mi- 
nero" entre la Comunidad Minera y la institucionalidad bajo la coordinación de las administraciones departamentales Gobernación de Nariño. Igualmente, es prioritario, en el corto plazo, es la estructuración de "Plan Sectorial Prospectivo para la MAPE del oro", con participación activa de las comunidades de pequeños mineros y la institucionalidad local, regional y nacional con el apoyo de la Universidad de Nariño.

De manera conjunta a lo anterior, es pertinente generar un programa minero-ambiental, basado en el desarrollo de procesos de producción limpia, particularmente la promoción y aplicación de tecnologías apropiadas. Las técnicas diseñadas se adaptaran a las condiciones locales en las que se desenvuelve la MAPE, especialmente, los equipos a introducir, deben ser de manufactura local, de fácil manejo y bajo costo que prometan ventajas visibles y directas a los mineros. Los equipos que han superado la fase experimental, se promocionarán entre la comunidad minera a través de una intensiva campaña de divulgación y se comenzará con su implementación, solamente cuando se considere que han sido apropiados por los mineros en forma suficiente, ya que la introducción de equipos inapropiados rompe la credibilidad de los asesores y entidades.

La creación de alicientes financieros para estimular su utilización es una estrategia eficaz, a la hora de introducir tecnologías apropiadas. Por ejemplo se deben priorizar proyectos para este fin, que se financien con dineros del Fondo de Ciencia, Tecnología e Innovación del Sistema General de Regalías en alianza con Colciencias, Instituto Geológico Colombiano, Grupos y Centros de investigación y universidades estatales y privadas.

La formación y capacitación de personal técnico en cuestiones minero ambientales es clave para garantizar la sostenibilidad de resultados de los diversos programas que se desarrollen al igual que el fortalecimiento de redes científicas y grupos de investigación. Implementar estrategias de control fiscal con el apoyo de los entes nacionales, regionales y locales de control (contralorías y procuradurías), y en coordinación con veedurías ciudadanas, que permitan la evaluación y seguimiento de los procesos de inversión de las regalías en los departamentos y municipios mineros.

Los gobiernos regionales y locales deberían apropiar recursos financieros del Sistema General de Regalías y también generarse un fondo especial de formalización minera con el objeto de financiar planes, programas, proyectos y actividades de inversión destinados a la MAPE. Si van a ingresar millones de dólares a las arcas públicas procedentes de las regalías por minería, sería irresponsable que no se utilice una parte de esos recursos para que el Estado garantice un impecable control de su gestión ambiental y también unos recursos para hacer las necesarias compensaciones ecológicas por los daños inevitables que la MAPE tiene para la biodiversidad y las aguas y se adelante con los más altos estándares ambientales.

Finalmente, es importante la expedición de un nuevo Código de Minas alrededor, del cual sea posible explicitar las especificidades, los derechos y los deberes de la minería artesanal y en pequeña escala.

\section{Conclusiones}

A partir de lo descrito anteriormente, la ejecución de los diversos programas de cooperación comunidad-gobierno mencionados pueden generar a mediano plazo una transformación de la MAPE a nivel de formalización, conciencia, conocimiento, y experiencias sociales, tecnológicas y ambientales y de organización que mejoren sustancialmente las condiciones de vida y trabajo de las comunidades de pequeños mineros tradicionales. En ese sentido, la situación deseada para una MAPE sostenible y responsable, se resume de la siguiente manera:

- Una MAPE reconocida política, social y ambientalmente.

- Unas políticas de formalización minera y proyectos minero ambientales coherentes y sostenibles para la MAPE.

- Un nuevo Código de Minas alrededor del cual sea posible explicitar las especificidades, los derechos y los deberes de la minería artesanal y en pequeña escala. 
- Una MAPE armonizada con las normas y las instituciones y que se desarrolla en un marco de gobernabilidad y gobernanza, de legalidad y con el apoyo de instituciones con presupuesto para programas, proyectos y actividades.

- Una MAPE que respete los derechos culturales y los territorios y costumbres de las minorías étnicas.

- Unas Autoridades mineras y ambientales que adopten procedimientos y términos de referencia accesibles y aplicables en la elaboración, presentación y aprobación de los estudios mineros y ambientales necesarios para la legalización de los proyectos MAPE.

- Una percepción ambiental positiva y reconocimiento de la importancia de la MAPE en la sociedad con respecto a las otras actividades productivas.

- Una opinión pública no tenga siempre dialogante y que no tenga siempre la percepción de que cualquier desarrollo minero conduce a un desastre social y ambiental.

- Unos sectores público, privado, no gubernamental y académico trabajando coordinada y mancomunadamente en pro de una MAPE sostenible y responsable.

- Una MAPE incluida en la planificación y ordenamiento territorial.

- Lo tecnológico articulado a lo ambiental en todas las fases del proyecto minero desde la exploración hasta el cierre de minas.

- Una MAPE con un buen nivel de educación contextualizada y contemplada en los niveles de educación superior, tecnológica y técnica.

- Unos resultados de casos exitosos publicados y socializados.

- Unas iniciativas de cooperación horizontal de transferencia social, tecnológica y ambiental en marcha.

- Unas técnicas minero ambientales desarrolladas localmente con base en la investigación aplicada con el apoyo de Colciencias y el Instituto Geológico Colombiano.

- Trabajo infantil completamente erradicado y equidad con el trabajo de las mujeres.

- Una MAPE y comunidades aledañas sensibilizadas social y ambientalmente y fortalecidas sus capacidades para la asociatividad.
- Una eficiente inversión de las regalías del oro, preferentemente, en la financiación de programas de formalización minera y proyectos minero ambientales.

- Que existan unos estándares concertados para concesionarios mineros de la MAPE.

- Que exista una Licencia Ambiental para todo el ciclo minero y que se realice un proceso de caducidad de los títulos mineros sin licencia ambiental.

- Que exista una información accesible y transparente.

- Que se realice una diversificación de las exportaciones con valor agregado del oro de la MAPE, a precios justos.

- Una Ley del Mercurio ejecutada exitosamente y que sirva de modelo en Latinoamérica y en el Mundo. Al respecto, se debe concertar con el gobierno, en el corto plazo, una Agenda de Actividades.

- Unas nuevas políticas mineras y ambientales con altas prioridades frente a la protección de la biodiversidad y del agua.

- Un procedimiento expedito en el proceso de sustracción de áreas que siguen restringidas debido a la Reserva Forestal del Pacífico de la Ley Segunda de 1959.

- Unos requerimientos concertados para la afiliación y ampliación de la cobertura en seguridad social con el fin prevenir y reducir los riesgos y accidentes laborales.

- Unos Planes de Manejo Ambientales viables con el fin de reducir los principales riesgos y daños a la salud de los mineros y sus familias y al medio ambiente

- Material explosivo suficiente para las labores mineras adquirido directamente de las Fuerzas Armadas Colombianas.

- Unos Trámites y procedimientos abreviados para la MAPE en la normatividad minera y ambiental, diferentes a los que se exigen para otro tipo de mediana y gran minería.

- Unas comunidades tradicionales mineras que no se dediquen, también, a la producción de drogas ilícitas.

- Unas comunidades mineras que eviten la influencia política en las decisiones de las organizaciones mineras y apartadas de grupos criminales. 
Finalmente, a partir del diagnóstico presentado en este texto, se requiere dotar al Ministerio de Minas y Energía, Ministerio de Ambiente y Desarrollo Territorial, CARs, ANM, SGC, Gobernaciones y Alcaldías de una alta capacidad técnica y de la suficiente independencia, así como establecer mecanismos para erradicar una eventual corrupción en estas entidades.

Si el Gobierno creó una Unidad Nacional de Intervención Contra la Minería Criminal (UNIMIC), promulgó diferentes Decretos y prepara una Ley para combatir la sustracción, tráfico y venta ilegal de productos mineros, también debe estructurar programas, proyectos y actividades que contribuyan a un reconocimiento y visibilización de la MAPE, armonizada con las normas y las instituciones y que se desarrolle en un marco de prácticas mineras responsables y sostenibles y de buenas relaciones con la Comunidad no Minera y con el Gobierno.

\section{Referencias}

Casas, I., Gómez, E., Rodríguez, L., Girón, S. \& Mateus, J. (2015). Hacia un plan nacional para el control de los efectos del mercurio en la salud en Colombia. Biomédica, 35 (Supl 2): 30-7.

Centro de Investigación y Educación Popular - CINEP. (2012). Minería, conflictos sociales y violación de derechos humanos en Colombia. CINEP.

Congreso de Colombia (2013). Ley 1658 del 15 de julio de 2013. Por medio de la cual se establecen disposiciones para la comercialización y el uso de mercurio en las diferentes actividades industriales del país, se fijan requisitos e incentivos para su reducción y eliminación y se dictan otras disposiciones.

Contraloría General de la República. (2013). Minería en Colombia. Derechos, políticas públicas y gobernanza. Bogotá: Contraloría General De La República.

Contraloría General de la República. (2014). Minería en Colombia Institucionalidad y territorio, paradojas y conflictos. Bogotá.

Correa, D. (2015). Transnacionalidad y minería en las áreas protegidas de Colombia. Tesis Doctoral. Universidad de Alicante. Recuperado de: http://hdl.handle.net/10045/53335

Defensoría del Pueblo. (2010) La minería de hecho en Colombia. Bogotá: Defensoría del Pueblo.

El Espectador (2014a). Colombia, uno de los países con la contaminación per cápita más alta del mundo: Santos. Recuperado el 14 de junio de 2014: http://www.elespectador.com/noticias/ politica/colombia-uno-de-los-paises-contaminacion-per-capitamas-articulo-469385

El Espectador (2014b). Pueblos carboneros viven peor que los cocaleros. Recuperado el 14 de junio de 2014: http:// www.elespectador.com/noticias/medio-ambiente/puebloscarboneros-viven-peor-los-cocaleros-articulo-468836

El Espectador (2014c). A seis asciende cifra de muertos por derrumbe de mina en Nariño. Recuperado el 14 de junio de 2014: http://www.elespectador.com/noticias/nacional/seis-asciendecifra-de-muertos-derrumbe-de-mina-narino-articulo-475439

Güiza, L. (2014). La minería manual en Colombia: una comparación con América Latina. Boletín Ciencias de la Tierra, 35. Doi: http://dx.doi.org/10.15446/rbct.n35.37056

Gutiérrez, J. (2015). Desarrollo de proveedores locales en el sector extractivo colombiano: cuellos de botella, factores de éxito $e$ implicaciones de política pública. Revista Ópera, 17: 5-25.

Hentschel, T., Hruschka, F. \& Priester, M. (2002). Global report on artisanal and small-scale mining. Report commissioned by the Mining, Minerals and Sustainable Development of the International Institute for Environment and Development, 20 (08).

Juárez, F. (2016). La minería ilegal en Colombia: Un conflicto de narrativas. El Agora USB, 16(1): 135-146.

Martínez, A. \& Aguilar, T. (2012). Impacto socioeconómico de la minería en Colombia. Informe para el Sector de Minería a Gran Escala. Fedesarrollo, Bogotá.

Ministerio de Minas y Energía (2012). Censo minero departamental 2010 - 2011. Recuperado de: https://www.minminas.gov. co/censominero

Molano, J., Ramírez, Ibagón, \& Duque, M.V. (2012). Minería: conflictos socioambientales, despojo y territorialidad. En: Toro-Pérez, C., Coronado, S. \& Roa, T. (eds). Minería, territorio y conflicto en Colombia. Bogotá: Universidad Nacional de Colombia.

Pantoja, F. (1999). Optimización del Proceso de la Amalgamación en la Pequeña Minería del Oro: Mejora de su Recuperación y Disminución de las Pérdidas de Mercurio. Tesis Doctoral. Universidad Autónoma de Madrid-E.T.S.I. de Minas de la Universidad Politécnica de Madrid. España.

Pantoja, F. (2000). Disminución de la Contaminación Ocasionada por el Mercurio en Latinoamérica. Revista Colombia, Ciencia y Tecnología, 18 (2).

Pantoja, F. (2001). Technologies to decrease the pollution by mercury in small gold mining in Latinoamerica. Ponencia para 6th Congress Mercury of Global Polution. Minamata, Japan.

Pantoja, F. (2002). Más oro y menos riesgos para los mineros. Memorias del Encuentro Regional de Ciencia y Tecnología en Colombia. Colciencias. Bogotá: Colombia.

Pantoja, F. (2003). Una visión de la minería del oro en pequeña escala en América Latina: problemas y soluciones. En: Martins, L. \& Carrión, P. (eds.) Integración de la Minería en la Ordenación del Territorio. Guayaquil: CYTED y ESPOL.

Pantoja, F. (2004). Mejoramiento tecnológico de la minería del oro en pequeña escala de Perú, Ecuador y Colombia apoyado por UNESCO y CYTED. Ponencia del IV Reunión de Coordinación de la Red XIII.E "Ordenamento do Território e Recursos Minerais" del Programa Iberoamericano de Ciencia y Tecnología para el Desarrollo-CYTED.

Pantoja, F. (2015). Limitantes y desafíos de la minería del oro artesanal y en pequeña escala - MAPE en Nariño. En: Taller regional sobre la iniciativa de transparencia de las industrias extractivas - EITI de Nariño. Foro Nacional por Colombia y Universidad de Nariño, 25 de septiembre de 2015.

Suárez, A., Rudas, G. \& Fierro, J. (2012) Territorio, financiarización y política minera en Colombia. En: Toro-Pérez, C., Coronado, S. \& Roa, T. (eds) Minería, territorio y conflicto en Colombia. Bogotá: Universidad Nacional de Colombia. 


\title{
CONTRIBUCIÓN AL DESARROLLO SOSTENIBLE LOCAL DE LOS PROYECTOS MDL EN EL SECTOR DE GENERACIÓN ELÉCTRICA POR BIOMASA: CASO INCAUCA S.A.*
}

\author{
CARLOS ANDRÉS VERGARA TAMAYO*** \& DIANA CAROLINA ORTIZ MOTTA*** \\ UNIVERSIDAD MILITAR NUEVA GRANADA
}

Recibido/ Received/ Recebido: 17/12/2014 - Aceptado/ Accepted / Aprovado: 24/11/2015

\section{Resumen}

La declaración presentada por la comunidad internacional a mediados del siglo XX frente al reconocimiento del fenómeno del cambio climático, dio origen a propuestas de la comunidad para la creación de mecanismos orientados al control y a la reducción de sus causas. Una de estas propuestas es el Protocolo de Kyoto, el cual tiene por objetivo la reducción de los Gases Efecto Invernadero (GEI) causantes del calentamiento global. Dicho protocolo planteó tres iniciativas, pero, tan solo una de ellas involucra la participación de países en vía de desarrollo como es el caso de Colombia; se trata de los Proyectos de Mecanismo de Desarrollo Limpio (MDL). En este sentido, el objetivo de este documento es comprender los aportes en términos del desarrollo sostenible local, a partir de la metodología multicriterio AHP, para el proyecto MDL de cogeneración y sustitución de combustible del Ingenio del Cauca S.A., registrado ante la Convención Marco de las Naciones Unidas para el Cambio Climático (CMNUCC.) De este trabajo se concluye que no existe una diferencia importante entre la situación "con proyecto" y la situación "sin proyecto", en otras palabras, la contribución al desarrollo social del Municipio de Miranda (Cauca), no está determinada por la puesta en marcha del proyecto MDL, sin embargo al analizar de manera global el ranking de las dos alternativas evaluadas es evidente que los actores involucrados prefieren la situación antes del proyecto que con este.

Palabras clave: Desarrollo sostenible local; MDL; Cambio climático; Protocolo de Kyoto; Análisis multicriterio.

\section{CONTRIBUTION TO LOCAL SUSTAINABLE DEVELOPMENT OF THE CDM PROJECTS IN THE BIOMASS POWER GENERA- TION SECTOR: INCAUCA S.A.CASE}

\begin{abstract}
The statement made by the international community in the mid-twentieth century against the recognition of the phenomenon of climate change, led to proposals from the community to create
\end{abstract}

Proyecto desarrollado en el Grupo de Estudios en Ciencias Económicas (CIE) de la Universidad Militar Nueva Granada (UMNG) Bogotá, Colombia. Resultado del proyecto de Investigación ECO-1216 denominado: "Proyectos del mecanismo de desarrollo limpio (MDL) en el sector de generación eléctrica por biomasa y su contribución al desarrollo sostenible en Colombia", aprobado y financiado por la Vicerrectoría de Investigaciones de la UMNG.

* Docente Investigador del Grupo CIE, Universidad Militar Nueva Granada (Bogotá-Colombia). Economista de la Universidad Nacional de Colombia (Medellín-Colombia), Magíster en Economía de Recursos Naturales y del Medio Ambiente de la Universidad de Concepción (Concepción-Chile). Dirección postal: Cra. 11 No. 101-80, Bogotá (Colombia), Centro de Investigaciones de la Facultad de Ciencias Económicas, Primer Piso, Bloque C. Teléfono: 6500000 Ext. 1306. Correo electrónico: carlos.vergara@unimilitar.edu.co

** Auxiliar de Investigación del Grupo CIE, Universidad Militar Nueva Granada, Economista de la Universidad Militar Nueva Granada (Bogotá-Colombia). Magíster en Estudios y Gestión del Desarrollo de la Universidad de la Salle (Bogotá-Colombia). Correo electrónico:diana.ortiz@unimilitar.edu.co 
mechanisms oriented to control and the reduce its causes. One of these proposals is the Kyoto Protocol, which aims at reducing greenhouse gas (GHG) emissions that cause global warming. This protocol outlined three initiatives, but only one of them involves the participation of developing countries as in the case of Colombia; they are the Clean Development Mechanism (CDM) Projects. In this sense, the objective of this document is to understand the contributions in terms of local sustainable development, from the multi-criteria methodology AHP for the cogeneration CDM project and fuel substitution of Ingenio del Cauca SA, registered with the United Nations Framework Convention on Climate Change (UNFCCC.) this paper concludes that there is no significant difference between the situation "with the project" and the situation "without the project", in other words, the contribution to the social development of the Municipality of Miranda (Cauca), is not determined by the implementation of the CDM project, however comprehensively analyzing the ranking of the two evaluated alternatives is evident that stakeholders prefer the situation before the project than with it.

Keywords: Local sustainable development; CDM; Climate change; Kyoto Protocol; Multicriteria analysis.

\title{
CONTRIBUIÇÃO AO DESENVOLVIMENTO SUSTENTÁVEL LOCAL DE PROJETOS MDL NO SETOR DE GERAÇÃO ELÉTRICA POR BIOMASA: CASO INCAUCA S.A.
}

\begin{abstract}
Resumo
A declaração apresentada pela comunidade internacional na metade do século XX frente ao reconhecimento do fenômeno da mudança climática deu origem a propostas de criação de mecanismos orientados ao controle e à redução de suas causas. Uma destas propostas é o Protocolo de Kyoto, que tem por objetivo a redução dos Gases Efeito Estufa causantes do aquecimento global. Este protocolo propôs três iniciativas, mas somente uma delas envolve a participação de países em via de desenvolvimento como é o caso da Colômbia. Trata-se dos Projetos de Mecanismo de Desenvolvimento Limpo (MDL). Neste sentido, o objetivo deste documento é compreender a contribuição em termos de desenvolvimento sustentável local, a partir da metodologia multicritério AHP, para o projeto MDL de cogeração e substituição de combustível do Talento do Cauca S.A., registrado ante a Convenção Marco das Nações Unidas para a Mudança Climática. Conclui-se neste trabalho que não existe uma diferença importante entre a situação "com projeto" e a situação "sem projeto". Em outras palavras, a contribuição ao desenvolvimento social do Município de Miranda (Cauca), não está determinada pela realização do projeto MDL. No entanto, ao analisar de maneira global o ranking das duas alternativas avaliadas, é evidente que os atores envolvidos preferem a situação anterior ao projeto do que com ele.
\end{abstract}

Palavras chave: Desenvolvimento sustentável local; MDL; Mudança climática; Protocolo de Kyoto; Análise multicritério.

Vergara, C. \& Ortiz, D. (2016). Contribución al desarrollo sostenible local de los proyectos MDL en el sector de generación eléctrica por biomasa: caso Incauca S.A. En: Revista de la Facultad de Ciencias Económica: Investigación y Reflexión. rev.fac.cienc.econ, XXIV (2), DOI: http://dx.doi. org/10.18359/rfce. 2218

JEL: P32, Q01, Q56, R11. 


\section{Introducción}

Las determinaciones internacionales frente al problema del calentamiento global y por consiguiente el cambio climático, permitieron el surgimiento de diversas alternativas de gestión ambiental, dentro de estas el Protocolo de Kyoto. Este surge bajo la Convención Marco de las Naciones Unidas Sobre Cambio Climático (CMNUCC) ${ }^{1}$, llevada a cabo en la ciudad de Kyoto (Japón) en $1997^{2}$, con el objetivo de reducir las emisiones de Gases Efecto Invernadero $(\mathrm{GEI})^{3}$ consideradas las causantes del problema del calentamiento global, en un 5\% durante un periodo de 2008 a 2012. El protocolo establece ciertos mecanismos que facilitan a los países industrializados alcanzar los compromisos adquiridos con acciones llevadas a cabo más allá de sus fronteras, dentro de éstos se encuentran los denominados proyectos de Mecanismo de Desarrollo Limpio (MDL) ${ }^{4}$, que a su vez, se convierten en el único mecanismo que permite que los países no industrializados hagan parte del protocolo y así alcanzar el objetivo de protección ambiental y de fomento y contribución del desarrollo sostenible (ONU, 1998).

Un planteamiento importante que surge a partir del Protocolo de Kyoto es la promoción del Desarrollo Sostenible, visto como una oportunidad para emplear energías con medios más limpios a los convencionales y así evitar la generación de emisiones de GEI. A partir de aquí y con el apoyo de nuevas propuestas sobre el Desarrollo Sostenible (ONU, 2012; SDSN, 2013 \& ONU, 2014), se pretenden revisar las cuatro dimensiones de éste: desarrollo económico, inclusión social, sostenibilidad ambiental y buena gobernabilidad, en un ejercicio de evaluación ex-post de los proyectos de Mecanismo de Desarrollo Lim-

1 Convención Marco de las Naciones Unidas para el Cambio Climático - CMNUCC. United Nations Framework Convention on Climate Change - UNFCCC.

2 A pesar de que el protocolo de Kyoto fue firmado el 11 de diciembre de 1997, solo entró en vigencia hasta que fue ratificado por el 55\% de las partes que el 16 de febrero de 2005 (De Quinto \& Ferreira, 2005).

3 Entre los Gases Efecto de Invernadero - GEI se encuentran: el dióxido de carbono (CO2), metano ( $\mathrm{CH} 4)$, óxido nitroso (N2O), hidrofluorocarbonos (HFC), perfluorocarbonos (PFC) y hexalfluoruro de azufre (SF6)

4 En inglés Clean Development Mechanism (CDM). pio (MDL) relacionados con energías limpias o renovables, dentro de las cuales se encuentra la energía generada a partir de biomasa, la cual se convierte en el objeto de análisis del presente documento.

Al respecto, Colombia cuenta con 6 proyectos MDL relacionados con energía generada a partir de biomasa y se ubica en el décimo tercer lugar a nivel mundial y el quinto a nivel de Latinoamérica y el Caribe (UNEP, 2014). En este sentido el Ingenio del Cauca S.A. (a partir de la cogeneración y sustitución de combustibles) se convierte en un caso de estudio interesante con características particulares lo que permite evidenciar la contribución de los proyectos de MDL en el sector de generación eléctrica por biomasa al desarrollo sostenible de Colombia. Dicha elección obedece entonces al análisis de la información contenida en el portal del PNUMA ${ }^{5}$ relacionado con la revisión de bases de datos $\mathrm{CDM} / \mathrm{JI}$ (UNEP RISOE CDM/JI Pipeline Analysis and Database) y los 95 Documentos de Diseño de Proyecto (PDD por sus siglas en inglés) ${ }^{6}$, presentados por Colombia ante la Convención Marco de las Naciones Unidas con corte a primero de Diciembre de 2014 y la información disponible de las empresas que tienen que ver con tales proyectos.

A pesar de que este documento reconoce que los postulados base para la creación tanto del Protocolo de Kyoto como de los Proyectos de Mecanismo de Desarrollo Limpio (MDL) que parten de doctos como Pigou o Coase, están soportados en la economía ambiental, no significa que la teoría que sustenta este documento sea ésta, por el contrario, y tal como se registra en el desarrollo metodológico, en la discusión, resultados y conclusiones de este escrito, es la Economía Ecológica área del conocimiento que reconoce un enfoque más holístico e interdisciplinar que busca imprimir la diferencia demostrando que el desarrollo económico no debe ser la única dimensión válida para el adelanto de iniciativas amigables con el ambiente de este tipo.

5 Programa de Naciones Unidas para el Medio Ambiente PNUMA, UNEP por sus siglas en inglés.

6 Un Documento de Diseño de Proyecto (PDD por sus siglas en inglés), es un formato que contiene toda la información del proyecto MDL y que es el único documento formal en la validación y registro del MDL ante las Naciones Unidas. 
Para el desarrollo de este documento se han dispuesto seis secciones, que le permitirán al lector comprender secuencialmente cómo los proyectos de Mecanismo de Desarrollo Limpio (MDL) en particular el proyecto "Cogeneración y Sustitución de Combustible en el Ingenio del Cauca S.A", contribuyen al desarrollo sostenible del municipio de Miranda (Departamento del Cauca). En tal sentido, el documento se compone entonces de una introducción, como bien se expone en esta primera sección. A manera seguida se presenta el marco teórico relacionado con la investigación, en el que además se encuentran las bases conceptuales; posteriormente se aborda la metodología denominada Análisis del Proceso Jerárquico (AHP, por su sigla en inglés). Continúa con la sección de resultados y el análisis de los hallazgos tanto cualitativos como cuantitativos y finaliza con una sección de conclusiones.

\section{Marco teórico}

\subsection{La problemática internacional del cambio climático}

A partir del reconocimiento del fenómeno del cambio climático por parte de la comunidad internacional se pronuncian los diferentes países a través de la Convención Marco de las Naciones Unidas sobre el Cambio Climático al definirlo como "un cambio de clima atribuido directa o indirectamente a la actividad humana que altera la composición de la atmósfera mundial y que se suma a la variabilidad natural del clima observada durante períodos de tiempo comparables" (ONU, 1992, p. 3).

Este proceso global se ha reconocido efectivamente como irreversible (Sánchez, citado en Canoura, 2009), esto debido a la acumulación de gases que generan el efecto invernadero y, por ende, aportan al cambio climático, en el momento ya existe una acumulación de emisiones con efectos irreversibles. En razón a lo anterior sus efectos y consecuencias no podrán ser contrarrestadas en su totalidad, tan sólo pueden ser atenuadas.

En Colombia, el Instituto de Meteorología y Estudios Ambientales -IDEAM-, como una de las instituciones gubernamentales determinantes, considera que: " $E l$ cambio climático es por lo tanto una de las amenazas más serias que atentan contra el bienestar y la salud humana, contra la economía y muchos de los ecosistemas naturales y, finalmente, contra el desarrollo humano sostenible" (IDEAM, 2002, p. 2). Esto representa claramente el efecto rebote ${ }^{7}$ de la degradación de los recursos naturales y el ambiente sobre el bienestar del ser humano.

Es importante mencionar que si bien existen algunas entidades encargadas de liderar estas actividades, todas las instituciones tanto nacionales como regionales deben fomentar la recolección, análisis y sistematización de la información del sector forestal, con el objetivo de revisar los mecanismos de flujo de información, hasta mejorar la calidad de los datos reportados; adicionalmente deben identificar los datos prioritarios que a nivel nacional, regional y local son útiles para el desarrollo de estudios nacionales e internacionales (IDEAM et al., 2006).

De acuerdo a lo anterior, el IDEAM en 2001, preparó la Primera Comunicación Nacional de Cambio Climático a presentar ante la Convención Marco de las Naciones sobre Cambio Climático-CMNUCC-, allí se presentaron resultados importantes que demuestran, que a pesar de que Colombia emite únicamente el 0,25\% de las emisiones globales será muy vulnerable a los efectos que se presenten por el Cambio Climático; el estudio prevé que para el año 2050 la temperatura promedio del aire aumentará entre 1 y $2^{\circ} \mathrm{C}$; las precipitaciones variarán aproximadamente un 15\%; desaparecerá el 78\% de la superficie de los nevados y el $56 \%$ de los páramos; y el mar ascenderá entre 40 y 60 centímetros (IDEAM et al., 2006)

Los avances y la buena disposición que Colombia ha demostrado frente al tema de cambio climático

\footnotetext{
El efecto rebote o paradoja de Jevons, fue mencionada por primera vez por William Stanley Jevons en su libro "The Coal Question" (La cuestión del carbón) en 1865, pretendiendo explicar el paradójico fenómeno de que al reducir el consumo de carbón de las máquinas de vapor gracias a mejoras tecnológicas, paradójicamente se aumentaba la demanda total. Estrictamente Alcott (2005, p. 8) la menciona como la paradoja que al "aumentar la eficiencia disminuye el consumo instantáneo pero incrementa el uso del modelo lo que provoca un incremento del consumo global".
} 
se pueden observar en la Segunda Comunicación Nacional ante la Convención Marco de las Naciones Unidas sobre Cambio Climático preparada por el Ministerio de Ambiente, Vivienda y Desarrollo Territorial, y el Instituto de Hidrología, Meteorología y Estudios Ambientales (IDEAM), allí queda la evidencia del reconocimiento que hemos tenido a nivel mundial, pues citan que: "En septiembre 18 de 2009, Colombia se convirtió en el quinto país de Latinoamérica y décimo segundo del mundo en proyectos elegibles bajo la modalidad MDL del Protocolo de Kyoto" (Barba et al., 2010, p. 184).

\subsection{Protocolo de Kyoto y Proyectos de Mecanismo de Desarrollo Limpio (MDL)}

Una de las iniciativas es el Protocolo de Kyoto, en las bases teóricas de este acuerdo se comprende la economía ambiental, fundamentalmente en los postulados de dos importantes economistas Arthur Cecil Pigou y Ronald H. Coase. El primero, desarrolló en 1920 su obra "Teoría del Bienestar" en la que incentiva al Estado a tomar medidas que mejoren la calidad de vida de sus ciudadanos, además reconocía que los mercados presentan externalidades tanto positivas como negativas, las cuales podrían mejorar mediante la creación de impuestos y subsidios. Este primer autor provee los asientos para penalizar a los países más contaminantes y al mismo tiempo premia a aquellos que mejoran sus prácticas en favor del ambiente (Alvater, 1998). Pero quizás quien más incidió en la determinación de esta política ambiental internacional fue el profesor Ronald $\mathrm{H}$. Coase, quien llevó a cabo un reconocido aporte en 1960, denominado: "El Problema del Costo Social", en el cual le resta protagonismo al Estado $e$ incentiva las condiciones de libre mercado a través de negociaciones descentralizadas, asignando al Estado un rol pasivo, esto es, de árbitro frente a los acuerdos voluntarios creados entre los generadores y receptores de contaminación.

Es en la Tercera Convención Marco de las Naciones Unidas sobre el Cambio Climático celebrada en 1997 donde 38 de los países más industrializados asumen compromisos de reducción de gases GEI hasta alcanzar un nivel promedio del $5,2 \%$ por debajo de los índices registrados para el año 1990, es- tos compromisos fueron recogidos en el "Protocolo de Kyoto" el cual fue adoptado en 1997 y ratificado en 2005. El protocolo de Kyoto se convirtió desde entonces en una de las principales muestras de compromiso y protección con el ambiente mediante objetivos que involucran un desarrollo sostenible ya que los gobiernos de los países firmantes actuaron bajo principios de equidad y responsabilidad común pero diferenciada aceptando restricciones frente a los niveles de emisiones de GEI y el compromiso de promover el desarrollo sostenible en otros países: subdesarrollados y en vías de desarrollo. A la fecha es el primer y único acuerdo vinculante que los países industrializados han ratificado y en donde se asumen reducciones cuantificadas de GEI como resultado del reconocimiento de su mayor responsabilidad en la crisis ambiental (ONU, 1998; Villavicencio, 2004).

Adicionalmente, investigaciones realizadas con anterioridad por organismos internacionales, determinaron que dentro de las principales causas que ocasionan el cambio climático se encuentra la acumulación de gases GEI en la atmósfera, por lo tanto en el protocolo se establece una serie de mecanismos para que los países industrializados puedan dar cumplimiento a los compromisos adquiridos. Para tal fin, el protocolo establece tres mecanismos de flexibilidad: el comercio de emisiones, la implementación conjunta (exclusivos para países industrializados), y el Mecanismo de Desarrollo Limpio (MDL). La alternativa de MDL, permite la posibilidad de que los países industrializados acompañen a los países en desarrollo con inversiones en proyectos que reduzcan GEI y promuevan el desarrollo sostenible en estos últimos, a la vez que el volumen de reducciones de GEI es reconocido para cumplir con los compromisos de los primeros (Villavicencio, 2004; Yamin, 2005; Stern, 2007; citados en Aleluia \& Leitão; 2009).

El objetivo de la implementación de proyectos MDL relaciona procesos de transferencia tecnológica para los países en vías de desarrollo, en especial en el campo de energías renovables y el manejo de desperdicios. Gran parte de los países que no han experimentado el MDL insisten en continuar con la tecnología que tradicionalmente utilizan, pero, aquellos que han tenido alguna experiencia con proyectos 
MDL logran combinarla con tecnología externa (Doranova, Costa \& Duysters, 2009). Por lo tanto la transferencia de tecnología se convierte en un objetivo indirecto de este tipo de proyectos, posibilitando el conocimiento y operación de tecnología local y de alguna manera, minimizando la importación y dependencia tecnológica en otros países.

\subsection{Los proyectos de Mecanismo de Desarrollo Limpio (MDL) y el desarrollo sostenible}

Si bien, el Mecanismo de Desarrollo Limpio (MDL) ha sido creado con el fin de atender dos objetivos simultáneamente: en primer lugar tratar de reducir las emisiones de Gases Efecto Invernadero (GEI) y en segundo lugar promover el desarrollo sostenible en los países no anexo I ${ }^{8}$ (Karakosta, Doukas \& Psarras 2009; Huang \& Barker, 2010; Sabogal, Hurtado \& Moreno, 2010), se hace necesario examinar la manera en que este cumple con su segundo objetivo bajo un enfoque holístico, por tanto a continuación se presentan algunas precisiones de cómo se alcanza el desarrollo sostenible a través de proyectos MDL.

Para Villavicencio (2004, p. 2), existen dos ideas fundamentales que predominan en el discurso sobre la contribución de los proyectos MDL al desarrollo sostenible de los países no anexo 1 o países en vía de desarrollo: "En primer lugar, los proyectos MDL, al reducir las emisiones de gases de efecto invernadero, promueven el desarrollo sustentable; y en segundo lugar los proyectos MDL, al atraer un flujo de inversión externa directa, son positivos para el logro de los objetivos de un desarrollo sustentable". De acuerdo a esto y al convertirse en canalizadores de inversión extranjera directa (IED), se asume que los efectos positivos se pueden desencadenar en: generación de divisas, transferencia de tecnología en beneficio del ambiente, efectos positivos en la balanza de pagos, manejo sostenible de los recursos, aumento de la inversión social, diversificación de la producción rural y apertura a nuevos mercados, generación de empleo e incluso disminución en la migración campesina (Mejía, 2005).

\footnotetext{
Países en vía de desarrollo.
}

El sin número de beneficios que surgen a partir de la inversión extranjera directa a causa de los proyectos MDL, se han justificado a través de la "Teoría de la filtración" propuesta por el Premio Nobel de Economía, Joseph Stiglitz en 2002, según la cual, los efectos positivos de la inversión extranjera directa, se filtran a través de toda la economía y llegan incluso a los estratos más pobres de la población (Villavicencio, 2004).

Sin embargo, Olsen \& Fenhann (2008) reconocen algunos de los inconvenientes presentados con los proyectos MDL en cuanto al desarrollo sostenible. $\mathrm{Se}$ ha comprobado que algunos proyectos MDL no logran los objetivos de desarrollo sostenible, para los que fueron creados, al estudiar las causas del incumplimiento es común encontrar desequilibrios entre los beneficios económicos que se obtienen en el mercado de carbono y los beneficios no económicos (sociales y ecológicos) que se pretenden con el logro del desarrollo sostenible. Otra de las causas referentes al no cumplimiento de los compromisos frente al desarrollo sostenible, surge en el momento en que van a ser verificadas las reducciones de GEI, este, es tal vez, uno de los momentos más importantes en el proceso, pues con la verificación del cumplimiento de reducciones se generan los $\mathrm{CERs}^{9}$ que posteriormente van a ser negociados en los mercados de carbono y de los cuales la empresa logra parte de su lucro económico; sin embargo, en el momento de la verificación no se exige ningún tipo de cumplimiento frente a los compromisos adquiridos en relación al desarrollo sostenible (Olsen \& Fenhann, 2008).

De esta manera se registran a la fecha de corte del presente trabajo (01 de diciembre de 2014), 8.647 proyectos MDL a nivel mundial, de los cuales el 30,28\% (2.618) manejan energía eólica, el 26,16\% (2.262) corresponden a hidroeléctricas y en el tercer lugar se encuentran los proyectos MDL, con una participación menor, que involucran energía

\footnotetext{
CER's son Certificados de Reducción de Emisiones que se miden como créditos equivalentes a una tonelada de $\mathrm{CO} 2$ los cuales son tenidos en cuenta para alcanzar los compromisos de reducción de emisiones adquiridos por los países en el Protocolo de Kyoto. Estos CER's son expedidos por las entidades operacionales designadas, bajo los parámetros y lineamientos de la Junta Directiva de MDL.
} 
por biomasa con un 9,03\% (781); de estos últimos Colombia cuenta con 6 proyectos y se ubica en el décimo tercer lugar a nivel mundial y el quinto a nivel de Latinoamérica y el Caribe, como se evidencia en la Tabla 1 (UNEP, 2014). Los proyectos registrados en Colombia se describen a continuación:

- MDL Retirado: Planta doble propósito de Propal: Evasión de metano y eficiencia energética.

- MDL Retirado: Cogeneración de azúcar, Ingenio Providencia.

- MDL Retirado: Cogeneración y desplazamiento de energía térmica por Incauca S.A.

- MDL Activo: Biomasa en la planta de cemento Caracolito por CEMEX Colombia.

- MDL Activo: Combustibles alternativos y proyectos de biomasa en la planta de cemento de Cúcuta por CEMEX Colombia.

- MDL Activo: Sustitución de combustible de carbón a residuos de bagazo de caña (biomasa) por Incauca S.A.
De acuerdo a lo anterior se evidencia que el proyecto MDL objeto de estudio en este documento "Sustitución de combustible de carbón a residuos de bagazo de caña (biomasa) por Incauca S.A.", se encuentra registrado, activo y con un tiempo de operación considerable, por lo tanto resulta oportuna y vigente la presente investigación.

Como se mencionó anteriormente, la presente investigación se apoya en el carácter multidimensional de desarrollo sostenible como lo describe Angulo (2010, p.4):

"Tal desarrollo será sostenible si vinculara las decisiones económicas con el bienestar social y ecológico, es decir, vincular la calidad de vida con la calidad del medio ambiente $y$, por lo tanto, con la racionalidad económica y el bienestar social. En otras palabras, el desarrollo es sostenible si mejora el nivel y la calidad de la vida humana al tiempo que garantiza y conserva los recursos naturales del planeta".

Tabla 1. Proyectos MDL con Biomasa por país

\begin{tabular}{|c|c|c|c|}
\hline \multicolumn{4}{|c|}{ Biomass CDM projects } \\
\hline No. & Country & Projects & MW \\
\hline 1 & India & 334 & 2584,893 \\
\hline 2 & China & 161 & 4331,01 \\
\hline 3 & Brazil & 54 & 1095,415 \\
\hline 4 & Malaysia & 43 & 276,25 \\
\hline 5 & Thailand & 31 & 469,862 \\
\hline 6 & Indonesia & 18 & 99,2 \\
\hline 7 & Vietnam & 16 & 36,5 \\
\hline 8 & Mexico & 14 & 165,2543 \\
\hline 9 & Chile & 13 & 234 \\
\hline 10 & Uruguay & 9 & 266,8 \\
\hline 11 & Argentina & 8 & 146,348 \\
\hline 12 & Pakistan & 7 & 27 \\
\hline 13 & Colombia & 6 & 26,2 \\
\hline 14 & Philippines & 5 & 52,5 \\
\hline 15 & Dominican Republic & 4 & 85,905 \\
\hline 16 & Honduras & 5 & 31,7 \\
\hline 17 & South Africa & 5 & 25,7 \\
\hline 18 & Sri Lanka & 5 & 25,5 \\
\hline 19 & Kenya & 4 & 43,125 \\
\hline 20 & Ecuador & 3 & 55,5 \\
\hline 21 & Costa Rica & 3 & 1,4 \\
\hline 22 & Morocco & 3 & o \\
\hline 23 & Panama & 2 & 0,5 \\
\hline 24 & Israel & 2 & 6,8 \\
\hline 25 & Egypt & 2 & 0 \\
\hline
\end{tabular}

Fuente: Tomado de CDM/JI.

\begin{tabular}{|r|l|r|r|}
\hline \multicolumn{4}{|c|}{ Blomass CDM projects } \\
\hline No. & \multicolumn{2}{|c|}{ Projectry } & MW \\
\hline 26 & Singapore & 2 & 2,81 \\
\hline 27 & Uganda & 2 & 0 \\
\hline 28 & El Salvador & 2 & 78,5 \\
\hline 29 & Peru & 2 & 37,5 \\
\hline 30 & Senegal & 2 & 25 \\
\hline 31 & Côte d'lvoire & 2 & 46 \\
\hline 32 & Swaziland & 1 & 20 \\
\hline 33 & Cambodia & 1 & 1,5 \\
\hline 34 & Nicaragua & 1 & 55 \\
\hline 35 & Bangladesh & 1 & 0 \\
\hline 36 & Guyana & 1 & 10 \\
\hline 37 & Guatamala & 1 & 0 \\
\hline 38 & Macedonia & 0 & 2,5 \\
\hline 39 & Moldova & 1 & 0 \\
\hline 40 & South Korea & 1 & 3 \\
\hline 41 & Tanzania & 1 & 15 \\
\hline 42 & Serbia & 0 & 7,5 \\
\hline 43 & Nigeria & 1 & 0 \\
\hline 44 & Sierra leone & 1 & 32 \\
\hline 45 & Tunesia & 1 & 0 \\
\hline 46 & Paraguay & 0 & 0 \\
\hline 47 & Lao PDR & 0 & 0 \\
\hline 48 & Mongolia & 0 & 0 \\
\hline & Total & 781 & 10423,67 \\
\hline & & & \\
\hline
\end{tabular}


Así mismo, dentro de las iniciativas para promover el desarrollo, el Secretario General de Naciones Unidas, Ban Ki-moon, creó la Red de Soluciones para el Desarrollo Sostenible (SDSN, 2013), con el objeto de movilizar el conocimiento global científico y tecnológico en los retos de desarrollo sostenible, incluidos el diseño y la implementación de la agenda global para el desarrollo sostenible post-2015. En dicha agenda la SDSN reconoce la visión Río+20 como un concepto integral que aborda cuatro dimensiones: sostenibilidad ambiental, inclusión social, desarrollo económico, y buena gobernabilidad.

De esta manera, Colombia también le apuesta a la redefinición de los Objetivos del Desarrollo del Milenio por Objetivos de Desarrollo Sostenible, iniciativa de la ONU donde se otorga suficiente importancia al componente ambiental dentro de las políticas internacionales como tal. Es así como en el país surge la Comisión interinstitucional de alto nivel para el alistamiento y efectiva implementación de los objetivos de desarrollo sostenible que pretende canalizar el apoyo de la cooperación internacional e incrementar el beneficio de la misma en función del desarrollo y las prioridades del país (ONU, 2012; SDSN, 2013; DNP, 2015).

Frente a esto, es importante tener en cuenta los factores clave que permiten lograr una gestión exitosa frente al desarrollo sostenible en las economías emergentes, en tal sentido (Nuschler, 2005, citado en Cotte \& Pardo, 2011), menciona algunos como la modernización de la producción, el apalancamiento de capital y la transferencia de conocimientos técnicos; asimismo aclara que, la gestión adecuada de estos factores debería generar una transformación radical de la economía.

Lo que debe destacarse de cualquier posición frente al desarrollo sostenible, es el llamado a cambiar las estrategias que se han venido desarrollando hasta ahora, desde los diferentes aportes disciplinares; se hace necesario entonces actuar frente a este concepto cambiante a lo largo del tiempo que garantice la estabilidad social y ecológica de las diferentes generaciones. En este sentido, las nuevas actuaciones deberán estar focalizadas principalmente hacia los países industrializados pues son los mayores consumidores de recursos naturales y los que más des- perdicios generan (Pierri, 2001; Angulo, 2010). El primer paso en esta línea debería darse en aras de evidenciar la responsabilidad de los países desarrollados y no desarrollados pero así también en verificar los resultados e incluso reevaluar las estrategias de orden internacional y su impacto regional y local, como corresponde al presente caso de estudio.

Finalmente, este acápite ofrece las bases para conceptualizar el problema global del cambio climático destacando tan solo una de las herramientas que se han empleado en la mitigación de este: El Protocolo de Kyoto. Los proyectos de Mecanismo de Desarrollo Limpio (MDL), dirigidos hacia los países en vías de desarrollo como Colombia pretenden no solo disminuir las emisiones de GEI sino también promover el desarrollo sostenible. En este sentido se justifica la necesidad de comprender los aportes en términos del desarrollo sostenible local, desde un enfoque alternativo denominado Ciencia Post-normal (el cual se ampliará más adelante) y la economía ecológica a partir de la metodología de análisis multicriterial, método AHP, como se aclara en la siguiente sección, para el proyecto MDL de cogeneración y sustitución de combustible del Ingenio del Cauca S.A., registrado ante la Convención Marco de las Naciones Unidas para el Cambio Climático (CMNUCC).

\section{Metodología}

Las décadas de los setentas y ochentas son consideradas el punto oficial de partida de las metodologías más completas para estudiar los problemas económicos, sociales y ambientales que requieren la valoración en más de un escenario. Una de estas metodologías es denominada Análisis Comparativo Cualitativo (QCA), citada por primera vez por Charles Ragin en 1987, esta metodología reúne un conjunto de técnicas lógicas para realizar análisis cualitativos de causalidad (Ragin, 1987, 2008, citados en Cotte \& Pardo, 2011).

Pese a esto, Funtowicz \& Ravetz (2004), en sus investigaciones sobre el problema de la sustentabilidad, y reconociendo las múltiples fuentes de conocimiento existentes, logran construir un nuevo marco analítico el cual es llamado "Ciencia Post-normal" que orienta la integración del conocimiento de sentido común en 
el procesamiento de información requerido para la comprensión de los fenómenos socioambientales. Y es bajo este enfoque que se pueden realizar estudios en el campo social facilitando las distintas perspectivas de los actores sociales; como por ejemplo, los modelos de análisis multicriterio.

Es así, como el análisis multicriterio, busca integrar las diferentes dimensiones de la realidad de una problemática, con el fin de dar una visión integral y un mejor acercamiento a la realidad. Esta metodología es adecuada para la toma de decisiones frente a "conflictos sociales, económicos y objetivos de conservación del medio ambiente, y además cuando confluyen una pluralidad de escalas de medición (físicas, monetarias, cualitativas, etc.)" (Saaty, 1977; Falconí \& Burbano, 2004).

Debido a que esta metodología requiere la agregación de opiniones de los diferentes actores de una problemática, surge un enfrentamiento entre lo monocriterial y lo multicriterial. Sin embargo, esta última se caracteriza porque el decisor tiene mayor libertad para expresar sus ideas, las opiniones se hacen más realistas y menos rígidas, de esta manera, al final el análisis multicriterio termina imponiéndose, aun cuando no todos los actores muestren la misma sensibilidad frente a los diferentes criterios (Saaty, 1987; Fernández \& Escribano, 2011), esto permite finalmente capturar una interesante diversidad de posturas de acuerdo a los aspectos a evaluar.

De otro lado, algunos organismos regionales han aportado a la literatura contemporánea mencionando la aplicación de estas metodologías como se observa en Pacheco \& Contreras (2008, p. 14) en su documento Manual Metodológico de Evaluación Multicriterio para Programas y Proyectos avalado por la serie de manuales CEPAL, los cuales reafirman que: "las técnicas de Evaluación Multicriterio permiten trabajar con varios criterios a la vez, identificar la importancia relativa de cada uno y evaluar entre distintas alternativas de proyecto, independiente de la naturaleza de los factores que están implícitos en una situación específica".

Para Comas et al. (2011, p. 3), la aplicación de los métodos multicriterio han pasado de ser una herra- mienta encargada de tomar la decisión (MCDM Multi Criteria Decision Making), a una herramienta de apoyo a la toma de decisiones (MCDA Multi Criteria Decision Aid) (Pacheco \& Contreras 2008; Saaty, 2003).

En tal sentido, Fernández \& Escribano (2011), analizan los dos modelos de decisión de análisis multicriterio, a fin de presentar sus contribuciones específicas en la investigación operativa; por un lado está "La toma de decisiones multicriterio (MCDM)", cuyo objetivo es describir o descubrir algo que pueda ser considerado como una entidad fija y siempre presente, ayudando al decisor a tomar una decisión correcta (siempre que la racionalidad de los axiomas sea aceptada por el decisor) y por otro lado "La ayuda a la decisión multicriterio (MCDA)", su objetivo es construir o crear algo que no pre-existe, debe ser fiable para ayudar a un actor en la toma de decisiones, iluminando el comportamiento del decisor ofreciéndole argumentos capaces de reforzar o debilitar sus propias convicciones.

La decisión multicriterio es apropiada en situaciones en las que un decisor debe realizar elecciones en presencia de múltiples criterios y múltiples actores, para una mayor comprensión, el decisor (sea individual o colectivo), debe elegir entre varias posibilidades que son denominadas "alternativas", el conjunto de alternativas se denomina "conjunto de elección" y en este conjunto existen diferentes puntos de vista llamados "criterios", muchos de ellos contradictorios; es así cómo se constituye un sistema multicriterio en donde finalmente el decisor al aceptar un punto de vista no podrá escoger la misma alternativa en presencia de otro criterio (Fernández \& Escribano, 2011).

Pacheco \& Contreras (2008), plantean distintos métodos de agregación que modelizan las preferencias a través de una función valor dentro de los cuales se encuentra el proceso analítico jerárquico o método AHP (Analytic Hierarchy Process) ${ }^{10}$, que conduce al sistema a un objetivo deseado como la solución de conflictos, un desempeño eficiente o

10 Conocido también como método mixto, por la posibilidad de relacionar información tanto cuantitativa como cualitativa. 
simplemente la felicidad total; este método posee tres principios fundamentales que dirigen el proceso de evaluación: i) construcción de jerarquías; ii) establecimiento de prioridades; y iii) consistencia lógica. En este sentido la metodología AHP se convierte en una herramienta determinante a la hora de evaluar las contribuciones correspondientes del proyecto MDL del Ingenio del Cauca S.A sobre el desarrollo sostenible local en el área de estudio previamente especificada.

\subsection{Desde lo cualitativo: instrumentos de reco- lección de información}

La metodología de análisis multicriterio llevada a cabo, permitió involucrar los actores relacionados con el proyecto MDL que tienen que ver con la generación eléctrica por biomasa, para poder establecer una aproximación a la contribución de estos al desarrollo sostenible. Dichos actores fueron seleccionados de acuerdo a un "Muestreo por Conveniencia", esta técnica de muestreo no probabilístico consiste en seleccionarlos conforme a lo establecido por el investigador según su accesibilidad o proximidad, no por que hayan sido seleccionados mediante un criterio estadístico (Casal \& Mateu, 2003).

Dentro de las razones por las cuales se toma la decisión de emplear dicha técnica se consideraron los paradigmas metodológicos de investigación mencionados, así como los límites de tiempo y de presupuesto, de tal manera que los diferentes tipos de actores (mencionados a continuación) participaran y se reflejarán en el ejercicio de investigación: representante de la compañía Incauca S.A., representante de la Alcaldía de Miranda (Cauca), comunidad de la vereda El Ortigal, y comunidad de la vereda Santa Ana.

En este sentido se diseñaron y aplicaron los diferentes instrumentos cuantitativos y cualitativos como: encuestas, entrevistas, grupos focales y análisis de información secundaria ${ }^{11}$. En todos los casos se manejaron dos escenarios: un escenario sin proyecto MDL, es decir, donde se contemple la situación

11 El diseño de estos instrumentos puede observarse en el Anexo. antes implementar o desarrollar el proyecto y un segundo escenario con proyecto MDL, después de la implementación del mismo.

Es de anotar que la definición de escalas de calificación se basó en la escala fundamental de Saaty (1987), en la cual se plantea que existe un límite psicológico según el cual las personas acostumbran a realizar juicios de valor en una escala de 1 a 9 (aproximadamente) siguiendo una escala lineal; es importante aclarar que esta tabla se utiliza para la comparación par a par, para cada uno de los criterios y entre cada una de las alternativas de selección.

Las entrevistas relacionadas se realizaron a dos de los principales actores: Incauca S.A. y la Alcaldía del Municipio de Miranda. De otro lado las encuestas se aplicaron a todos los actores. Esta fue dividida en tres (3) partes así: La primera parte está compuesta por diez (10) preguntas en las que se debe calificar de 1 a 5 , siendo 1 la calificación más baja y 5 la calificación más alta. La segunda parte está compuesta por siete (7) preguntas, las cuales contienen diferentes opciones de respuesta como: expresiones en porcentaje, cantidades y otros. Y la tercera y última parte, busca que se ordenen algunos criterios (ranking) de acuerdo a su importancia de 1 a 7 , siendo 1 la calificación menos importante y 7 la calificación más importante.

\subsection{Unificación de información cualitativa y cuantitativa}

En la última parte del tratamiento de la información fue necesario homogeneizar cuantitativa y cualitativamente las diferentes fuentes de información, esto obedeció al proceso de triangulación de fuentes que permitiera confrontar las diferentes fuentes de información obtenida y luego re-escalarlas de 1 a 5 (Sandoval, 2002).

\subsubsection{Información secundaria}

En cuanto al análisis del informe de sostenibilidad de Incauca S.A., los resultados que la empresa muestra en este tienen que ver con la presencia del proyecto MDL, la información no se encuentra completa para los 17 indicadores evaluados, y por esta razón 
se presenta un vacío, debido también a que no se cuenta con informes de sostenibilidad que se hayan presentado antes de implementarse el proyecto MDL para poder realizar una comparación entre las alternativas $\sin y$ con proyecto.

Para la empresa Incauca S.A., el proyecto MDL es muy favorable principalmente en cuanto a la disponibilidad de energía eléctrica que al ser generada con biomasa contribuye con el mejoramiento de la calidad de vida de los colombianos. A través de un uso racional y eficiente de la energía, se logra una disminución en la emisión de gases nocivos para la salud; adicionalmente se cuenta con una iniciativa planteada por la empresa y acogida por la comunidad de Padilla (vereda ubicada a una hora de la planta), la cual consiste en el desarrollo y puesta en marcha de una cooperativa de corte y transporte de hoja de caña (residuos utilizados en el nuevo proceso de sustitución de combustibles) (Incauca S.A., 2011).

En materia de energía, Incauca S.A., es auto-sostenible. El bagazo de la caña resultante de la molienda se emplea en las calderas para ser utilizado como combustible en la generación del vapor de alta presión, que se emplea en las turbinas de los molinos para lograr su movimiento y en los turbogeneradores para generar la energía eléctrica que requiere la Empresa. El excedente se vende a la red pública. El bagazo sobrante en esta etapa, es empleado en la industria papelera. El vapor de escape de las turbinas se emplea en las operaciones de evaporación y cocimiento de los jugos azucarados. Los residuos orgánicos generados en la producción de azúcar y etanol como cachaza, ceniza, basuras de patios de caña y vinaza concentrada, se transforman en abono orgánico (compost) aplicable en la agricultura como mejorador del suelo (Incauca S.A., 2011).

Teniendo en cuenta el informe de sostenibilidad (Información secundaria) de la empresa Incauca S.A., la alternativa con proyecto MDL resulta más favorable. Debido a que no se contó con informes de sostenibilidad de Incauca S.A., antes de implementarse el proyecto MDL, se tomó como referencia para evaluar la alternativa sin proyecto, la entrevista rea- lizada al Ingeniero John Jairo León, persona encargada de implementar y monitorear el proyecto MDL en Incauca S.A., por lo que se concluyó que la alternativa sin proyecto es menos favorable para Incauca S.A.

\subsubsection{Entrevistas y grupos focales}

Se llevó a cabo la dinámica del grupo focal con las comunidades de las veredas Santa Ana y El Ortigal, ubicadas en el Municipio de Miranda, debido a que estas veredas son las más cercanas al ingenio, tan solo hasta en la etapa de campo se evidencio que dichas veredas decidieron no hacer parte del proyecto, pues desde que se socializo el mismo en 2008 , la comunidad no encontró suficiente motivación en el componente social que el proyecto proponía. Lo que se pudo observar, teniendo en cuenta la percepción por parte de la comunidad, es que la alternativa sin proyecto MDL es más favorable, debido a que la comunidad que se vio beneficiada con el proyecto MDL se determinó fuera del área de estudio.

En cuanto a la Alcaldía de Miranda, se reconocen aportes del proyecto MDL, se afirma que es favorable y ha beneficiado de manera importante a la comunidad aledaña, argumenta además que hay un problema de acuerdo a las dinámicas sociales y económicas, donde las comunidades siempre exponen algunas actitudes renuentes a las acciones de la empresa, lo cual genera choques importantes dada la misma concepción del desarrollo local.

Los grupos focales tienen como objetivo conocer la mayor cantidad de información tradicional tanto de la actividad cotidiana de los pobladores como de lo desarrollado por la empresa en esa zona. Finalmente, los grupos focales se desarrollaron con los recolectores de caña de azúcar de las dos veredas más cercanas al área de influencia donde se lleva a cabo el proyecto: El Ortigal y Santa Ana. No se logró realizar el grupo focal con la comunidad de Padilla, pues esta no aparecía registrada en el PDD, y en el momento de la visita en campo se presentaron serios problemas de orden público en la zona. 


\subsection{Análisis multicriterio como herramienta de evaluación del proyecto MDL Incauca S.A.}

Al usar la evaluación multicriterio (Multiple Criteria Decision Aid o MCDA) para el caso de estudio, específicamente aplicando el método de proceso de jerarquía analítica (Analytic Hierarchy Process o AHP), apoyado en el manual de la CEPAL de Pacheco \& Contreras (2008), con algunas modificaciones que se presentan en la Ilustración 1.

De esta manera se analizaron e incluyeron las cuatro dimensiones del desarrollo sostenible, planteadas en la última cumbre de Río + 20 que culminó en junio de 2012 (Dimensión de Sostenibilidad Ambiental, Inclusión Social, Desarrollo Económico y Gobernabilidad), a las cuales les fueron asignados siete (7) criterios relevantes para evaluar la contribución del MDL Incauca S.A. al desarrollo sostenible del Municipio de Miranda: i) efectos en la gestión ambiental percibidos por el uso de los residuos de cosecha; ii) generación de beneficios no monetarios a partir de los residuos de cosecha; iii) inversión atraída para el aprovechamiento de residuos de cosecha; iv) generación y calidad de empleo en actividades relaciona- das con el uso de residuos de cosecha; v) beneficios netos generados por los residuos de cosecha; vi) incentivos para la adopción de tecnologías y procesos técnicos en el aprovechamiento de residuos de cosecha; vii) fortalecimiento de organizaciones civiles $y$ de procesos participativos para el uso de residuos de cosecha; de igual manera se establecieron los indicadores correspondientes a cada uno de estos criterios de forma jerárquica tal como se muestra en la Tabla 2.

Desde la postura positivista la decisión de aplicar el muestreo por conveniencia como técnica no probabilística relaciona un sesgo importante debido a que la muestra consultada no sería suficientemente representativa de acuerdo a la población estudiada y asimismo comprometería la aleatoriedad en la selección correspondiente, sin embargo desde la ciencia posnormal, en la cual se enmarca el presente ejercicio de investigación, la subjetividad presentada durante el proceso de implementación correspondiente es inherente a la metodología empleada, como sucede con cualquier ejercicio de investigación, lo cual no compromete la validez de los resultados y hallazgos relacionados. Pese a estas

Ilustración 1. Metodología de análisis multicriterio aplicada al proyecto MDL de generación de energía eléctrica, a partir de los residuos de caña de azúcar por parte de Incauca S.A.

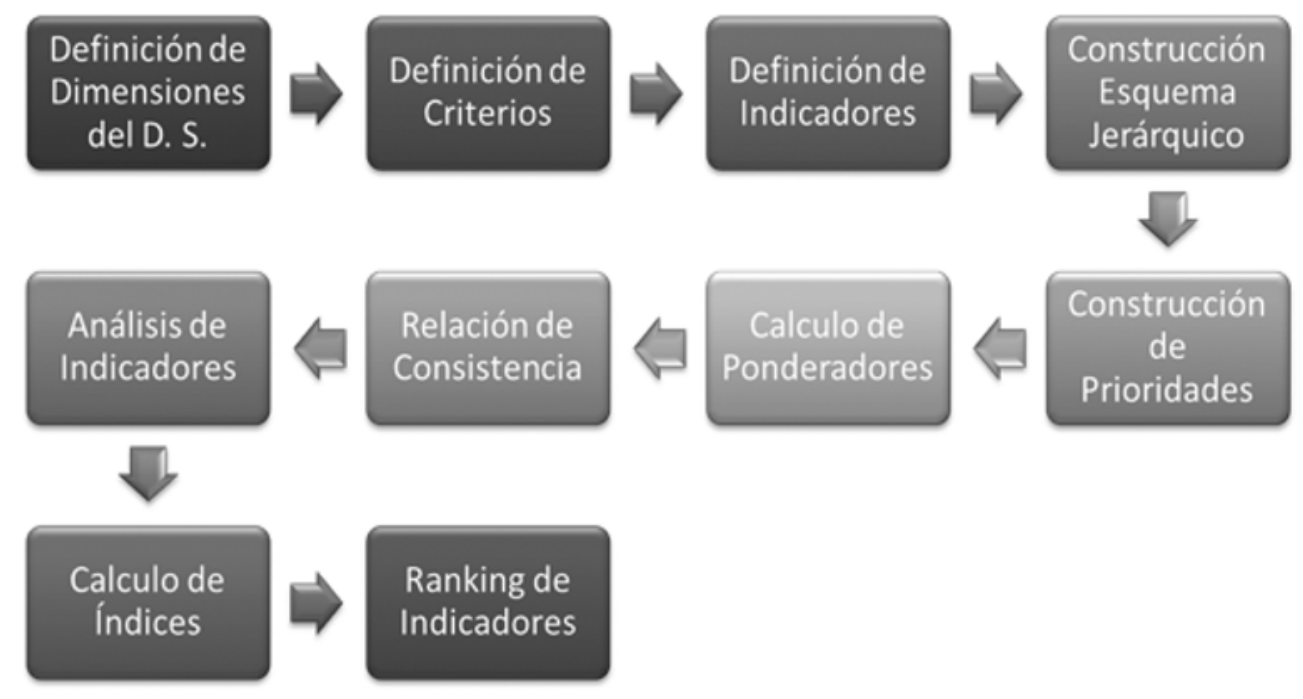

Fuente: Adaptación a partir de Pacheco \& Contreras (2008). 
Tabla 2. Conformación de dimensiones, criterios e indicadores

\begin{tabular}{|c|c|c|}
\hline $\begin{array}{l}\text { Dimensiones del Desarrollo } \\
\text { Sostenible }\end{array}$ & Criterio & Indicador \\
\hline \multirow{4}{*}{ Sostenibilidad Ambiental } & \multirow{4}{*}{$\begin{array}{l}\text { Efectos en la gestión ambiental percibidos por el } \\
\text { uso de los residuos de cosecha. }\end{array}$} & Percepción de los efectos en la gestión del agua. \\
\hline & & Percepción de los efectos en la gestión del suelo. \\
\hline & & Percepción de los efectos en la gestión del aire. \\
\hline & & Percepción de los efectos en la gestión de la biodiversidad. \\
\hline \multirow{2}{*}{ Inclusión Social } & \multirow{2}{*}{$\begin{array}{l}\text { Generación de beneficios no monetarios a partir de } \\
\text { los residuos de cosecha. }\end{array}$} & $\begin{array}{l}\text { Número de programas de inclusión social asociados al uso de } \\
\text { residuos de cosecha. }\end{array}$ \\
\hline & & $\begin{array}{l}\text { Efectividad de los programas de inclusión social asociados al } \\
\text { uso de residuos de cosecha. }\end{array}$ \\
\hline \multirow{8}{*}{ Desarrollo Económico } & $\begin{array}{l}\text { Inversión atraída para el aprovechamiento de Bio- } \\
\text { masa. }\end{array}$ & $\begin{array}{l}\text { Capitales atraídos para el aprovechamiento de residuos de } \\
\text { cosechas. }\end{array}$ \\
\hline & \multirow{3}{*}{$\begin{array}{l}\text { Generación y calidad de empleo en actividades rela- } \\
\text { cionadas con el uso de residuos de cosecha. }\end{array}$} & $\begin{array}{l}\text { Empleos generados por el manejo dado a los residuos de co- } \\
\text { sechas. }\end{array}$ \\
\hline & & $\begin{array}{l}\text { Duración de contratos del empleo generado por el manejo } \\
\text { dado a los residuos de cosechas. }\end{array}$ \\
\hline & & $\begin{array}{l}\text { Prestaciones sociales y seguridad social del empleo generado } \\
\text { por el manejo dado a los residuos de cosechas. }\end{array}$ \\
\hline & \multirow{2}{*}{$\begin{array}{l}\text { Beneficios netos generados por los residuos de } \\
\text { cosecha. }\end{array}$} & $\begin{array}{l}\text { Costo-beneficio (económico) en uso de residuos de cose- } \\
\text { chas. }\end{array}$ \\
\hline & & $\begin{array}{l}\text { Nivel de satisfacción por los beneficios económicos genera- } \\
\text { dos a partir de los residuos de cosecha. }\end{array}$ \\
\hline & \multirow{2}{*}{$\begin{array}{l}\text { Incentivos para la adopción de tecnologías y pro- } \\
\text { cesos técnicos en el aprovechamiento de residuos } \\
\text { de cosecha. }\end{array}$} & $\begin{array}{l}\text { Número de programas de apoyo para la adopción de tecnolo- } \\
\text { gías y procesos técnicos en el uso de residuos de cosecha. }\end{array}$ \\
\hline & & $\begin{array}{l}\text { Efectividad de los programas para la adopción de tecnologías } \\
\text { y procesos técnicos en el uso de residuos de cosecha. }\end{array}$ \\
\hline \multirow{3}{*}{ Gobernabilidad } & \multirow{3}{*}{$\begin{array}{l}\text { Fortalecimiento de organizaciones civiles y de pro- } \\
\text { cesos participativos para el uso de residuos de } \\
\text { cosecha. }\end{array}$} & $\begin{array}{l}\text { Número de procesos participativos implementados en la ges- } \\
\text { tión ambiental de residuos de cosecha. }\end{array}$ \\
\hline & & $\begin{array}{l}\text { Número de pobladores organizados o asociados o que parti- } \\
\text { cipan de procesos de planificación del manejo o aprovecha- } \\
\text { miento de los residuos de cosecha. }\end{array}$ \\
\hline & & $\begin{array}{l}\text { Efectividad de iniciativas que fomentan la participación de po- } \\
\text { bladores en el manejo de residuos de cosecha. }\end{array}$ \\
\hline
\end{tabular}

Fuente: Elaboración propia. 
necesarias discusiones metodológicas, se aplica la metodología AHP de manera rigurosa haciendo uso de esta técnica de selección muestral, reconociendo de antemano algunas potencialidades y limitaciones como bien lo resumen Vergara \& Lozada (2015) en la Tabla 3.

\section{Resultados y análisis}

\subsection{Resultados trabajo de campo}

En la primera parte del instrumento Encuesta, se puede observar la calificación generada por cada actor para cada indicador evaluado con dos escenarios posibles (sin proyecto MDL y con proyecto MDL) y con un rango de calificación de 1 a 5 , siendo el 1 el menos importante y el 5 el más importante:

- Los indicadores de sostenibilidad de un escenario sin proyecto son más favorables pues se afectan menos los recursos naturales de la zona y hay más opciones de empleo.

- Los indicadores sociales, en los dos escenarios (con y sin proyecto MDL), tienen muy bajas calificaciones, es decir que así exista o no exista el proyecto se afectan los recursos naturales sin implicaciones importantes sobre el empleo. A excepción de los beneficios económicos correspondientes a la dimensión de desarrollo económico y los indicadores ambientales correspondientes a la dimensión de sostenibilidad ambiental.

Los indicadores de gobernabilidad en los dos escenarios presentan una calificación muy baja, es decir con proyecto MDL o en ausencia de este el resultado para los indicadores no es favorable.

Dentro del procedimiento metodológico, posterior al trabajo de campo, se define la construcción de prioridades a través del ranking de los actores los cuales ordenaron los criterios de acuerdo a su nivel de importancia, este método es conocido como estandarización sencilla, a partir de allí se construyó la matriz en donde las columnas $(\mathrm{C} 1, \ldots \mathrm{C} 7)$ represen$\tan$ los criterios y las filas las encuestas $(\mathrm{E} 1, \ldots \mathrm{E} 18)$ aplicadas (Tabla 4).

Tabla 3. Potencialidades y limitaciones de la metodología

\begin{tabular}{|l|l|}
\hline $\begin{array}{c}\text { Potencialidades de la Metodología de Análisis Multicriterio por el } \\
\text { método de Proceso de Jerarquía Analítica (AHP) }\end{array}$ & $\begin{array}{l}\text { Limitaciones de la Metodología de Análisis Multicriterio por el método } \\
\text { de Proceso de Jerarquía Analítica (AHP) }\end{array}$ \\
\hline Pluralidad de Percepciones & Subjetividad \\
\hline Captura de Preferencias & Generalidad \\
\hline Procedimiento Riguroso & Limitaciones Cognitivas \\
\hline Toma de Decisiones & Sesgo en la Selección de Actores \\
\hline Flexibilización & Asimetría \\
\hline Convergencias y Divergencias & Presupuesto \\
\hline
\end{tabular}

Fuente: Elaboración propia a partir de Vergara \& Lozada (2015). 
Tabla 4. Construcción de prioridades

\begin{tabular}{|l|c|c|c|c|c|c|c|}
\hline & c1 & c2 & c3 & c4 & c5 & c6 & c7 \\
\hline E1 & 7 & 3 & 6 & 1 & 2 & 4 & 5 \\
\hline E2 & 5 & 4 & 3 & 7 & 6 & 1 & 2 \\
\hline E3 & 5 & 3 & 6 & 7 & 2 & 4 & 1 \\
\hline E4 & 7 & 3 & 6 & 1 & 2 & 4 & 5 \\
\hline E5 & 5 & 3 & 6 & 7 & 2 & 4 & 1 \\
\hline E6 & 5 & 3 & 6 & 7 & 2 & 4 & 1 \\
\hline E7 & 4 & 5 & 3 & 7 & 6 & 1 & 2 \\
\hline E8 & 4 & 5 & 3 & 7 & 6 & 1 & 2 \\
\hline E9 & 4 & 5 & 3 & 7 & 6 & 1 & 2 \\
\hline E10 & 1 & 2 & 7 & 6 & 5 & 4 & 3 \\
\hline E11 & 3 & 5 & 4 & 7 & 6 & 2 & 1 \\
\hline E12 & 3 & 5 & 4 & 7 & 6 & 2 & 1 \\
\hline E13 & 3 & 1 & 5 & 7 & 2 & 6 & 4 \\
\hline E14 & 2 & 1 & 6 & 7 & 3 & 5 & 4 \\
\hline E15 & 2 & 5 & 1 & 7 & 6 & 3 & 4 \\
\hline E16 & 5 & 4 & 3 & 7 & 2 & 1 & 6 \\
\hline E17 & 3 & 4 & 2 & 7 & 1 & 6 & 5 \\
\hline E18 & 3 & 4 & 2 & 7 & 1 & 6 & 5 \\
\hline PR0MED10 & 4 & 4 & 4 & 6 & 4 & 3 & 3 \\
\hline
\end{tabular}

\begin{tabular}{|c|c|}
\hline CRITERIOS & CALIFICACIÓN \\
\hline 1 & menos importante \\
\hline 2 & \\
\hline 3 & \\
\hline 4 & \\
\hline 5 & \\
\hline 6 & \\
\hline 7 & más importante \\
\hline
\end{tabular}

\begin{tabular}{|l|}
\hline C: Criterios \\
\hline E: Encuestas \\
\hline
\end{tabular}

Fuente: Elaboración propia.

\subsection{Resultados tratamiento de datos}

De otro lado, el cálculo de ponderadores se lleva a cabo transformado la matriz anterior en ceros (0) y unos (1) de acuerdo a la relación de importancia entre las columnas y las filas, resaltando la relación positiva con unos y relación negativa con ceros, tal como se muestra en la Tabla 4. Para el cálculo de los ponderadores simplemente se suman las filas y columnas y se calcula el porcentaje que cada uno representa en el total.
Para llevar a cabo este análisis se construyó una matriz de comparaciones, donde se ingresaron los juicios respecto a la importancia relativa de los criterios. Debido a que fue posible determinar qué criterio era más importante que otro, se utilizó el método sencillo de estandarización, para completar la matriz de comparaciones con ceros y unos según correspondiera, según lo muestra la Tabla 5 (Pacheco \& Contreras, 2008, p. 63). 
Tabla 5. Método sencillo de estandarización

\begin{tabular}{|c|c|c|c|c|c|c|c|c|c|}
\hline & C1 & C2 & C3 & C4 & C5 & C6 & C7 & SUMA & PONDERADOR \\
\hline $\mathrm{C} 1$ & & 0 & 0 & 1 & 0 & 0 & 0 & 1 & 0.07 \\
\hline C2 & 0 & & 0 & 1 & 0 & 0 & 0 & 1 & 0.07 \\
\hline C3 & 0 & 0 & & 1 & 0 & 0 & 0 & 1 & 0.07 \\
\hline C4 & 0 & 0 & 0 & & 0 & 0 & 0 & 0 & 0.00 \\
\hline C5 & 0 & 0 & 0 & 1 & & 0 & 0 & 1 & 0.07 \\
\hline C6 & 1 & 1 & 1 & 1 & 1 & & 0 & 5 & 0.36 \\
\hline $\mathrm{C7}$ & 1 & 1 & 1 & 1 & 1 & 0 & & 5 & 0.36 \\
\hline SUMA & 2 & 2 & 2 & 6 & 2 & 0 & 0 & & \\
\hline PONDERADOR & 0.14 & 0.14 & 0.14 & 0.43 & 0.14 & 0.00 & 0.00 & & \\
\hline
\end{tabular}

Fuente: Elaboración propia.

Se puede observar que dentro de la matriz de ponderación de los 7 criterios evaluados y una vez realizado el promedio de ponderación por cada criterio de las 18 encuestas realizadas, el criterio que consideran los diversos actores encuestados (INACUCA S.A, Alcaldía de Miranda, comunidad de la vereda El Ortigal y comunidad de la vereda Santa Ana), como de mayor importancia es el criterio 4, que corresponde a la generación y calidad de empleo en actividades relacionadas con el uso de residuos de cosecha. Los criterios más importantes seguidos al criterio 4, son los criterios 1, 2, 3 y 5 , mientras que los criterios que se consideran como de menor importancia dentro de los 7 criterios evaluados por los diversos actores, son los criterios 6 y 7 .

Dentro de la aplicación de la metodología AHP, la consistencia permite asegurar que exista una lógica inherente a la misma de acuerdo a las respuestas obtenidas a través de los diferentes juicios de valor, otorgados por los actores dados los diversos crite- rios relacionados. En este sentido se llevó a cabo la comprobación de la consistencia de los juicios ingresados en la matriz de comparaciones, pues se debe corroborar que al fijar prioridades para elementos o actividades de algún criterio, estos deben ser válidos en la vida real. Pacheco \& Contreras (2008 p.54), mencionan que el AHP "mide la inconsistencia global de los juicios mediante la Proporción de Consistencia, que es el resultado de la relación entre el Índice de Consistencia y el Índice Aleatorio. El Índice de Consistencia es una medida de la desviación de consistencia de la matriz de comparaciones a pares y el Índice Aleatorio es el índice de consistencia de una matriz recíproca aleatoria, con recíprocos forzados, del mismo rango de escala de 1 hasta 9". El valor de la relación de consistencia no debe superar el 10\% para demostrar que es un juicio informado. Para el cálculo de la relación de consistencia se parte de la ecuación:

$$
\lambda \max =V^{*} B
$$


En donde ( $\lambda \max )$ es el máximo valor propio de la matriz de comparaciones a pares; $(\mathrm{V})$ es el vector de prioridades que se obtuvo en la matriz de comparaciones y (B) es la suma de los elementos de cada columna de la matriz a comparaciones a pares $(\mathrm{Pa}-$ checo \& Contreras, 2008).

Para nuestro ejercicio el valor de la relación de consistencia nos dio como resultado 1,70. Sin embargo, a partir de aquí podemos calcular el índice de consistencia (CI) mediante la siguiente ecuación:

$$
C I=(\lambda \max -n) /(n-1)
$$

Donde (n) es el número de criterios que hemos venido trabajando y el valor que nos arroja el índice de consistencia es de $-0,88$. Finalmente para obtener el índice de consistencia nos hace falta el índice aleatorio (RI), el cual se toma de una tabla elaborada por Saaty (1997), que muestra los índices de consistencia para una serie de matrices aleatorias con recíprocos forados, para nuestro caso es de 1,32. Finalmente se resuelve la Relación de Consistencia bajo la ecuación:

$$
(R C=C I / R I)
$$

El resultado fue de $-0,67$, ratificando que los juicios trabajados son consistentes en el ejercicio y que no es necesario reevaluar los juicios nuevamente con los expertos.

El análisis de los indicadores, involucra entonces los valores cualitativos, empleando escalas que permitan su homologación numérica, para lograr esto se definieron cuidadosamente unos atributos con su correspondiente valor numérico y a partir de allí se cuantificaron las entrevistas, los grupos focales y parte de la información secundaria que se obtuvo de literatura relacionada con el proyecto y el área de estudio.

Finalmente el cálculo de índices, consiste simplemente en tomar los valores de los ponderadores previamente hallados y multiplicarlos por los valores normalizados de los indicadores, permite establecer un orden jerárquico dando preferencia aquel que obtuvo mayor puntuación en la evaluación, en este sentido puede observarse que en términos globales es más favorable una situación sin proyecto MDL $(0,37)$ que una situación con proyecto $\operatorname{MDL}(0,47)$, como se evidencia en las Tablas 6 y 7.

\begin{tabular}{|c|c|c|c|c|}
\hline \multirow{2}{*}{ Criterio } & \multirow{2}{*}{ Alternativa } & $\begin{array}{c}\text { Valor } \\
\text { normalizado }\end{array}$ & \multirow{2}{*}{$\begin{array}{c}\text { Ponderador } \\
\text { de cada } \\
\text { criterio }\end{array}$} & \multirow{2}{*}{ Resultado } \\
\hline & & $\begin{array}{l}\text { Promedio de } \\
\text { las fuentes }\end{array}$ & & \\
\hline \multirow{2}{*}{ Criterio 1} & Con & 3.03 & 0.14 & 0.43 \\
\hline & $\operatorname{Sin}$ & 2.99 & 0.14 & 0.43 \\
\hline \multirow{2}{*}{ Criterio 2} & Con & 3.08 & 0.14 & 0.44 \\
\hline & $\operatorname{Sin}$ & 2.92 & 0.14 & 0.42 \\
\hline \multirow{2}{*}{ Criterio 3} & Con & 1.85 & 0.14 & 0.26 \\
\hline & $\operatorname{Sin}$ & 0.95 & 0.14 & 0.14 \\
\hline \multirow{2}{*}{ Criterio 4} & Con & 3.95 & 0.43 & 1.69 \\
\hline & $\operatorname{Sin}$ & 2.53 & 0.43 & 1.08 \\
\hline \multirow{2}{*}{ Criterio 5} & Con & 2.98 & 0.14 & 0.43 \\
\hline & $\operatorname{Sin}$ & 3.54 & 0.14 & 0.51 \\
\hline \multirow{2}{*}{ Criterio 6} & Con & 3.47 & 0.00 & 0.00 \\
\hline & $\operatorname{Sin}$ & 2.14 & 0.00 & 0.00 \\
\hline \multirow{2}{*}{ Criterio 7} & Con & 3.60 & 0.00 & 0.00 \\
\hline & Sin & 2.58 & 0.00 & 0.00 \\
\hline
\end{tabular}

Tabla 6. Cálculo de índices

Fuente: Elaboración propia.

Tabla 7. Establecimiento de ranking global

\begin{tabular}{|c|c|}
\hline SIN PROYECTO & CON PROYECTO \\
\hline 0.37 & 0.47 \\
\hline
\end{tabular}

Fuente: Elaboración propia.

\subsection{Análisis de resultados}

Debido a que el objetivo del estudio se centra en la incidencia que el del proyecto MDL en mención sobre el desarrollo sostenible, fueron analizadas las 
cuatro dimensiones, planteadas en la última cumbre de Río + 20 (ONU, 2012) que culminó en junio de 2012, obteniendo los siguientes resultados:

Se puede observar que dentro de la matriz de ponderación de los 7 criterios evaluados, durante la fase de salida de campo y una vez realizado el promedio de ponderación por cada criterio de las 18 encuestas realizadas:

- El criterio que los diversos actores encuestados (Incauca S.A., Alcaldía de Miranda, comunidad de la vereda El Ortigal y comunidad de la vereda Santa Ana), consideraron de mayor importancia es el número 4, que corresponde a: $\mathrm{La}$ Generación y calidad de empleo en actividades relacionadas con el uso de residuos de cosecha.

- Los criterios que le siguieron en importancia, son los criterios $1,2,3$ y 5 .

- Los criterios que se consideraron como de menor importancia dentro de los 7 criterios evaluados por los diversos actores, fueron los criterios 6 y 7 .

\subsubsection{Dimensión de sostenibilidad ambiental}

La metodología permitió establecer que la percepción frente a los efectos de la gestión ambiental tanto en el agua, el suelo, la biodiversidad y el aire no representan diferencias importantes entre las prácticas llevadas a cabo antes del proyecto y las prácticas llevadas a cabo a partir del proyecto MDL, dicha afirmación se valida porque el primer criterio analizado "Efectos en la gestión ambiental percibidos por el uso de los residuos de cosecha", presenta participaciones del 0,43 ambas situaciones (con y sin proyecto).

Sin embargo, es importante resaltar que a partir del momento en que se da inicio a los procesos propios del MDL, surge un cambio en la combustión que se lleva a cabo al interior de la planta favoreciendo el aire (reduciendo las emisiones de GEI), pero, como dicha combustión parte de los residuos de cosecha cambia la forma en la que dichos residuos son recogidos, involucrando maquinaria tecnificada que no favorece las condiciones del suelo y la biodiversidad, entre algunos otros componentes.

\subsubsection{Dimensión de inclusión social}

Los indicadores relacionados con la dimensión social del desarrollo sostenible, diseñados para revisar la generación de beneficios no monetarios, fueron orientados hacia el número de programas de inclusión social asociados al uso de residuos de cosecha y la efectividad de tales programas, en tal sentido, la metodología demuestra que la situación "con proyecto" favorece más al desarrollo social del municipio con una participación promedio del 0,44 frente a la situación "sin proyecto" con una participación de tan solo 0,42 .

Es importante reconocer la iniciativa planteada por la empresa Incauca S.A. y acogida por la comunidad de Padilla (vereda ubicada a una hora de la planta), la cual consiste en el desarrollo y puesta en marcha de una cooperativa de corte y transporte de hoja de caña (residuos utilizados en el nuevo proceso de sustitución de combustibles). Al mismo tiempo, se hace necesario presentar las inconformidades manifestadas por otras veredas más cercanas a la planta de Incauca S.A. en Miranda como la vereda El Ortigal y Santa Ana quienes manifiestan que tal iniciativa no genera beneficios tangibles para ellos. Debido a la negativa de participar por parte de las veredas cercanas, la empresa de vio obligada a socializar el proyecto con las veredas más alejadas, encontrando aceptación en la vereda Padilla, donde finalmente se llevó a cabo la iniciativa social.

\subsubsection{Dimensión de desarrollo económico}

En la dimensión de Desarrollo Sostenible, se analizó un criterio denominado "Inversión atraída para el aprovechamiento de residuos de cosecha", el cual obtuvo una de las menores participaciones en el desarrollo económico del municipio con tan solo un 0,14 . Cabe mencionar, que la información disponible frente a la inversión atraída por el MDL, no logró ser ratificada en fuentes secundarias de información y tampoco con los grupos focales llevados a cabo a lo largo del trabajo de campo, esta informa- 
ción fue proporcionada únicamente por los dueños y desarrolladores del proyecto en Incauca S.A.

En esta misma dimensión, encontramos los criterios con mayor y menor información y discusión de todos los analizados por la metodología; aquel más importante de todo el análisis es el denominado "generación y calidad del empleo en actividades relacionadas con el uso de residuos de cosecha" y se encontró, que la alternativa sin proyecto tiene una menor participación $(1,08)$ frente a la alternativa con proyecto $(1,69)$. A partir de la información cualitativa se puede inferir que la alternativa sin proyecto requiere emplear más recurso humano en la recolección del bagazo y posteriormente esta labor fue tecnificada y reemplazada por maquinaria que no permite el empleo de la misma cantidad de personas, pese a ello, la alternativa con proyecto logró desarrollar una cooperativa de corte y transporte de hoja de caña que vincula laboralmente a muchos de los empleados ocasionales que existían antes del MDL.

Cabe resaltar que la compañía Incauca S.A. manifiesta que las condiciones laborales para todas las personas vinculadas con la cooperativa de hoja verde mejoraron ostensiblemente, debido a que tienen la oportunidad de formalizar su actividad, cotizar prestaciones sociales e incluso adelantar capacitaciones con la Fundación Carvajal, entidad que apoya a los pobladores y a la empresa en el proceso de puesta en marcha de dicha cooperativa.

Adicionalmente, el criterio denominado "beneficios netos generados por los residuos de cosecha", representa, según la metodología, una participación promedio en el desarrollo social del municipio, con un 0,43 , esto puede ser explicado de acuerdo a algunas fuentes de información secundaria y la entrevista llevada a cabo a la compañía dueña y desarrolladora del proyecto, en donde se manifiesta que gracias al MDL se han adelantado importantes planes sociales que benefician a la comunidad.

\subsubsection{Dimensión de gobernabilidad}

La dimensión de gobernabilidad fue analizada por medio del criterio denominado "fortalecimiento de organizaciones civiles y de procesos participativos para el uso de residuos de cosecha", tal criterio tiene una participación nula bajo los dos escenarios analizados, del 0,00. Esto refleja una clara problemática de interacción de Incauca S.A. con la comunidad de Miranda, dada una debilidad en los procesos de participación por parte de los representantes de la comunidad involucrada en el presente estudio.

Esto podría obedecer a lo que se evidencia en la alternativa sin proyecto (según la percepción cualitativa) cuando el desconocimiento de los procesos participativos implementados en la gestión ambiental del municipio y la poca participación de la comunidad en procesos de planificación y aprovechamiento de los residuos de cosecha corresponde a un elemento de conflicto.

Sin embargo, como se mencionó anteriormente, la Alcaldía de Miranda reconoce la participación de la compañía Incauca S.A. en el adelanto de alternativas que van en favor del ambiente, a pesar de dimensionar algunos contrastes de la visión del desarrollo local entre las comunidades y la empresa, la cual ha aportado en este sentido a través de interesantes iniciativas como el de la cooperativa de Hoja Verde.

\section{Conclusiones}

La presente investigación se llevó a cabo con la metodología de análisis multicriterio, la cual busca integrar las diferentes dimensiones de la realidad de una problemática, con el fin de dar una visión integral y un mejor acercamiento a la realidad. En el ejercicio práctico se pudo observar que esta metodología permite identificar la pluralidad de percepciones de los actores que intervienen en el proceso, así como también sus preferencias, convergencias y divergencias. A pesar de que se reconocen ciertas limitaciones inherentes a la metodología y al mismo trabajo de campo, de acuerdo a la subjetividad relacionada con la selección de los actores, no compromete la validez de los resultados y hallazgos obtenidos, más aún cuando el estudio se ciñó a los presupuestos teóricos que involucra un enfoque tanto cualitativo como cuantitativo de investigación. 
Atendiendo al objetivo de la investigación de analizar los proyectos de Mecanismo de Desarrollo Limpio (MDL) del sector de generación de energía eléctrica por biomasa en Colombia: en particular el proyecto MDL de sustitución de combustibles en Incauca S.A., y tal como fue mencionado en la metodología, se desarrolló el presente trabajo de investigación bajo dos escenarios: el primero contemplando la situación "sin proyecto", es decir, analizando las diferentes situaciones antes del proyecto y en ausencia del mismo; y el segundo contemplando la situación "con proyecto", analizando las situaciones presentadas desde el diseño y puesta en marcha de éste.

De acuerdo a lo anterior, como resultado definitivo se puede evidenciar que no existe una diferencia importante entre la situación "con proyecto" y la situación "sin proyecto", sin embargo al analizar de manera global el ranking de las dos alternativas es evidente que los actores involucrados prefieren la situación sin proyecto a la situación con proyecto, en otras palabras, puede deducirse del presente estudio que la contribución al desarrollo sostenible del Municipio de Miranda, Cauca, no está determinada por la puesta en marcha del proyecto MDL. De esta manera la información proporcionada por las diferentes fuentes de información consultadas y validadas con la metodología de análisis multicriterio indican que las situaciones presentadas con anterioridad al proyecto MDL o en ausencia del mismo resultan contribuir prácticamente en la misma medida con la situación actual en presencia del MDL al desarrollo social del municipio.

Por lo tanto, el método AHP es claro al indicar que los promedios de los datos recuperados son ínfimamente distintos entre estas situaciones, debido a que la diferencia entre estos valores es tan solo del 0,10 puntos, donde la contribución al desarrollo sostenible del Municipio de Miranda (Cauca), está algo más aventajada con la situación en ausencia del proyecto que con el mismo.

Cabe resaltar que debido a que uno de los objetivos del MDL es la propagación de alternativas favorables para el ambiente que reduzcan GEI, el proyecto de Incauca S.A. cumple con tal exigencia, al realizar el cambio en la combustión al interior de la planta favoreciendo el aire dado el otorgamiento de los CER's asociados al proyecto, pero, a pesar de ello se incorpora maquinaria tecnificada que no necesariamente favorece las condiciones del suelo y la biodiversidad y asimismo desplaza la mano de obra local.

Es evidente que si bien los proyectos MDL representan alternativas para incidir en el desarrollo sostenible de los países en vías de desarrollo, no todos tienen el reconocimiento por parte de algunos actores, dentro de ellos las comunidades aledañas a los mismos, en donde se observa el impacto correspondiente. En este sentido es de gran relevancia examinar más de cerca la interacción institucional Empresa -Estado- Comunidad, para optimizar estos procesos, los cuales deberán redundar en resultados de desarrollo sostenible local como un concepto multidimensional.

La mayor preocupación de los actores (Incauca S.A., Alcaldía de Miranda, comunidad de la vereda El Ortigal y comunidad de la vereda Santa Ana) gira en torno a las condiciones de empleo, de tal modo que el criterio 4 (generación y calidad de empleo en actividades relacionadas con el uso de residuos de cosecha), debe responder a las condiciones que la comunidad necesita, pues, la oferta de empleo es poca y la calidad del mismo no garantiza un nivel de vida favorable.

A pesar de que el proyecto MDL fue socializado a la comunidad antes de su implementación y allí se especificaron los beneficios que de este podrían surgir como la creación de la cooperativa de corte y transporte de caña "Hoja Verde", la comunidad de veredas cercanas al ingenio (El Ortigal y Santa Ana) decidieron no hacer parte de la cooperativa, en consecuencia, sólo participó la vereda Padilla (ubicada a una hora de la planta). Posteriormente, cuando la cooperativa se puso en funcionamiento y se brindaron beneficios y privilegios a los socios se negó toda posibilidad de ingreso de las demás veredas circundantes, impidiendo con esto que el proyecto y la iniciativa que surgió del mismo pudiese llegar a tener mayor acogida, es por esto que la empresa Incauca S.A. junto con la fundación Carvajal (apoyo 
en los procesos de diseño y puesta en marcha de la cooperativa) deben propiciar estos espacios y ampliarlos a un mayor número de beneficiarios.

El presente ejercicio de investigación pretende aportar herramientas analíticas para los tomadores de decisiones de políticas ambientales a nivel local, regional y nacional, constituyéndose igualmente en un elemento de discusión académica y científica en aras de fomentar la aplicación de metodologías alternativas que trasciendan del reduccionismo científico para dar respuesta a la complejidad multidimensional del desarrollo sostenible local.

\section{Referencias}

Alcott, B. (2005). Jevons' paradox. Ecological Economics 54 (1): 9-21. Doi:10.1016/j.ecolecon.2005.03.020

Aleluia, J. \& Leitao, J. (2009). International entrepreneurship and technology transfer: the CDM's reality in China. Munich Personal RePEc Archive, № 16150. Online at: http://mpra. ub.uni-muenchen.de/16150/. Diciembre de 2009.

Alvater E. (1998). Obstáculos en la trayectoria del desarrollo. En libro: Los retos de la globalización. Ensayo en homenaje a Theotonio Dos Santos. Segrera, F. (ed.). UNESCO, Caracas, Venezuela. Disponible en: http://bibliotecavirtual.clacso.org. ar/ar/libros/unesco/alvater.rtf

Angulo, N. (2010) Pobreza, medio ambiente y desarrollo sostenible. Nómadas. Revista Crítica de Ciencias Sociales y Jurídicas, 26.

Barba D., Garavito S., López S., Nieves H., Olarte C., Ortega S. \& Santos L. (2010). Segunda comunicación nacional ante la CMNUCC. Capítulo 3. (Online). Recuperado de: http:// www.slideshare.net/inviertaencolombia/sector-tecnologaslimpias-proexport p. 184).

Canoura, C. (2009). América Latina ante los efectos irreversibles de un planeta más caliente. Primer Informe Regional sobre Cambio Climático. Tierramérica Medio Ambiente y Desarrollo.

Casal, J. \& Mateu, E. (2003). Tipos de Muestreo. Rev. Epidem. Med. Prev., 1: 3-7.

Comas, E., Bosch, A., Cuéllar, M. \& Gamboa, G. (2011). Sostenibilidad de la producción porcina en Cataluña (España). Aplicación del análisis multicriterio. Publicado bajo licencia de Redibec en: http://www.redibec.org/IVO/rev18_01. pdf. Iberoamericana de Economía Ecológica Vol. 18: 1-19.

Cotte, A. \& Pardo, C. (2011). Qualitative comparative analysis (QCA): an application for the industry. Quality \& Quantity International Journal of Methodology, 1: 1-8.

De Quinto, J. \& Ferreira, J. (2005). Instrumentos para el desarrollo de los MDL: una oportunidad para Latinoamérica. UNISCI Discussion Papers.

DNP - Departamento Nacional de Planeación (2015). Objetivos de Desarrollo Sostenible (ODS): Agenda de Desarrollo Post-2015 de la Organización de las Naciones Unidas. Disponible en: https://colaboracion.dnp.gov.co/CDT/Prensa/Publicacio-
nes/05\%20Objetivos\%20de\%20Desarrollo\%20Sostenible\%20 para\%20la\%20web.pdf

Doranova, A., Costa, I. \& Duysters, G. (2009). Knowledge base determinants of technology sourcingin clean development mechanism projects. UNU-MERIT, Keizer Karelplein19, Maastricht 6211TC, The Netherlands. Energy Policy, 38: 5550-5559.

Falconí, F. \& Burbano, R. (2004). Instrumentos económicos para la gestión ambiental: decisiones monocriteriales versus decisiones multicriteriales. Revista Iberoamericana de Economía Ecológica, 1: 11-20.

Fernández, G. \& Escribano, M. (2011). La ayuda a la decisión multicriterio: orígenes, evolución y situación actual. Memorias del V Congreso Internacional de Historia de la Estadistica y de la Probabilidad. Disponible en: http://www.ahepe.es/ VICongreso/descargas/Gabriela_Fdz_Barberis.pdf

Funtowicz, S. \& Ravetz, J. (2004). La ciencia post-normal: ciencia con la gente. Madrid: Icaria.

Huang, Y. \& Barker, T. (2010). The Clean Development Mechanism and low carbon development: A panel data analysis, University of Cambridge. Energy Econ., doi:10.1016/j. eneco.2011.08.010

IDEAM, Ministerio del Medio Ambiente \& Departamento Nacional de Planeación. (2002). Lineamientos de política de cambio climático: resumen ejecutivo.

IDEAM, Ministerio de Ambiente, Vivienda y Desarrollo Territorial \& PNUD. (2006). Estrategias de Reducción de Incertidumbre de las Variables Básicas en la Estimación de Gases de Efecto Invernadero (GEI). (Módulos Cambio en el Uso de la Tierra y Silvicultura, Energía - Sector Transporte y Agricultura).

Incauca S.A. (Ingenio del Cauca S.A. - Incauca S.A.) (2011). Informe de sostenibilidad 2010-2011. Disponible en: http:// www.incauca.com/sites/default/files/archivos/Informe $\% 20$ Sostenibilidad\%202010-2011.pdf

Karakosta, C. Doukas, H. \& Psarras, J. (2009). Directing clean development mechanism towards developing countries' sustainable development priorities. National Technical University of Athens, School of Electrical and Computer Engineering, Energy Policy Unit of the Management and Decision Support Systems Laboratory (EPU-NTUA), 9, IroonPolytechniou Str., 157 - 80, Athens, Greece.

Mejía, C. (2005). Mecanismo de Desarrollo Limpio: una debilidad convertida en oportunidad. Pensamiento y Gestión, (18): 138-150.

Olsen, K \& Fenhann, J. (2008). Sustainable development benefits of clean development mechanism projects A new methodology for sustainability assessment based on text analysis of the project design documents submitted for validation. UNEP Ris $\varnothing$ Centre on Energy, Climate and Sustainable Development (URC), Risø National Laboratory, PO Box 49, 4000 Roskilde, Denmark.

ONU (1992). Organización de Naciones Unidas. Convención marco de las Naciones Unidas sobre cambi1o climático. Washington D.C. ONU.

ONU (1998). Organización de Naciones Unidas. Protocolo de Kyoto de la Convención Marco de las Naciones Unidas sobre el cambio climático. Kyoto: ONU.

ONU (2012). Organización de Naciones Unidas. Conferencia de las Naciones Unidas sobre el Desarrollo Sostenible (Rio+20). El Futuro que Queremos. Río de Janeiro (Brasil). ONU. 2012. A/CONF.216/L.1 
ONU (2014). Organización de Naciones Unidas. El camino hacia la dignidad para 2030: Acabar con la pobreza y transformar vidas protegiendo el planeta. Informe de síntesis del secretariado general sobre la agenda de desarrollo sostenible después de 2015. A/69/700

Pacheco, J \& Contreras, E. (2008). Manual metodológico de evaluación multicriterio para programas y proyectos. Serie Manueales de la CEPAL, № 58: 1-111. Instituto Latinoamericano y del Caribe de Planificación Económica y Social (ILPES).

Pierri, N. (2001). Historia del concepto de desarrollo sustentable. Capítulo II: 287-81. En: De Pierri, N. \& Foladori, G. (2001) ¿Sustentabilidad? Desacuerdos sobre el desarrollo sustentable, Uruguay: Trabajo y Capital.

Saaty, T. (1977). A scaling method for priorities in hierarchical structures. Journal of mathematical psychology 15(3): 234-281.

Saaty, T. (1987). The Analytic Hierarchy Process-What It Is And How It Is Used. Mat/d Modelling, 9 (3-5): 161-176.

Saaty, T. (1997). Toma de Decisiones Para Líderes. Universidad de Santiago de Chile.

Saaty, T. (2003). Decision-making with the AHP: Why is the Principal Eigenvector necessary? European Journal of Operational Research, 145(1): 85-91.
Sabogal J., Hurtado E. \& Moreno E. (2010). Evaluación de los proyectos de mecanismo de desarrollo limpio presentados a la UNFCCC: los criterios de sostenibilidad entre 2004 y 2008. Revista Facultad de Ciencias Económicas, 18 (1).

Sandoval, C. (2002). Investigación Cualitativa. Programa de Especialización en Teoría Métodos y Técnicas de Investigación Social. Instituto Colombiano para el Fomento de la Educación Superior ICFES

SDSN - Red de Soluciones para el Desarrollo Sostenible. (2013) Una Agenda de Acción para el Desarrollo Sostenible. Disponible en: www.unsdsn.org.

UNEP (2014). Programa de las Naciones Unidas para el Medio ambiente. Centre on Energy Climate and Sustainable Developent. Copenhagen (Dinamarca). Recuperado de http:// http://www.cdmpipeline.org/

Vergara, C. \& Lozada, J. (2015). Método de proceso de jerarquía analítica: potencialidades y limitaciones en Colombia: caso de estudio proyecto MDL Incauca S.A. Memorias IX Congreso de Investigaciones Universidad Militar Nueva Granada. Bogotá.

Villavicencio, A. (2004). Mitos y realidad del mecanismo de desarrollo limpio. Revista Iberoamericana de Economía Ecológica, 1: 56-65. 


\title{
LA PARTICIPACIÓN FEMENINA EN PUBLICACIONES COLOMBIANAS DE ECONOMÍA Y ADMINISTRACIÓN INDEXADAS EN SCOPUS (1974-JUNIO DE 2014)*
}

\author{
JENNY-PAOLA LIS-GUTIÉRREZ"** \& CLORITH-ANGÉLICA BAHOS-OLIVERA*** \\ FUNDACIÓN UNIVERSITARIA KONRAD LORENZ - UNIVERSIDAD NACIONAL DE COLOMBIA
}

Recibido/ Received/ Recebido: 05/02/2015 - Aceptado/ Accepted/ Aprovado: 07/04/2016

\section{Resumen}

A partir de la construcción de: (i) indicadores de género (distribución horizontal, distribución vertical, índice de feminidad, índice de masculinidad, índice de Duncan, índice de segregación, índice de contribución al sexismo e índice de interacción), (ii) un análisis bibliométrico descriptivo y evaluativo, segmentado por el sexo de los autores, y (iii) representaciones de cartografía temática y estadística, se pretendió establecer si existe una brecha de género en la producción académica nacional en Economía y Administración, esto, a pesar de que el número de autoras en ciencias económicas se haya incrementado en años recientes. Los resultados indican que los artículos con mujeres como autoras principales no superaron el $27 \%$ y como co-autoras solo fue del $24 \%$. A su vez se identificó que los mejores indicadores en cuanto a reiteración de las citaciones (índices $\mathrm{H}, \mathrm{R}$ y A) los obtienen los artículos escritos por hombres sin co-autoría femenina. Finalmente se logró establecer que los indicadores de género calculados con respecto al número de autores, reiteran la brecha de género y la masculinización en la publicación científica en ciencias económicas, sin embargo, no hay evidencia de segregación en las tres áreas analizadas.

Palabras clave: Bibliometría; Cienciometría; Economía; Administración; Índices bibliométricos; Indicadores de género; Brecha de género; Scopus.

\section{WOMEN'S PARTICIPATION IN ECONOMY AND ADMINISTRATION COLOMBIAN PUBLICATIONS INDEXED IN SCOPUS (1974 - JUNE 2014)}

\begin{abstract}
From the construction of: (i) gender indicators (horizontal distribution, vertical distribution, rate of femininity, masculinity index, Duncan index, segregation index, contribution to sexism index and interaction index), (ii) a descriptive and evaluative bibliometric analysis, segmented by sex of the authors, and (iii) representations of thematic and statistical cartography, was intended to establish whether there is a gender gap in national academic production in Economics and Management, this, despite the number of female authors in economics has increased in recent years. The results

Candidata a doctora en Ingeniería, en el área de Industria y Organizaciones (Universidad Nacional de Colombia), Magíster en Análisis de problemas políticos, económicos e internacionales (Universidad Externado de Colombia), Magíster en Sociedades contemporáneas comparadas Europa-América Latina (Paris III- Sorbonne Nouvelle), especialidad en Geografía y Planeación (IHEAL), Economista (Universidad Nacional de Colombia). Se desempeña actualmente como Directora del Centro de Investigaciones de la Escuela de Negocios de la Fundación Konrad Lorenz, y docente catedrática de las universidades Externado de Colombia, Central y del Instituto de Altos Estudios para el Desarrollo. Dirección postal: Carrera 9 bis No. 62 - 43 (Bogotá - Colombia). Teléfono: (057-1) 3472311 Ext. 228. Correo electrónico: jenny.lis@konradlorenz.edu.co

..." Estudiante de la Maestría en Estudios Sociales de la Ciencia y Economista (Universidad Nacional de Colombia). Profesional de Centro de Apoyo a la Investigación Económica-CAIE del Banco de la República. Correo electrónico: thelik313@gmail.com
\end{abstract}

Artículo de reflexión 
indicate that articles with women as main authors did not exceed $27 \%$ and as co-authors was only 24\%. In turn it was identified that the best indicators as to repeated citations (index H, R and A) get articles written by men without female co-authorship. Finally it was established that gender indicators calculated relative to the number of authors reiterate the gender gap and masculinization in scientific publication in economics, however, there is no evidence of segregation in the three areas analyzed. Keywords: Bibliometrics; Scientometrics; Economy; Management; Bibliometric index; Gender indicators; Gender gap; Scopus.

\section{A PARTICIPAÇÃO FEMININA EM PUBLICAÇÕES COLOMBIANAS DE ECONOMIA E ADMINISTRAÇÃO INDEXADAS EM SCOPUS (1974 - JUNHO DE 2014) \\ Resumo}

A partir da construção de: (i) indicadores de gênero (distribuição horizontal, distribuição vertical, índice de feminidade, índice de masculinidade, índice de Duncan, índice de segregação, índice de contribuição ao sexismo e índice de interação), (ii) uma análise bibliométrica descritiva e avaliativa, segmentada pelo sexo dos autores, e (iii) representações de cartografia temática e estatística, pretendeu-se estabelecer se existe uma brecha de gênero na produção acadêmica nacional em economia e administração, apesar de que o número de autoras em ciências econômicas tenha se incrementado nos anos recentes. Os resultados indicam que os artigos com mulheres como autoras principais não superaram $27 \%$ e como coautoras só foi de $24 \%$. Por outro lado identificou-se que os melhores indicadores quanto a reiteração das citações (índices $\mathrm{H}, \mathrm{R}$ e A) são obtidos por artigos escritos por homens sem coautoria feminina. Finalmente conseguiu-se estabelecer que os indicadores de gênero calculados com relação ao número de autores, reiteram a brecha de gênero e a masculinização na publicação científica em ciências econômicas, não havendo evidência, no entanto, de segregação nas três áreas analisadas.

Palavras chave: Bibliometria; Cienciometria; Economia; Administração; Índices bibliométricos; Indicadores de gênero; Brecha de gênero; Scopus.

Lis-Gutiérrez, J-P. \& Bahos-Olivera, C-A. (2016). La participación femenina en publicaciones colombianas de economía y administración indexadas en Scopus (1974 - junio de 2014). En: Revista de la Facultad de Ciencias Económica: Investigación y Reflexión. rev.fac.cienc.econ, XXIV (2), DOI: http://dx.doi.org/10.18359/rfce.2219

JEL: 010, R19, Y90, Z00.

\section{Introducción}

El interés por la comunicación científica y la bibliometría ha ido en aumento en décadas recientes. Al igual que los análisis de género aplicados a diferentes disciplinas. A pesar de lo anterior, son pocos los trabajos que relacionan estas dos aproximaciones.

En este documento se propone un análisis sobre la participación de las mujeres en las publicaciones de origen colombiano en economía y administración, basado en la información del servicio de indización y resumen SCOPUS ${ }^{1}$ durante el período enero de

Sistema de información científica desarrollado por Elsevier en noviembre de 2004, la información puede analizarse considerando 31 campos de conocimiento, 313 categorías temáticas (de acuerdo a la clasificación de Scopus), 10 regiones geográficas, 233 países, 21.500 revistas arbitradas, de las cuales más de 4.200 son de libre acceso, 113.000 libros, 60 millones de registros en total (Scopus, 2016). 
1974 y junio de 2014. Esto con el fin de identificar si existe una brecha de género en la producción académica que se visibiliza en uno de los índices bibliográficos más reconocidos.

Los indicadores que serán considerados en este trabajo dan cuenta tanto de la bibliometría descriptiva como evaluativa ${ }^{2}$ : volumen de la producción medido mediante el número de documentos, tipología de documentos, idiomas de escritura, número de citaciones, filiación institucional de los autores, fuentes, principales revistas (González, Guerrero \& Moya, 2009), análisis de países, los índices H, G, R, i10 y A (Hirsch, 2005; Egghe, 2006; Jin, Liang, Rousseau \& Egghe, 2007; Túñez \& de Pablos, 2013) $e$ indicadores de género distribución horizontal, distribución vertical, índice de feminidad, índice de masculinidad, índice de Duncan, índice de segregación, índice de contribución al sexismo e índice de interacción. Para algunos de los indicadores se empleará la representación de cartografía estadística ${ }^{3}$.

La estructura del documento es la siguiente. Inicialmente se hará una revisión de la literatura reciente. En la segunda parte se realiza una descripción de los indicadores básicos de las publicaciones. Posteriormente, se elabora un análisis de las citaciones recibidas por los documentos y los índices $\mathrm{H}, \mathrm{G}, \mathrm{R}$, i10 y A. En el siguiente segmento se presentan los resultados de los indicadores de género. En la última

2 Los estudios bibliométricos se clasifican dependiendo de las fuentes y los análisis que se realizan. En el primer caso, pueden estar basados en: bibliografías; servicios de indización y resúmenes (generalmente se emplean los Índices bibliográficos de citaciones): referencias o citaciones (análisis de citaciones); y en directorios o catálogos colectivos de títulos de revistas (Araújo \& Arencibia, 2002). En el segundo caso, existen dos subcategorías: la bibliometría "descriptiva, que trata de aspectos puramente cuantitativos, como distribución geográfica, documental, temática y su productividad y [la] evaluativa, que añade a la primera estudios de evaluación de la actividad científica" (Rubio, 1999, p. 1).

3 La importancia de usar este tipo de herramientas, de acuerdo con Jatobá \& Gomes (2012, p. 63), reside en que: "O uso da cartografia digital para o ensino da Geocartografia é importante por se tornar um instrumento capaz de envolver as pessoas para análise de sua própria realidade e visualizar informações complexas com maior agilidade e qualidade, sem esquecer que a atividade se torna mais prazerosa e menos cansativa". parte, se expondrán algunas consideraciones finales a manera de conclusiones.

\section{Revisión de la literatura}

\subsection{Los estudios bibliométricos recientes}

Pritchard (1969, p. 348) definió la bibliometría como "la aplicación de los métodos estadísticos y matemáticos dispuestos, para definir los procesos de la comunicación escrita, la naturaleza y el desarrollo de las disciplinas científicas mediante técnicas de recuento y análisis de la comunicación” Rehn \& Kronman (2008) por su parte, la entendieron como una herramienta de comparación de las publicaciones en investigación, en un tema en específico, asociado a su evolución e impacto generado, a partir de indicadores. Estos últimos corresponden a datos estadísticos que permiten analizar las distintas características de las publicaciones científicas, con base en la difusión y transmisión del conocimiento derivado de la investigación (Filippo \& Fernández, 2002).

En este apartado se realizará una revisión de los estudios recientemente en los cuales se aplican herramientas bibliométricas. En los análisis de campos de investigación específicos se encuentran los trabajos de Costa (2015) quien analiza la innovación en la enseñanza en finanzas entre 2005 y 2015. Por su parte, Arias, Velasco \& Novo (2015) estudiaron los fundamentos y las nuevas tendencias de la violencia de género y Restrepo \& Urbizagástegui (2016) analizaron las características de las publicaciones en ISI y Scopus sobre pueblos indígenas. El documento de Martínez et al. (2014), identificó mediante cocitaciones la base intelectual de la fisioterapia. Por su parte, López et al. (2014a), estudió la producción española sobre atención primaria, entre 2008 y 2012; Armfield et al. (2014) realizó un análisis de 17.932 publicaciones para el campo de la telemedicina; Portugal et al. (2014), consideraron el período 1980-2010 sobre la literatura de negocios internacionales en fusiones y adquisiciones.

En este mismo ámbito se encuentran el artículo de Yu, Davis \& Dijkeman (2014) discutieron la evolución del campo de la investigación de la simbiosis 
industrial (IS), en relación con la ecología industrial (IE), mediante los análisis de citas, cocitación y redes, identificaron el desarrollo de temas de investigación y la evolución de la red de investigación. Igualmente, Brones, Monteiro de Carvalho \& de Senzi Zancul (2014) buscaron establecer la intersección entre el ecodiseño y la gestión de proyectos, sin embargo, el análisis de la literatura reveló que los principios de gestión de proyectos se abordan de manera limitada en los artículos especializados sobre diseño ecológico, y que no hay artículos específicos sobre la gestión del proyecto que consideren las cuestiones de dirección de desarrollo de productos del medio ambiente y la sostenibilidad ambiental.

Otro ámbito de reciente aplicación de bibliometría está asociado con el análisis de métricas para los autores y el perfeccionamiento de las técnicas bibliométricas. Tales son los casos de los trabajos de Machado et al. (2016) quienes propusieron la aplicación de las leyes de la bibliometría para identificar patrones en las estructuras de contratación de docentes de las instituciones de educación superior. Delgado (2016) quien a partir de Google Scholar propuso nuevas técnicas. Por su parte, Ortiz \& Hidalgo (2016) aplicaron a la co-autoría la teoría de grafos para identificar comunidades académicas. Arias (2015) presentó nuevas aproximaciones metodológicas a partir de la estadística multivariante, de los métodos Biplot y análisis de redes sociales, para estudiar los patrones de colaboración.

Igualmente, Ale Ebrahim et al. (2014) estudiaron el caso de dos investigadores que utilizan herramientas de marketing para sus publicaciones, encontrando evidencia de que la visibilidad artículo mejora en gran medida el impacto, medido por la citación. A su vez, el trabajo de Abramo et al. (2014) analizó en qué medida los científicos italianos más productivos logran artículos muy citados y qué porcentaje de los artículos más citados se logra por los científicos que son los más productivos en Web of Science. Brzezinski (2014), evaluó en la distribución de las citas la "ley de potencia" (power-law behaviour) y encontró que su aplicación es adecuada para los trabajos más citados en Física y Astronomía, pero no para el resto de áreas. Vieira, Cabral \& Gomes (2014) analizaron el poder predictivo de los indica- dores bibliométricos frente a los resultados de las evaluaciones por pares y la obtención de los niveles académicos de profesor Asociado y Catedrático en universidades portuguesas.

Una tercera manera de clasificar los trabajos recientes son aquellos que critican las métricas actuales. Por ejemplo, el documento de Bouyssou \& Marchant (2014) realizó una revisión, comparación y crítica de los índices y ranking que permiten evaluar los autores. Amodio \& Brugnano (2014) mostraron las debilidades de las métricas para construir rankings de artículos (PaperRank) y de páginas web (PageRank) y formularon una propuesta para corregir dichas debilidades. Hagen (2014) analizó los efectos de establecer un tratamiento igual (ponderación) a autores principales y co-autores; estableciendo que las métricas de los co-autores pueden llegar a ser superiores a las de los autores principales. Schreiber (2014) estudió las debilidades y dificultades de la comparación inter-temporal al aplicar el P100, que corresponde a una escala de calificación basada en los percentiles.

La siguiente tendencia, es una de las más tradicionales y corresponde a la aplicación de bibliometría a revistas o publicaciones de un área específica. Silva Andrade et al. (2016) utiliza la sociometría (análisis de redes) para analizar los "turning points" de 103 artículos en el área de la estrategia. Gregorio, Rativa \& Peralta (2015) analizan las revistas colombianas en el campo de las ciencias sociales empleando el Journal Citation Report (JCR) de ISI Web of Science (WoS). Por su parte, Valcárcel de Laiglesia et al. (2014) realizaron el estudio para 4 revistas de biomedicina; Alonso et al. (2014) analizaron las publicaciones derivadas de los congresos anuales de la Sociedad Española de Cardiología, de 2002, 2005 y 2008; Koc \& Boz (2014) elaboran el estudio para las 3 revistas más importantes en turismo entre 2003 y 2012 (Annals of Tourism Research, Tourism Management and Journal of Travel Research); Joyce, Kelly \& Sugrue (2014) trabajaron 27 revistas para identificar los 100 artículos con mayor impacto en el tema de quemaduras. Melo (2013) utilizó los artículos de la revista Gestão \& Regionalidade entre 2005 y 2012 para su trabajo. 
El último grupo de trabajos que se puede identificar es el relacionado con la evaluación de la producción en país específico. Ponomariov \& Toivanen (2014) estudiaron el papel de las capacidades nacionales de conocimientos para Brasil entre 2005-2009, identificando el ascenso de la investigación de Brasil y el incremento en la citación. De Oliveira et al. (2014) analizan la producción científica brasileña sobre dificultades de aprendizaje entre 2001 y 2011. Veiga et al. (2014) estudian la dinámica de las publicaciones nacionales, con respecto a la cirugía de rodilla entre 2000 y 2011. Si Niu (2014) trabaja a partir de la colaboración científica internacional de entre Australia y China.

\subsection{Mujer y academia}

Los trabajos sobre la relación entre mujeres y educación han ido en aumento en años recientes. Por ejemplo, Eraso (2016) mediante una investigación histórica analiza la participación de la mujer en la historia colombiana enfocándose en la medicina. Por su parte, Caputo, Vargas \& Requena (2016) y Requena, Vargas \& Caputo (2016) encuentran evidencia de que la participación de las mujeres en la academia venezolana está llegando a un estado estacionario, el cual depende de la carrera universitaria elegida, y que la brecha entre géneros tiene una tendencia a desaparecer, según la evidencia de los últimos 20 años. De Pablos \& Gil (2011) analizan para el caso español la posición de las mujeres españolas en términos de stock educativo y de resultados en el mercado laboral, comparándolo con resultados de países europeos. Así mismo, estudian el impacto en el bienestar de las mujeres de su nivel educativo de educación superior. Lemarchand (2010) a partir de cifras de la UNESCO (2009), analiza las estadísticas de participación de mujeres en el número total de investigadores del planeta. Lemarchand encuentra que a nivel mundial, para 2009, esta proporción era 29\%, pero en América Latina era de $46 \%$.

Papadópulos \& Radakovich (2006) identificaron para América Latina que hasta 2003, había una feminización incipiente en Bolivia y Perú; la feminización lograba la equidad en la matrícula en Colombia, Chile, Costa Rica, Cuba, El Salvador y México; la feminización era media en Argentina, Brasil y Venezuela; y la feminización era alta en Uruguay, República Dominicana y Panamá.

Igualmente, son múltiples los documentos que analizan la relación entre docencia y género. Por ejemplo, el trabajo de Lozano, Iglesias \& Martínez (2016) analiza la brecha de género en la Universidad de Alicante, encontrando que la presencia de académicas sigue siendo muy limitada, a pesar de las reformas universitarias sobre igualdad. Por su parte, Zapata (2010) sobre equidad de género y personal científico en universidades alemanas; Bustos \& Blázquez (2003), Buquet et al. (2006), Buquet, Cooper \& Rodríguez (2010) y Buquet, Hernández \& Jiménez (2011), para el caso de la UNAM y sus diferentes dependencias; García (1992) sobre las características socio-demográficas de las mujeres académicas y análisis de género en la Universidad de Guadalajara (García, 2004, 2009; Escolano, 2006, 2009), para el rol de las académicas en caso de las universidades españolas; Bailyn (2003) sobre las mujeres académicas en el MIT, entre otros. Asimismo, Estébañez (2007) y Gálvez (2009) identifican el fenómeno de las "tijeras", relacionado con una tendencia inversa de la presencia femenina y la evolución en la formación académica, en la formación universitaria las mujeres en conjunto son mayoritarias, mientras que en la formación posgradual su presencia va reduciéndose.

Ahora bien, aunque la relación entre género y ciencia ha sido de interés de algunos investigadores colombianos, la mayor parte de trabajos se concentran en el análisis agregado y no en áreas específicas. Los trabajos de Tovar (2002, 2004, 2005), fueron pioneros en discutir de manera crítica los indicadores de género aplicados a estadísticas nacionales de ciencia y tecnología. El trabajo de Daza (2010) presenta un análisis descriptivo sobre estadísticas e indicadores relacionados con la presencia de hombres y mujeres en el SNCTI durante el período 2000-2010, mostrando con cifras las brechas de género que aún persisten. Igualmente, Daza \& Pérez (2008) reflexionaron sobre los indicadores de género, en el campo de la ciencia y la tecnología a la luz de estudios latinoamericanos, proponiendo 4 estrategias para el caso colombiano: (i) reformular 
las preguntas y objetivos de los indicadores de género tradicionales; (ii) elaboración de indicadores de redes sociales y otros relacionados con lo que ocurre al interior de los grupos sociales; (iii) elaboración de encuestas de percepción pública de la ciencia y análisis cuantitativos de consumo y difusión de la ciencia; (iv) incluir la perspectiva de género en las políticas públicas.

Por su parte, Albert, González \& Mora (2011) estudiaron los determinantes (sexo, el nivel educativo y la situación en el mercado laboral de los padres, la composición familiar y la renta) de la demanda de educación universitaria en Colombia con datos de las Encuestas de hogares (ENH y ECH). Identifican que el porcentaje de mujeres en la universidad colombiana en el primer lustro del siglo XXI era mayor que el de hombres, situación que era contraria a la presentada en el decenio de $1980^{4}$. No obstante, también hay trabajos que analizan el "efecto tijera" en Colombia (OCyT, 2009). Pérez (2012) indicó que en 2011, el 64\% de los graduandos colombianos eran mujeres, sin embargo, de ellas solamente el $34 \%$ accede a maestrías y $20 \%$ al doctorado.

\subsection{Mujer y bibliometría}

Como se mencionó anteriormente, los trabajos que incluyen los análisis de género en los análisis bibliométricos son pocos. A continuación se hace un recuento de algunos de los más recientes.

Sos Peña (2015) analiza el impacto de 8 psicólogas norteamericanas pioneras, empleando la bibliometría para estudiar su influencia en Social Sciences Citation Index, (SSCI), entre 1900 y 1999. La autora logró identificar su importancia y alta citación en campos como: psicología infantil, historia de la psicología y lenguaje.

Ortega et al. (2015) realizaron un estudio bibliométrico sobre el papel de la mujer en 333 tesis doctorales de ciencias del deporte en España, conside-

4 Este fenómeno de feminización de la matrícula femenina también es abordado por: Albert (2000), quien señala un aumento de la participación de las mujeres en la educación superior para España; Correa (2003) para Colombia; y Bonilla et al. (2005) para Puerto Rico. rando variables como: autoría, dirección, miembros del tribunal y presidencia de tribunal, identificando un alto grado de masculinización en las cuatro variables mencionadas.

Por su parte Benoit (2015) a partir de las publicaciones del Observatoire de sciences et de technologies (OST) y los artículos de la Public Library of Science (PLoS), en total 85.131 artículos, identificó que la participación femenina es cercana al 35\% solamente y analizó el efecto "Cenicienta", según el cual, las mujeres deben hacer más esfuerzos para ser reconocidas como autores acreditados.

Tomei et al. (2014) analizan mediante el índice $\mathrm{H}$ para evaluar si existían diferencias de género de acuerdo con el rango académico y la productividad de la investigación entre los neurocirujanos hombres y mujeres. Los análisis se hicieron a partir de la información de 1.052 cirujanos de 84 instituciones diferentes. Se identificó que los hombres tenían estadísticamente mayor productividad de la investigación (en promedio un índice $\mathrm{H}$ de 13,3) que sus colegas mujeres (en promedio un índice $\mathrm{H}$ de 9,5).

En el área de la salud, también se encuentra el estudio de López et al. (2014b). Este trabajó estableció que las mujeres académicas en oftalmología siguen estando sub-representadas entre los profesores titulares. Aunque las mujeres superan a los hombres en la productividad académica durante las últimas etapas de sus carreras, el bajo impacto académico de su producción durante las primeras etapas puede impedir su avance académico y explicar, en parte, la disparidad de género en altos puestos académicos.

El trabajo de Brooks, Fenton \& Walker (2014) empleó los datos de las escuelas de negocios del Reino Unido, encontrando que hay diferencias importantes entre la calidad de las revistas en las cuales publican hombres y mujeres, en las áreas de gestión $y$ contabilidad. Igualmente, identificaron que las mujeres que son capaces de utilizar las redes de coautor con personas fuera de su institución publican en las revistas de mayor calificación. 
Por su parte, Abramo, D’Angelo \& Murgia (2013) analizan el rol de las mujeres académicas italianas en la colaboración científica. Los autores analizan la propensión a la colaboración de los académicos según los campos, disciplinas y formas de colaboración: intramural, extramural nacional e internacional. Sus resultados indicaron que las mujeres investigadoras registran una mayor capacidad de colaborar en todas las formas analizadas, con excepción de la colaboración internacional, donde todavía hay una brecha en comparación con sus colegas masculinos.

A su vez, Weiss, Kovshilovskaya \& Breyer (2012) identificaron que la tasa de crecimiento de las publicaciones y la visibilidad de la producción académica de las mujeres en urología era superior a la tasa de crecimiento de la presencia de mujeres en el área. Concluyen que las mujeres en urología son miembros activos y productivos de la comunidad académica en urología.

Aleixandre et al. (2007) analizan la paridad de la autoría de los artículos publicados en Enfermedades Infecciosas y Microbiología Clínica (EIMC). A partir de los registros del Science Citation Index-Expanded 1 entre 2001-2005. De los 2.163 autores, 943 fueron mujeres $(43,6 \%)$, la presencia y la productividad de las mujeres en las instituciones más reconocidas fue más baja que las de los hombres.

Finalmente, Kretschmer \& Aguillo (2005) desarrollaron tres indicadores aplicadas a redes académicas en internet: cooperación de género, tasa de visibilidad web y centralidad de género en las redes. Establecieron que en la red analizada Collnet, no hay diferencias significativas en la colaboración, pero la visibilidad es mayor para aquellos trabajos de coautores masculinos únicamente.

Después de haber establecido las tendencias más representativas en la producción sobre bibliometría y enfoque de género, se procederá a realizar el análisis para identificar los patrones de la producción colombiana en economía y administración.

\section{Indicadores básicos}

\subsection{Datos y metodología}

El primer paso para iniciar el ejercicio de bibliometría consistió en seleccionar el índice bibliográfico a utilizar. Se eligió Scopus y no ISI, dado que la cobertura de países latinoamericanos es mayor en el primer índice. En segundo lugar se estableció como criterio de búsqueda en Scopus el siguiente algoritmo: AFFILCOUNTRY (Colombia) AND (LIMIT-TO(SUBJAREA, "ECON") OR LIMIT-TO (SUBJAREA, "BUSI"). Esto quiere decir que la búsqueda arrojó documentos de autores cuya filiación correspondía a una institución que se encontrara en Colombia y que hubieran publicado en el área de economía (economics, econometrics and finance - EEF) o administración (business, management and accounting - BMA). A continuación, se llevó a cabo una depuración para verificar que todos los documentos pertenecieran a autores colombianos. Posteriormente, se adicionó el número de autores y autoras, y se calculó el porcentaje de mujeres dentro del total de autores. Así mismo, se estableció si la mujer era autora principal o no. Finalmente, se inició el análisis de los indicadores que se presenta a continuación.

\subsection{Volumen de la producción}

El número de documentos indexados en Scopus del área de $\mathrm{BMA}^{5}$ fue 410, de EEF 758 y de ambas disciplinas 145, en los cuales participó al menos un autor de origen colombiano. Como se aprecia en la Ilustración 1, las publicaciones en BMA solamente adquieren continuidad desde 1995, alcanzando su valor máximo en 2013 (97 publicaciones ${ }^{6}$ ). En el caso de las publicaciones de EEF, el mayor valor alcanzado se presenta también en 2013, con 144 productos $^{7}$.

5 Esta clasificación corresponde a la dada por Scopus a la publicación en la cual se difundió el trabajo.

6 Incluyendo las publicaciones que pertenecen a ambas categorías.

7 Incluyendo las publicaciones que pertenecen a ambas categorías. 
Ilustración 1. Consolidado del volumen de producción académica en las áreas de BMA y EEF (enero de 1974-junio de 2014)

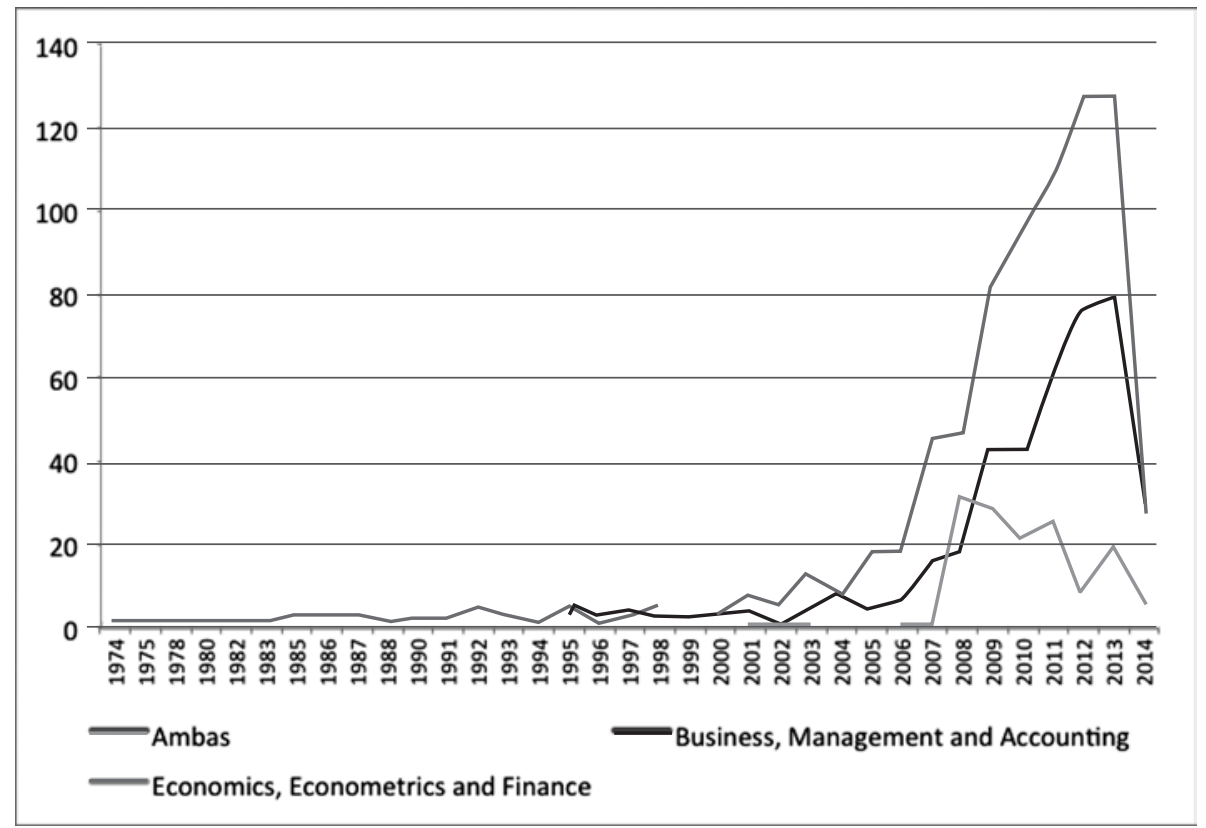

Fuente: Elaboración propia a partir de los datos de Scopus.

$\mathrm{Al}$ analizar el volumen de producción, dependiendo de la presencia de las mujeres como autoras, se encuentra que en el agregado, el 60,2\% de los trabajos fueron escritos por hombres, sin participación de ninguna mujer. Solamente en el 21,78\% de los artículos las mujeres fueron las autoras principales.
En economía el porcentaje de artículos escritos sólo por hombres es mayor (64,6\%). El área con mayor tasa de autoras principales es BMA con $26,3 \%$ (Tabla 1 e Ilustración 2).

Tabla 1. Volumen de producción académica en las áreas de BMA y EEF, por sexo (enero de 1974-junio de 2014)

\begin{tabular}{|l|c|c|c|c|c|c|c|c|}
\hline & Ambas & $\%$ & BMA & $\%$ & EEF & $\%$ & Total & $\%$ \\
\hline No hay autoras mujeres & 82 & $56,60 \%$ & 216 & $52,70 \%$ & 490 & $64,60 \%$ & 788 & $60,02 \%$ \\
\hline Hay autoras mujeres, pero no son principales & 36 & $24,80 \%$ & 86 & $21,00 \%$ & 117 & $15,40 \%$ & 239 & $18,20 \%$ \\
\hline El autor principal es mujer & 27 & $18,60 \%$ & 108 & $26,30 \%$ & 151 & $19,90 \%$ & 286 & $21,78 \%$ \\
\hline Total general & $\mathbf{1 4 5}$ & $100,00 \%$ & $\mathbf{4 1 0}$ & $100,00 \%$ & $\mathbf{7 5 8}$ & $100 \%$ & $\mathbf{1 . 3 1 3}$ & $100 \%$ \\
\hline
\end{tabular}

Fuente: Elaboración propia a partir de los datos de Scopus. 
Ilustración 2. Volumen de producción académica en las áreas de BMA y EEF, por sexo (enero de 1974-junio de 2014)



Fuente: elaboración propia a partir de los datos de Scopus.

En la Ilustración 3 se aprecia que las publicaciones de hombres, sin la participación de mujeres siempre han sido superiores a las publicaciones de las mujeres; la diferencia se acentúa a partir de 2005. No obstante lo anterior, al considerar la tasa de crecimiento anual (Ilustración 4), se aprecia que la incorporación de mujeres en la producción académica se ha incrementado más que la participación de los hombres.

Una mirada por tipología de los documentos, muestra que la mayor parte de trabajos en las áreas de BMA y EEF corresponde a artículos publicados: $90,34 \%$ y $77,07 \%$ respectivamente, en el caso de ambas disciplinas esta participación es de 91,03\%.
La segunda mayor participación en BMA es documentos de conferencia $(7,80 \%)$, mientras que para EEF son los reviews (3,69\%). En la categoría otros se incluyen notas, erratas, editoriales, cartas al editor, y short review (Tabla 3).

En la Tabla 2 también puede apreciarse que el área en la cual hay mayor paridad en la autoría de artículos, corresponde al BMA en la cual 50,78\% de los trabajos son escritos por hombres sin la participación de mujeres. Por su parte, el área de EEF presenta un comportamiento masculinizado, ya que 63,39\% de los artículos durante el período fueron escritos por hombres únicamente. 
Ilustración 3. Evolución del volumen de producción académica en las áreas de BMA y EEF, por sexo (enero de 1974-junio de 2014)

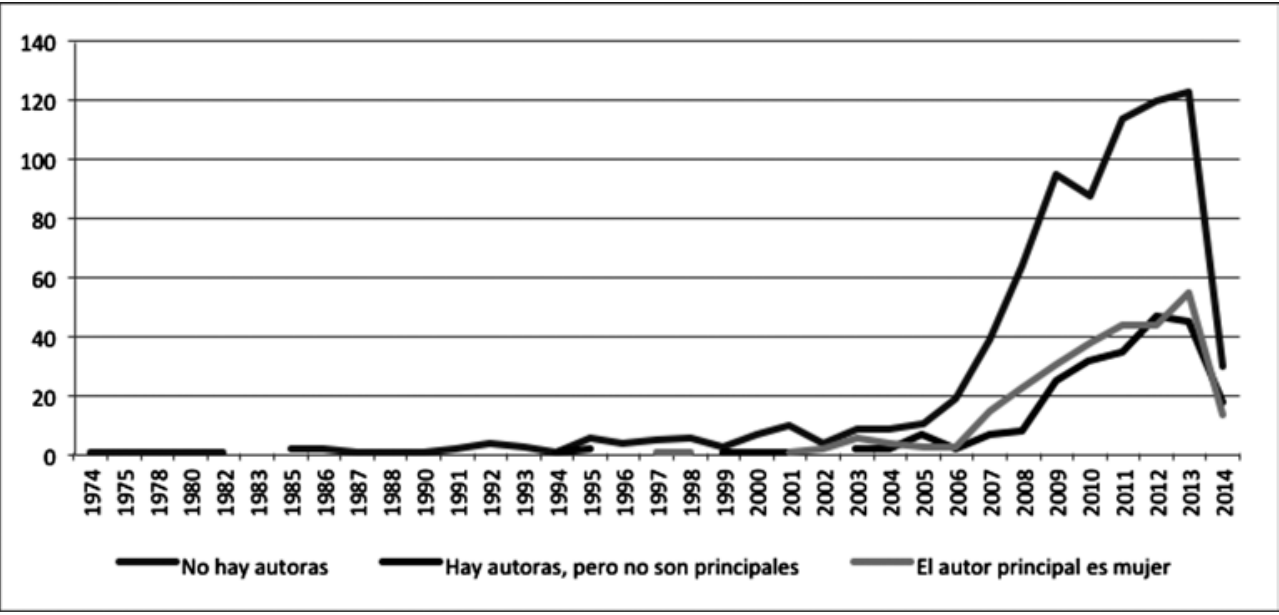

Fuente: Elaboración propia a partir de los datos de Scopus.

Ilustración 4. Tasa de crecimiento del volumen de producción académica en las áreas de BMA y EEF, por sexo (enero de 1974-junio de 2014)

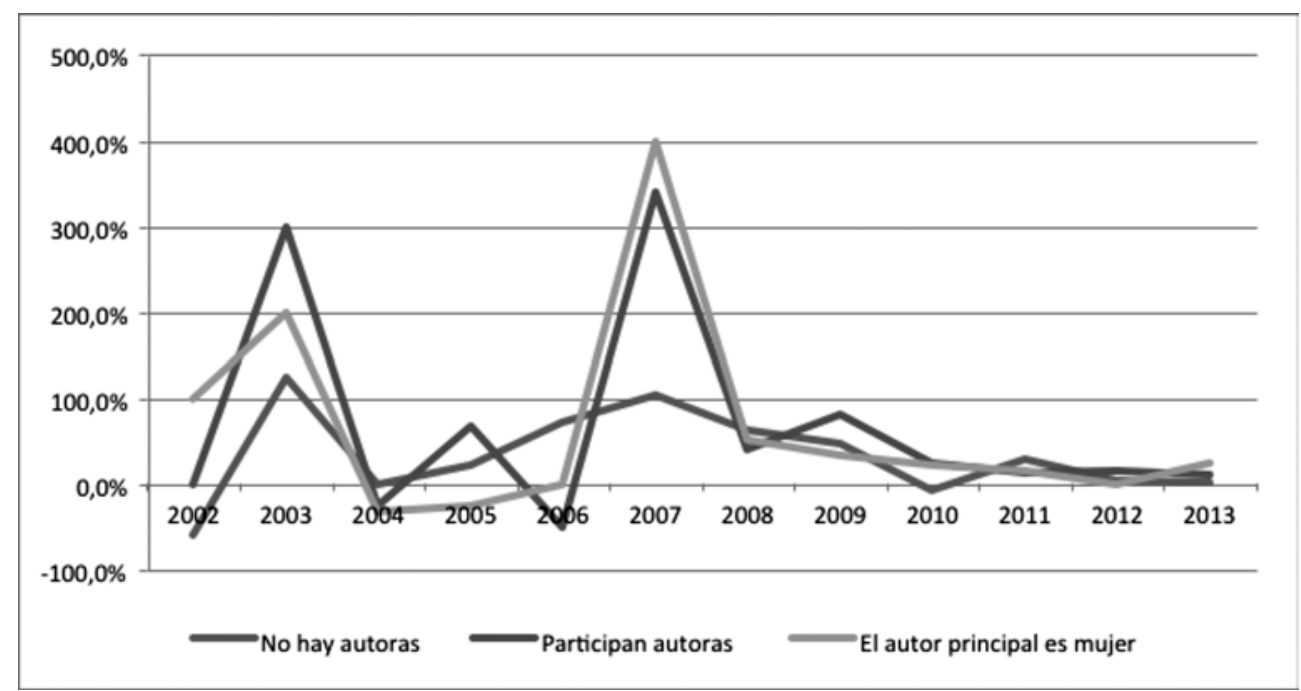

Fuente: Elaboración propia a partir de los datos de Scopus. 
Tabla 2. Tipos de documentos Fuente: elaboración propia a partir de los datos de Scopus

\begin{tabular}{|c|c|c|c|c|}
\hline & No hay autoras mujeres & Hay autoras mujeres, pero no son principales & El autor principal es mujer & Total \\
\hline Ambas & 82 & 36 & 27 & 145 \\
\hline Artículos & 79 & 29 & 24 & 132 \\
\hline Conferencia & 2 & 2 & & 4 \\
\hline Review & 1 & 5 & 3 & 9 \\
\hline BMA & 216 & 86 & 108 & 410 \\
\hline Artículos & 162 & 70 & 87 & 319 \\
\hline Capítulo de libro & 7 & 1 & 3 & 11 \\
\hline Conferencia & 15 & 7 & 10 & 32 \\
\hline Review & 12 & 8 & 3 & 23 \\
\hline Otros & 20 & 0 & 5 & 25 \\
\hline EEF & 490 & 117 & 151 & 758 \\
\hline Artículos & 444 & 109 & 142 & 695 \\
\hline Capítulo de libro & 5 & & 2 & 7 \\
\hline Conferencia & 3 & 2 & 2 & 7 \\
\hline Otros & 17 & 2 & 1 & 20 \\
\hline Review & 21 & 4 & 4 & 29 \\
\hline Total & 788 & 239 & 286 & 1.313 \\
\hline
\end{tabular}

Fuente: Elaboración propia a partir de los datos de Scopus.

\subsection{Fuentes}

Considerando de manera agregada el área de ciencias económicas, la revista con mayor número de artículos de autores con al menos uno de origen colombiano es Cuadernos de Economía con 113 artículos, seguida de Cuadernos de Administración con 98 trabajos. Cabe resaltar que las primeras 8 posiciones son ocupadas por revistas colombianas: Cuadernos de Economía, Cuadernos de Administración, Innovar, Revista de Economía Institucional, Ensayos Sobre Política Económica, Revista de Economía del Rosario, Desarrollo y Sociedad y Cuadernos de Desarrollo Rural (Tabla 3).

De acuerdo con la Tabla 4, en términos absolutos, la revista en la cual más artículos con participación de mujeres han sido publicados durante el período, fue Cuadernos de Administración (98 trabajos, $42,9 \%$ ), seguido de la revista Innovar (87 trabajos, $42,5 \%)$. Las revistas que se encuentran en la Tabla 5 concentran 44,5\% del total de artículos en los cuales hay autores femeninos (234 de 525), y el $49 \%$ de los artículos cuya autora principal es una mujer (140 de 286).

Así mismo, debe mencionarse que dentro de las revistas con mayor participación femenina también se encuentran las revistas que en proporción mayor número de artículos de autores hombres han difundido. Tales son los casos de Economía Institucional (80\%), Cuadernos de Economía (78,6\%), Journal of Development Economics (75\%), Revista de economía del Rosario $(74,3 \%)$ y Desarrollo y Sociedad (73,5\%). 
Tabla 3. Principales revistas que publicaron artículos en EEF o BMA (enero de 1974 - junio de 2014) ${ }^{8}$

\begin{tabular}{|c|c|c|c|c|}
\hline Revista & País & Ambas & $\begin{array}{l}\text { Business, Management } \\
\text { and Accounting }\end{array}$ & $\begin{array}{c}\text { Economics, Econometrics } \\
\text { and Finance }\end{array}$ \\
\hline Cuadernos de Economía & Colombia & & & 113 \\
\hline Cuadernos de Administración & Colombia & 98 & & \\
\hline Innovar & Colombia & & 87 & \\
\hline Revista de Economía Institucional & Colombia & & & 85 \\
\hline Ensayos Sobre Política Económica & Colombia & & & 50 \\
\hline Revista de Economía del Rosario & Colombia & & & 35 \\
\hline Desarrollo y Sociedad & Colombia & & & 34 \\
\hline Cuadernos de Desarrollo Rural & Colombia & & & 31 \\
\hline Journal of Development Economics & Holanda & & & 24 \\
\hline Ecological Economics & Holanda & & & 17 \\
\hline Academia & Venezuela & & 15 & \\
\hline Journal of Business Research & Holanda & & 12 & \\
\hline Journal of Technology Management and Innovation & Chile & & 11 & \\
\hline Journal of the Operational Research Society & Reino Unido & & 10 & \\
\hline Economic Modelling & Holanda & & & 9 \\
\hline Journal of Cleaner Production & Holanda & & 9 & \\
\hline Banking Law Journal & Estados Unidos & 8 & & \\
\hline Energy Economics & Holanda & & & 8 \\
\hline Food Policy & Estados Unidos & & & 8 \\
\hline
\end{tabular}

Fuente: Elaboración propia a partir de los datos de Scopus.

La mayor parte de las revistas que concentran las publicaciones de mujeres son colombianas. De las 15 revistas que se muestran en la Tabla 4,8 son colombianas.

Hay 148 fuentes que han publicado solamente trabajos de autores hombres en ciencias económicas.

Cabe mencionar que:

- La mayor parte de las revistas que concentran las publicaciones de mujeres son colombianas.
De las 15 revistas que se muestran en la Tabla 4,8 son colombianas.

- Hay 148 fuentes que han publicado solamente trabajos de autores hombres en ciencias económicas.

- Hay 45 fuentes que sólo han publicado trabajos en los cuales hay autoras. Algunas de dichas publicaciones están relacionadas con salud, turismo y ciencias agronómicas. 
Tabla 4. Revistas con mayor número de artículos en los que hayan participado al menos una mujer (enero de 1974 junio de 2014)

\begin{tabular}{|c|c|c|c|c|c|c|c|c|c|}
\hline Revista & $\begin{array}{l}\text { No hay } \\
\text { autoras }\end{array}$ & $\begin{array}{l}\text { Hay autoras } \\
\text { pero no son } \\
\text { principales }\end{array}$ & $\begin{array}{l}\text { El autor } \\
\text { principal } \\
\text { es mujer }\end{array}$ & $\begin{array}{l}\text { Participa } \\
\text { al menos } \\
\text { una mujer }\end{array}$ & Total & $\begin{array}{l}\text { No hay } \\
\text { autoras } \\
(\%)\end{array}$ & $\begin{array}{l}\text { Hay autoras } \\
\text { pero no son } \\
\text { principales } \\
(\%)\end{array}$ & $\begin{array}{c}\text { El autor } \\
\text { principal } \\
\text { es mujer } \\
(\%)\end{array}$ & $\begin{array}{c}\text { Participa al } \\
\text { menos una } \\
\text { mujer (\%) }\end{array}$ \\
\hline $\begin{array}{l}\text { Cuadernos de } \\
\text { Administración }\end{array}$ & 56 & 19 & 23 & 42 & 98 & $57,1 \%$ & $42,9 \%$ & $23,5 \%$ & $42,9 \%$ \\
\hline Innovar & 50 & 13 & 24 & 37 & 87 & $57,5 \%$ & $42,5 \%$ & $27,6 \%$ & $42,5 \%$ \\
\hline $\begin{array}{l}\text { Cuadernos de } \\
\text { Economia }\end{array}$ & 81 & 14 & 18 & 32 & 103 & $78,6 \%$ & $31,1 \%$ & $17,5 \%$ & $31,1 \%$ \\
\hline $\begin{array}{l}\text { Ensayos Sobre } \\
\text { Política Económica }\end{array}$ & 30 & 8 & 12 & 20 & 50 & $60,0 \%$ & $40,0 \%$ & $24,0 \%$ & $40,0 \%$ \\
\hline $\begin{array}{l}\text { Revista de } \\
\text { Economia Institucional }\end{array}$ & 68 & 7 & 10 & 17 & 85 & $80,0 \%$ & $20,0 \%$ & $11,8 \%$ & $20,0 \%$ \\
\hline $\begin{array}{l}\text { Cuadernos de } \\
\text { Desarrollo Rural }\end{array}$ & 15 & 2 & 14 & 16 & 31 & $48,4 \%$ & $51,6 \%$ & $45,2 \%$ & $51,6 \%$ \\
\hline World Development & 14 & 4 & 7 & 11 & 25 & $56,0 \%$ & $44,0 \%$ & $28,0 \%$ & $44,0 \%$ \\
\hline $\begin{array}{l}\text { Journal of Technology } \\
\text { Management and } \\
\text { Innovation }\end{array}$ & 1 & 4 & 6 & 10 & 11 & $9,1 \%$ & $90,9 \%$ & $54,5 \%$ & $90,9 \%$ \\
\hline $\begin{array}{l}\text { Revista de Economia } \\
\text { del Rosario }\end{array}$ & 26 & 3 & 6 & 9 & 35 & $74,3 \%$ & $25,7 \%$ & $17,1 \%$ & $25,7 \%$ \\
\hline Desarrollo y Sociedad & 25 & 5 & 4 & 9 & 34 & $73,5 \%$ & $26,5 \%$ & $11,8 \%$ & $26,5 \%$ \\
\hline $\begin{array}{l}\text { Journal of Business } \\
\text { Research }\end{array}$ & 4 & 5 & 3 & 8 & 12 & $33,3 \%$ & $66,7 \%$ & $25,0 \%$ & $66,7 \%$ \\
\hline Ecological Economics & 10 & 2 & 5 & 7 & 17 & $58,8 \%$ & $41,2 \%$ & $29,4 \%$ & $41,2 \%$ \\
\hline $\begin{array}{l}\text { Journal of Develop- } \\
\text { ment Economics }\end{array}$ & 18 & 4 & 2 & 6 & 24 & $75,0 \%$ & $25,0 \%$ & $8,3 \%$ & $25,0 \%$ \\
\hline Academia & 10 & 2 & 3 & 5 & 15 & $66,7 \%$ & $33,3 \%$ & $20,0 \%$ & $33,3 \%$ \\
\hline $\begin{array}{l}\text { Peace Economics, } \\
\text { Peace Science and } \\
\text { Public Policy }\end{array}$ & 3 & 2 & 3 & 5 & 8 & $37,5 \%$ & $62,5 \%$ & $37,5 \%$ & $62,5 \%$ \\
\hline
\end{tabular}

Fuente: Elaboración propia a partir de los datos de Scopus.

Ahora bien, el número total de fuentes en el período analizado asciende a 357 , pero aquellas que han publicado entre uno y dos documentos (268) concentran el $25,97 \%$ del total de la producción publicada, lo que equivale a 341 trabajos. Visto desde otro enfoque las primeras 10 revistas (8 de las cuales son colombianas) centralizan el $44,33 \%$ de la producción académica en ambas disciplinas (582 artículos). Al considerar de manera independiente los autores hombres y mujeres (Tabla 5 e Ilustración 5), la tendencia a que las publicaciones con uno o dos artículos concentren la mayor parte de trabajos, 
se mantiene. Para el caso de la mujer como autora principal corresponde al 47,55\%, para al menos una mujer como autora es el $41,9 \%$ y para sólo autores hombres es del 30,96\%.

\subsection{Idioma de publicación}

Como se aprecia en la Tabla 6, el idioma de publicación más relevante en el agregado es el inglés. No obstante, al considerar el número de documentos que fueron publicados en revistas que abarcan las dos áreas, el idioma más frecuente es español. Otro elemento a considerar es que en EEF se publicaron documentos en francés, mientras que en BMA no fue así. No obstante, en BMA hay trabajos publicados en portugués, húngaro y croata.

El mismo comportamiento, se presenta al analizar la segmentación por sexo. El 71\% de los artículos escritos sólo por hombres fueron escritos en inglés.
El 79\% de los trabajos donde participan mujeres, pero no son autoras principales, fueron escritos en este mismo idioma. Para el caso de las autoras principales esta cifra asciende al $76 \%$. El segundo idioma de mayor publicación es español (Tabla 7).

\subsection{Autores}

Dentro de los autores con mayor producción sólo se encuentran dos mujeres: Ana María Iregui del Banco de la República y Jennifer Lafont de la Universidad de Córdoba (Tabla 8). En los 1.313 trabajos analizados, participaron 3.156 autores, de los cuales sólo 756 eran mujeres, es decir el 24\%. En las publicaciones multidisciplinarias la participación de las mujeres fue de $25,1 \%$, en BMA $26,9 \%$ y en EEF 21,6\%. En otras palabras, en el agregado se presenta un fenómeno de masculinización de la producción académica de autores colombianos, en ciencias económicas.

Ilustración 5. Número de documentos publicados sobre EEF y BMA por fuente (enero de 1974-junio de 2014)

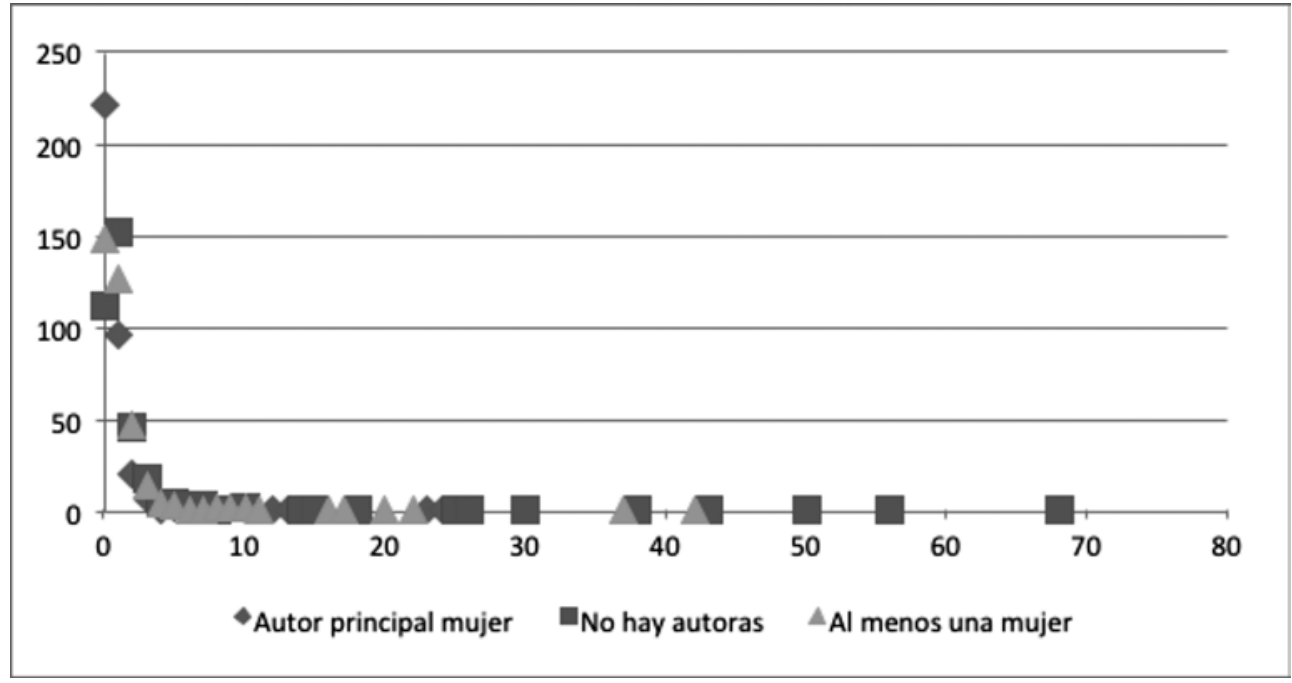

Fuente: Elaboración propia a partir de los datos de Scopus. 
Tabla 5. Número de documentos publicados sobre EEF y BMA por fuente (enero de 1974-junio de 2014)

\begin{tabular}{|c|c|c|c|}
\hline \multirow[b]{2}{*}{ Número de documentos } & \multicolumn{3}{|c|}{ Fuentes } \\
\hline & $\begin{array}{c}\text { Autor principal } \\
\text { mujer }\end{array}$ & No hay autoras & Al menos una mujer \\
\hline 0 & 222 & 112 & 148 \\
\hline 1 & 96 & 152 & 126 \\
\hline 2 & 20 & 46 & 47 \\
\hline 3 & 7 & 18 & 14 \\
\hline 4 & 1 & 5 & 4 \\
\hline 5 & 2 & 4 & 3 \\
\hline 6 & 2 & 3 & 1 \\
\hline 7 & 1 & 3 & 1 \\
\hline 8 & & 1 & 2 \\
\hline 9 & & & 2 \\
\hline 10 & 1 & 2 & 2 \\
\hline 11 & & & 1 \\
\hline 12 & 1 & & \\
\hline 13 & 1 & & \\
\hline 14 & 1 & 1 & \\
\hline 15 & & 1 & \\
\hline 16 & & & 1 \\
\hline 17 & & & 1 \\
\hline 18 & & 1 & \\
\hline 20 & & & 1 \\
\hline 22 & & & 1 \\
\hline 23 & 1 & & \\
\hline 24 & 1 & & \\
\hline 25 & & 1 & \\
\hline 26 & & 1 & \\
\hline 30 & & 1 & \\
\hline 37 & & & 1 \\
\hline 38 & & 1 & \\
\hline 42 & & & 1 \\
\hline 43 & & 1 & \\
\hline 50 & & 1 & \\
\hline 56 & & 1 & \\
\hline 68 & & 1 & \\
\hline
\end{tabular}

Fuente: elaboración propia. 
Tabla 6. Idioma de elaboración de los trabajos publicados sobre EEF y BMA por fuente (enero de 1974-junio de 2014)

\begin{tabular}{|l|c|c|c|c|}
\hline & Ambas & $\begin{array}{c}\text { Business, Management and } \\
\text { Accounting }\end{array}$ & $\begin{array}{c}\text { Economics, Econometrics } \\
\text { and Finance }\end{array}$ & Total \\
\hline Inglés & 44 & 289 & 403 & 736 \\
\hline Español & 100 & 112 & 350 & 562 \\
\hline Portugués & 1 & 7 & 0 & 8 \\
\hline Francés & & 1 & 4 & 4 \\
\hline Húngaro & & 1 & & 1 \\
\hline Croata & & 1 & & 1 \\
\hline
\end{tabular}

Fuente: Elaboración propia a partir de los datos de Scopus.

Tabla 7. Idioma de elaboración de los trabajos publicados sobre EEF y BMA por fuente (enero de 1974-junio de 2014)

\begin{tabular}{|l|c|c|c|c|}
\hline \multicolumn{1}{|c|}{ Idioma } & No hay autoras & $\begin{array}{c}\text { Hay autoras, pero no son el } \\
\text { autor principal }\end{array}$ & Autora principal & Total \\
\hline Inglés & 561 & 190 & 217 & 968 \\
\hline Español & 224 & 44 & 65 & 333 \\
\hline Croata & & & 1 & 1 \\
\hline Francés & 3 & 5 & 1 & 4 \\
\hline Húngaro & & $\mathbf{2 3 9}$ & 1 & 1 \\
\hline Portugués & $\mathbf{7 8 8}$ & & $\mathbf{2 8 6}$ & $\mathbf{1 . 3 1 3}$ \\
\hline Total & & & & 1 \\
\hline
\end{tabular}

Fuente: Elaboración propia a partir de los datos de Scopus.

\subsection{Países en los cuales se publican los trabajos de origen colombiano}

Para la elaboración de este apartado, se utilizó la información de la base de datos del total de las revistas incluidas en Scopus a junio de 2014. A partir de ella, se identificó el país de origen de la publicación en la cual se difundieron los documentos de origen colombianos. Los resultados se pueden visualizar en Ilustración 6 y la Tabla 9.
En el agregado 533 de los 1.313 artículos (40,59\%) fueron publicados en fuentes colombianas, 236 en publicaciones holandesas (17,97\%), 205 en fuentes del Reino Unido (15,61\%), 196 en revistas americanas (14,93\%). Cabe mencionar que si se analizan de forma independiente los trabajos de BMA y EEF, los resultados cambian un poco. La mayor parte de trabajos de BMA se publicó en revistas de origen estadounidense (98), seguido de Colombia (87) y Reino Unido (84). En el caso de los documentos de EEF, la mayoría se publicó en revistas colombianas (348), seguido de Holanda (157) y Reino Unido (114). 
Tabla 8. Principales autores de la producción en EEF y BMA (enero de 1974 - junio de 2014)

\begin{tabular}{|c|c|c|c|c|c|c|c|}
\hline Autor & Artículos & Afiliación & $\begin{array}{l}\text { Documentos } \\
\text { totales } \\
\text { en la base }\end{array}$ & $\begin{array}{c}\text { Índice } \\
\text { H }\end{array}$ & $\begin{array}{c}\text { Citaciones } \\
\text { totales }\end{array}$ & $\begin{array}{l}\text { Documentos de } \\
\text { la base que lo } \\
\text { citan }\end{array}$ & Coautores \\
\hline Otero, J. & 27 & Universidad del Rosario & 38 & 7 & 140 & 129 & 11 \\
\hline Cárdenas, J.C. & 19 & Universidad de los Andes & 33 & 12 & 682 & 498 & 61 \\
\hline Alvis, A. & 16 & Universidad de Córdoba & 21 & 3 & 41 & 34 & 17 \\
\hline Montoya Torres, J.R. & 13 & Universidad de la Sabana & 45 & 6 & 121 & 105 & 57 \\
\hline Ríos, L.A. & 13 & Universidad de Antioquia & 64 & 9 & 289 & 235 & 65 \\
\hline Páez, M.S. & 12 & Universidad de Córdoba & 29 & 7 & 119 & 92 & 28 \\
\hline Gómez González, J.E. & 12 & Banco de la República & 18 & 3 & 18 & 15 & 21 \\
\hline Dyner, l. & 11 & Universidad Nacional de Colombia & 30 & 9 & 238 & 225 & 50 \\
\hline Bogliacino, F. & 10 & Universidad Konrad Lorenz & 16 & 4 & 44 & 34 & 13 \\
\hline Gonzalez, A. & 10 & Banco de la República & 16 & 4 & 27 & 26 & 35 \\
\hline Duque Oliva, E.J. & 9 & Universidad Nacional de Colombia & 10 & 1 & 3 & 3 & 4 \\
\hline Vélez Pareja, I. & 9 & $\begin{array}{l}\text { Principio del formulario } \\
\text { Universidad Tecnológica de } \\
\text { BolívarFinal del formulario }\end{array}$ & 10 & 1 & 12 & 9 & 11 \\
\hline Marín, J.M. & 9 & Universidad de Antioquia & 43 & 8 & 249 & 219 & 49 \\
\hline Iregui, A.M. & 9 & Banco de la República & 10 & 2 & 13 & 13 & 5 \\
\hline Lafont, J.J. & 9 & $\begin{array}{l}\text { Principio del formulario } \\
\text { Universidad de CórdobaFinal } \\
\text { del formulario }\end{array}$ & 14 & 3 & 28 & 25 & 20 \\
\hline Alvarez, C. & 9 & $\begin{array}{l}\text { Principio del formulario } \\
\text { Universidad de MedellínFinal } \\
\text { del formulario }\end{array}$ & 14 & 2 & 15 & 13 & 9 \\
\hline Arango, L.E. & 8 & $\begin{array}{l}\text { Principio del formulario } \\
\text { Banco de la RepúblicaFinal } \\
\text { del formulario }\end{array}$ & 14 & 3 & 23 & 22 & 14 \\
\hline Ensuncho, A.E. & 8 & $\begin{array}{l}\text { Principio del formulario } \\
\text { Universidad de CórdobaFinal } \\
\text { del formulario }\end{array}$ & 11 & 3 & 29 & 17 & 12 \\
\hline Zuleta, H. & 8 & Universidad de los Andes & 14 & 4 & 37 & 26 & 6 \\
\hline Vargas, J.F. & 8 & Universidad del Rosario & 9 & 2 & 30 & 30 & 10 \\
\hline Castrillon, O.D. & 8 & Universidad Nacional de Colombia & 14 & 3 & 19 & 13 & 16 \\
\hline
\end{tabular}

Fuente: elaboración propia a partir de los datos de Scopus. 
Ahora bien, los países con mayor publicación de artículos con participación de mujeres son Colombia (182), Holanda (94), Reino Unido (91) y Estados Unidos (83). Este mismo orden se mantiene para los artículos cuyo autor principal es una mujer y para aquellos en los cuales ninguna mujer participa (Tabla 10). En publicaciones de Dinamarca y Ucrania, a pesar de que hay publicaciones en el área de autores hombres, no hay ninguna en la que al menos una autora haya participado.

Tabla 9. Países en los cuales se difunden los artículos de autores colombianos (enero de 1974 - junio de 2014)

\begin{tabular}{|c|c|c|c|c|}
\hline País & Ambas & $\begin{array}{l}\text { Business, Management } \\
\text { and Accounting }\end{array}$ & $\begin{array}{c}\text { Economics, Econometrics } \\
\text { and Finance }\end{array}$ & Total \\
\hline Alemania & 1 & 19 & 8 & 28 \\
\hline Australia & & 3 & & 3 \\
\hline Brasil & & 3 & 3 & 6 \\
\hline Canadá & & 6 & 1 & 7 \\
\hline Chile & & 15 & 13 & 28 \\
\hline Colombia & 98 & 87 & 348 & 533 \\
\hline Corea del Sur & & & 2 & 2 \\
\hline Croacia & & 2 & & 2 \\
\hline Dinamarca & & 1 & & 1 \\
\hline España & 3 & 7 & 13 & 23 \\
\hline Estados Unidos & 13 & 98 & 85 & 196 \\
\hline Filipinas & 2 & & 1 & 3 \\
\hline Francia & 1 & & 1 & 2 \\
\hline Grecia & & 1 & & 1 \\
\hline Holanda & 17 & 62 & 157 & 236 \\
\hline México & & & 8 & 8 \\
\hline Nueva Zelanda & & & 1 & 1 \\
\hline Reino Unido & 7 & 84 & 114 & 205 \\
\hline Serbia & & 1 & & 1 \\
\hline Singapore & 3 & & 1 & 4 \\
\hline Sudádrica & & & 1 & 1 \\
\hline Ucrania & & 1 & & 1 \\
\hline Venezuela & & 20 & 1 & 21 \\
\hline
\end{tabular}

Fuente: elaboración propia a partir de los datos de Scopus. 
Ilustración 6. Países en los cuales se difunden los artículos de autores colombianos en ciencias económicas (enero de 1974 - junio de 2014)



Fuente: elaboración propia a partir de Scopus, empleando Philcato.

Tabla 10. Países en los cuales se difunden los artículos de autores colombianos (discriminados por sexo, enero de 1974 - junio de 2014)

\begin{tabular}{|c|c|c|c|c|c|}
\hline País & No hay autoras & $\begin{array}{l}\text { Hay autoras, pero no } \\
\text { son las principales }\end{array}$ & Autora principal & $\begin{array}{l}\text { Al menos una } \\
\text { autora }\end{array}$ & Total \\
\hline Colombia & 351 & 71 & 111 & 182 & 533 \\
\hline Holanda & 142 & 54 & 40 & 94 & 236 \\
\hline Reino Unido & 114 & 41 & 50 & 91 & 205 \\
\hline Estados Unidos & 113 & 44 & 39 & 83 & 196 \\
\hline Alemania & 10 & 6 & 12 & 18 & 28 \\
\hline Chile & 12 & 7 & 9 & 16 & 28 \\
\hline España & 14 & 3 & 6 & 9 & 23 \\
\hline Venezuela & 12 & 4 & 5 & 9 & 21 \\
\hline Canadá & 3 & 1 & 3 & 4 & 7 \\
\hline México & 5 & 1 & 2 & 3 & 8 \\
\hline Brasil & 4 & 1 & 1 & 2 & 6 \\
\hline Croacia & & & 2 & 2 & 2 \\
\hline Filipinas & 1 & 2 & & 2 & 3 \\
\hline Francia & & & 2 & 2 & 2 \\
\hline Australia & 2 & & 1 & 1 & 3 \\
\hline
\end{tabular}




\begin{tabular}{|l|c|c|c|c|c|}
\hline \multicolumn{1}{|c|}{ País } & No hay autoras & $\begin{array}{c}\text { Hay autoras, pero no } \\
\text { son las principales }\end{array}$ & Autora principal & $\begin{array}{c}\text { Al menos una } \\
\text { autora }\end{array}$ & Total \\
\hline Corea del Sur & 1 & & 1 & 1 & 2 \\
\hline Grecia & & 1 & & 1 & 1 \\
\hline Nueva Zelanda & & 1 & 1 & 1 & 1 \\
\hline Serbia & & & & 2 & 4 \\
\hline Singapur & 2 & 2 & 1 & 0 & 1 \\
\hline Sudáfrica & 1 & & & & 1 \\
\hline Dinamarca & 1 & & & & 1 \\
\hline Ucrania & & & & & 1 \\
\hline
\end{tabular}

Fuente: elaboración propia a partir de los datos de Scopus.

\section{Análisis de citaciones e indicadores}

En este apartado se realiza un análisis de las citaciones y los principales indicadores asociados.

\subsection{Análisis de citaciones}

De los 1.313 trabajos elaborados en el período mencionado, 772 documentos no habían sido citados aún; es decir, el 58,80\% de los documentos producidos entre enero de 1974 y junio de 2014 no habían tenido ninguna repercusión en la producción académica posterior. De otra parte, el número total de citas recibidas durante el período correspondió a 4.115 , en otras palabras, 3,13 citas en promedio por documento realizado y 7,6 citas en promedio por documento realmente citado. Como se aprecia la Ilustración 6, la mayor parte de los documentos elaborados desde 1974 recibe entre 1 y 8 citas, concentrando el 32,29\% de los trabajos y el $27,4 \%$ de las citas recibidas. Este hecho contrasta con el hecho de que 3 documentos concentren el $7,04 \%$ de las citas (Tabla 11).

Ahora bien, de acuerdo con la Tabla 12, los artículos tienen mayor probabilidad de impactar la producción académica posterior si el autor principal es un hombre, pero cuenta con co-autoras. En el caso de autores hombres sin co-autoras, los artículos publicados en revistas multidisciplinarias son menos ci- tados (65,9\%). Los artículos con coautores hombres y mujeres publicados en revistas del área de BMA fueron citados con una frecuencia de 53,5\%. Los trabajos cuyo autor principal es una mujer fueron citados con mayor dificultad si aparecían en revistas multidisciplinarias. La mayor probabilidad de citación en este último caso ocurre en revistas de EEF.

\section{2. Índices $H, G, R$, i10 y $A$}

Aunque tradicionalmente, sólo se calcula el índice $\mathrm{H}$ (Hirsch, 2005, p. 16569) ${ }^{9}$, recientemente se han empleado otros indicadores (Lozano \& Rodríguez, 2012; Arencibia \& Carvajal, 2008) como el G (Egghe, 2006, p. 133) ${ }^{10}$, el i10 ${ }^{11}$, el R (Jin, Liang, Rous-

9 El concepto del índice h aparece en el año 2005 con el trabajo de Hirsh. Su cálculo corresponde a "(...) ordenar los trabajos de un autor de forma decreciente en virtud de las citas recibidas por cada trabajo. En el momento en el que el rango (posición en la lista) supera o iguala al valor de la cita, ahí tenemos nuestro índice h. esto significa que el autor tiene $\mathrm{h}$ trabajos con al menos h citas" (Grupo Scimago, 2007, p. 47).

10 Para el cálculo del Índice G, se listan los artículos de un autor en orden descendente de acuerdo con el número de citas recibidas por cada uno de ellos. Posteriormente, en una segunda columna se calcula el valor del cuadrado del digito que refleja la posición del artículo en la lista (g2). Y en una tercera se refleja el número de citas acumuladas $(\mathrm{H})$. El índice g lo determina la posición del último artículo en el que el valor del cuadrado de esa posición es inferior al número de citas acumuladas (López \& de Pablos, 2013, p. 136; Arencibia \& Carvajal, 2008, p. 3).

11 El índice i10 corresponde al número de publicaciones que han sido citadas al menos 10 veces. 
Ilustración 7. Número de citas vs número de artículos



Fuente: elaboración propia a partir de los datos de Scopus.

Tabla 11. Documentos con mayor número de citas

\begin{tabular}{|l|l|c|l|l|l|}
\hline \multicolumn{1}{|c|}{ Autor } & \multicolumn{1}{|c|}{ Título } & \multicolumn{1}{c|}{$\begin{array}{c}\text { Año de } \\
\text { publicación }\end{array}$} & \multicolumn{1}{c|}{ Fuente } & $\begin{array}{c}\text { Número } \\
\text { de citas }\end{array}$ & \multicolumn{1}{c|}{$\begin{array}{c}\text { Tipo de } \\
\text { documento }\end{array}$} \\
\hline $\begin{array}{l}\text { Cardenas J.C., Stranlund J., } \\
\text { Willis C. }\end{array}$ & $\begin{array}{l}\text { Local environmental control and insti- } \\
\text { tutional crowding-out }\end{array}$ & 2000 & World Development & 122 & Artículo \\
\hline Barrios E. & $\begin{array}{l}\text { Soil biota, ecosystem services and } \\
\text { land productivity }\end{array}$ & 2007 & Ecological Economics & 96 & Artículo \\
\hline Esfahani H.S., Ramirez M.T. & $\begin{array}{l}\text { Institutions, infrastructure, and econo- } \\
\text { mic growth }\end{array}$ & 2003 & $\begin{array}{l}\text { Journal of Development } \\
\text { Economics }\end{array}$ & 87 & Artículo \\
\hline Brander J.A. & Chapter 27 Strategic trade policy & 1995 & $\begin{array}{l}\text { Handbook of Internatio- } \\
\text { nal Economics }\end{array}$ & 82 & Capítulo de libro \\
\hline $\begin{array}{l}\text { Bento A.M., Cropper M.L., Mo- } \\
\text { barak A.M., Vinha K. }\end{array}$ & $\begin{array}{l}\text { The effects of Urban spatial structure } \\
\text { on travel demand in the United States }\end{array}$ & 2005 & $\begin{array}{l}\text { Review of Economics } \\
\text { and Statistics }\end{array}$ & 82 & Artículo \\
\hline
\end{tabular}

Fuente: elaboración propia a partir de los datos de Scopus. 
Tabla 12. Documentos citados por sexo en la autoría

\begin{tabular}{|l|c|c|c|c|c|}
\hline & No & Si & Total & No (\%) & Si (\%) \\
\hline Sin autoras & 482 & 306 & 788 & $61,2 \%$ & $38,8 \%$ \\
\hline Ambas & 54 & 28 & 82 & $65,9 \%$ & $34,1 \%$ \\
\hline BMA & 127 & 89 & 216 & $58,8 \%$ & $41,2 \%$ \\
\hline EEF & 301 & 189 & 490 & $61,4 \%$ & $38,6 \%$ \\
\hline Hay autoras, pero no son principales & 126 & 113 & 239 & $52,7 \%$ & $47,3 \%$ \\
\hline Ambas & 23 & 13 & 36 & $63,9 \%$ & $36,1 \%$ \\
\hline BMA & 40 & 46 & 86 & $46,5 \%$ & $53,5 \%$ \\
\hline EEF & 63 & 54 & 117 & $53,8 \%$ & $46,2 \%$ \\
\hline La autora es principal & 164 & 122 & 286 & $57,3 \%$ & $42,7 \%$ \\
\hline Ambas & 21 & 6 & 27 & $77,8 \%$ & $22,2 \%$ \\
\hline BMA & 68 & 40 & 108 & $63,0 \%$ & $37,0 \%$ \\
\hline EEF & 75 & 76 & 151 & $49,7 \%$ & $50,3 \%$ \\
\hline Total & $\mathbf{7 7 2}$ & $\mathbf{5 4 1}$ & $\mathbf{1 3 1 3}$ & $\mathbf{5 8 , 8} \%$ & $\mathbf{4 1 , 2} \%$ \\
\hline
\end{tabular}

Fuente: elaboración propia a partir de los datos de Scopus.

seau \& Egghe, 2009, p. 236) ${ }^{12}$ y el A (Jin, Liang, Rousseau \& Egghe, 2009, p. 237) ${ }^{13}$. El análisis de citas realizado anteriormente permite calcular cada uno de ellos (Tabla 13).

Tabla 13. Índices bibliográficos

\begin{tabular}{|l|c|c|c|c|c|}
\hline & $\begin{array}{c}\text { Índice } \\
\text { H }\end{array}$ & $\begin{array}{c}\text { Índice } \\
\mathbf{R}\end{array}$ & $\begin{array}{c}\text { Índice } \\
\mathbf{G}\end{array}$ & $\mathbf{I 1 0}$ & $\begin{array}{c}\text { Índice } \\
\mathbf{A}\end{array}$ \\
\hline Total cienciaseconómicas & 8 & 20,6 & 44 & 111 & 53 \\
\hline Ambas disciplinas & 3 & 5,84 & 12 & 5 & 11,3 \\
\hline BMA & 6 & 11,7 & 26 & 29 & 22,7 \\
\hline EEF & 8 & 15,4 & 40 & 77 & 29,8 \\
\hline
\end{tabular}

Fuente: elaboración propia a partir de los datos de Scopus.

12 El índice R (Jin, Liang, Rousseau \& Egghe, 2009, p. 236) corresponde a la raíz cuadrada de la sumatoria de citas recibidas por los artículos que hacen parte del índice $\mathrm{H}$.

13 El índice A (Jin, Liang, Rousseau \& Egghe, 2009, p. 237) corresponde a la sumatoria de citas recibidas por los artículos que hacen parte del índice $\mathrm{H}$ dividida entre el índice $\mathrm{H}$.
Considerando los resultados de los índices anteriores se puede deducir que existen diferencias significativas en el impacto de la producción académica de autores con filiación institucional colombiana en las áreas de Economía (Economics, Econometrics and Finance - EEF) y Administración (Business, Management and Accounting - BMA), ya que en todos los casos los indicadores de BMA son más bajos que los de EEF. A su vez, los valores de las revistas que incluyen ambas disciplinas son significativamente menores que los de BMA.

Ahora bien, en la Tabla 14, se muestran los mismos indicadores, pero haciendo la distinción del sexo de los autores. Los índices H, R y A de los autores masculinos sin co-autoría femenina son mayores tanto en el agregado y como segmentando por área de la publicación. A su vez estos indicadores son mayores para los artículos cuyo autor principal es una mujer, en comparación con los trabajos en los cuales hay participación femenina, pero el autor principal es un hombre. 
El indicador I10 es superior para los trabajos en los cuales no participan mujeres, pero a diferencia de los indicadores anteriores, los trabajos publicados en co-autoría con mujeres y cuyo autor principal es hombre tienen un I10 más grande que los artículos en los cuales el autor principal es mujer.

Tabla 14. Índices bibliográficos según sexo en la autoría

\begin{tabular}{|l|c|c|c|c|}
\hline & Índice H & Índice R & I10 & Índice A \\
\hline Sin autoras & 26 & 37,53 & 38 & 54,19 \\
\hline Ambas & 7 & 7,21 & 3 & 7,42 \\
\hline BMA & 11 & 15,03 & 20 & 20,55 \\
\hline EEF & 14 & 24,61 & 36 & 43,29 \\
\hline $\begin{array}{l}\text { Hay autoras, pero no son } \\
\text { principales }\end{array}$ & 8 & 14,52 & 27 & 26,38 \\
\hline Ambas & 4 & 4 & 3 & 4 \\
\hline BMA & 8 & 9,48 & 12 & 11,25 \\
\hline EEF & 7 & 10,25 & 19 & 15 \\
\hline La autora es principal & 9 & 17,21 & 23 & 32,89 \\
\hline Ambas & 3 & 2,45 & 0 & 2 \\
\hline BMA & 9 & 10,15 & 11 & 11,44 \\
\hline EEF & 9 & 13 & 19 & 18,78 \\
\hline
\end{tabular}

Fuente: elaboración propia a partir de los datos de Scopus.

\section{Indicadores de género}

En este apartado se presentan los indicadores de género que se encuentran en la Tabla 17 (Anexos), aplicados al número de autores (Tabla 15). Como ya se había visto en la sección de autores, el 24\% son mujeres y el $76 \%$ son hombres. La mayor parte de autores (hombres o mujeres) publicaron trabajos en el área de EEF. En las publicaciones multidiscuiplinares y de BMA la distribución vertical de las mujeres es superior a la de los hombres.

El índice de feminidad (IF) indica que por cada 100 hombres hay 32 mujeres en el agregado. El IF más alto se presenta en las publicaciones de BMA (37). Por su parte el índice de masculinidad (IM), es decir, número de hombres por cada 100 mujeres, fue de 317 en el agregado. El IM más alto se presentó en las publicaciones de EEF.

Al establecer la relación entre el IM y el IF, se puede indicar que dentro de un grupo de 100 personas, por cada mujer que publique en una revista multidisciplinar lo harán aproximadamente 9 hombres, en el área BMA por cada mujer habrá aproximadamente 7 autores hombres, y en el EEF esta relación será 1 a 13.

El indicador de segregación indica que considerando la proporción de autores y autoras, en relación con la población del mismo sexo, no hay señales de segregación en alguno de los tipos de publicación: multidisciplinar, BMA y EEF. Sin embargo, el índice de disimilitud establece que el $6,61 \%$ de los autores hombres deberían publicar en otra área para hubiera paridad completa.

En cuanto al índice de contribución al sexismo se aprecia que todas las áreas de publicación favorecen la masculinización, sin embargo, EEF es la que más la favorece al tener un valor superior a la unidad. De forma consistente, con un mayor IF, BMA es la que menos favorece la masculinización.

Finalmente, el indicador de interacción establece que un autor que publique en alguna de las tres áreas de ciencias económicas, tiene que en promedio por cada 10 autores, este interactuará con aproximadamente 8 hombres y 2 mujeres.

\section{Consideraciones finales}

El documento presentado muestra la combinación entre un análisis bibliométrico y de género. Aunque el debate sobre el papel de la mujer en el mundo académico se ha centrado en el estudio de los diversos fenómenos que podrían ser la causa de la brecha de género, son pocos los trabajos que busquen cuantificarla en la esfera de la producción y publicación académica. 
Tabla 15. Indicadores de género aplicados al sexo de los autores

\begin{tabular}{|l|c|c|c|c|}
\hline \multicolumn{1}{|c|}{ Variable } & Ambas & BMA & EEF & Total \\
\hline Hombres autores & 298 & 827 & 1274 & 2399 \\
\hline Mujeres autoras & 100 & 305 & 352 & 757 \\
\hline Total autores & 398 & 1132 & 1626 & 3156 \\
\hline Distribución horizontal hombres & $9,44 \%$ & $26,20 \%$ & $40,37 \%$ & $76,01 \%$ \\
\hline Distribución horizontal mujeres & $3,17 \%$ & $9,66 \%$ & $11,15 \%$ & $23,99 \%$ \\
\hline Distribución vertical hombres & $12,42 \%$ & $34,47 \%$ & $53,11 \%$ & $100,00 \%$ \\
\hline Distribución vertical mujeres & $13,21 \%$ & $40,29 \%$ & $46,50 \%$ & $100,00 \%$ \\
\hline Índice de feminidad (IF) & 34 & 37 & 28 & 32 \\
\hline Índice de masculinidad (IM) & 298 & 271 & 362 & 317 \\
\hline IM /IF & 8,88 & 7,35 & 13,10 & 10,04 \\
\hline Indicador de segregación & & & & 0,0660612 \\
\hline Índice de disimilaridad de Duncan & & & & $6,61 \%$ \\
\hline Índice de contribución al sexismo & 0,95619388 & 0,88631463 & 1,08987 & \\
\hline Índice de interacción & & & & 7,57589284 \\
\hline
\end{tabular}

Fuente: elaboración propia a partir de los datos de Scopus.

El análisis realizado permitió identificar que se presenta un fenómeno de masculinización de la producción académica de autores colombianos, en ciencias económicas. Si bien el número de autoras en Economía y Administración ha ido en aumento, su participación aún es limitada, pero debe aclararse que la incorporación de mujeres en la producción académica se ha incrementado más que la participación de los hombres.

El área con mayor tasa de autoras principales fue BMA con $26,3 \%$ y es precisamente el área en la cual hay mayor paridad en la autoría de artículos, $50,78 \%$ de los trabajos son escritos por hombres sin la participación de mujeres.

En términos absolutos, la revista en la cual más artículos con participación de mujeres han sido publicados durante el período, fue Cuadernos de Administración (98 trabajos, 42,9\%), seguida de la revista Innovar (87 trabajos, 42,5\%). Frente a las fuentes, se identificó también que la mayor parte de las revistas que concentran las publicaciones de mujeres son colombianas. Hubo 148 fuentes que habían publicado solamente trabajos de autores hombres en ciencias económicas. Los países con mayor publicación de artículos con participación de mujeres fueron Colombia (182), Holanda (94), Reino Unido (91) y Estados Unidos (83).

En los 1.313 trabajos analizados, participaron 3.156 autores, de los cuales sólo 756 eran mujeres, es decir el 24\%. En las publicaciones multidisciplinarias la participación de las mujeres fue de 25,1\%, en BMA 26,9\% y en EEF 21,6\%.

Adicionalmente, se identificó que los artículos tienen mayor probabilidad de impactar la producción académica posterior -es decir, al menos llegar a ser citado una vez-, si el autor principal es un hombre, pero cuenta con co-autoras. No obstante, los mejores indicadores en cuanto a reiteración de las cita- 
ciones (índices $\mathrm{H}, \mathrm{R}$ y A) los obtienen los artículos escritos por hombres sin co-autoría femenina.

Los indicadores de género calculados con respecto al número de autores, reiteran la brecha de género y la masculinización en la publicación científica de ciencias económicas, siendo EEF la que más contribuye a la masculinización, durante el período analizado. Sin embargo, los indicadores no evidencian que haya una dinámica de segregación en las tres áreas analizadas.

Para los futuros trabajos a realizar queda la pregunta latente de identificar ¿cuáles son los factores o las razones que explican el fenómeno de masculinización de la producción académica de autores colombianos en ciencias económicas?

\section{Referencias}

Abramo, G., Cicero, T. \& D'Angelo, C. (2014). Are the authors of highly cited articles also the most productive ones? Journal of Informetrics, 8(1): 89-97.

Abramo, G., D’Angelo, C. \& Murgia, G. (2013). Gender differences in research collaboration. Journal of Informetrics, 7(4): 811-822.

Albert, C. (2000). Higher education demand in Spain; the influence of labour market signals and family background. Higher Education, 40(2): 147-162.

Albert, C., González, C. \& Mora, J. (2011). Análisis de la evolución y caracterización de la demanda de educación universitaria en Colombia (Borradores de Economía y Finanzas, 28). Cali: ICESI. Disponible en: http://bibliotecadigital.icesi.edu.co/ biblioteca_digital/bitstream/10906/67533/1/analisis_evolucion_caracterizacion.pdf

Ale Ebrahim, N., Salehi, H., Embi, M., Habibi, F., Gholizadeh, H. \& Motahar, S. (2014). Visibility and Citation Impact. International Education Studies, 7(4): 120-125.

Aleixandre, R., González, G., Alonso, A., Castellano, M. \& Valderrama, J. (2007). Valoración de la paridad en la autoría de los artículos publicados en la Revista Enfermedades Infecciosas y Microbiología Clínica durante el quinquenio 2001-2005. Enfermedades Infecciosas y Microbiología Clínica, 25(10): 619-626.

Alonso, A., Aleixandre, R., Vidal, A., Anguita, M., Chorro, F., Bolaños, M., Castelló, L., Navarro, C. \& Valderrama, J. (2014). Publicaciones derivadas de las comunicaciones a los congresos anuales de la Sociedad Española de Cardiología. Revista Española de Cardiología, 67(1): 15-21.

Amodio, P. \& Brugnano, L. (2014). Recent advances in bibliometric indexes and the PaperRank problem. Journal of Computational and Applied Mathematics, 267: 182-194.

Araújo, J. \& Arencibia, R. (2002). Informetría, bibliometría y cienciometría: aspectos teórico-prácticos. ACIMED, 10 (4): 5-6.
Arencibia, R. \& Carvajal, R. (2008). Los índices H, G y R: su uso para identificar autores líderes en el área de la Comunicación durante el período 2001-2006. ACIMED, 17(4).

Arias, E., Velasco, J. \& Novo, M. (2016). Análisis bibliométrico sobre la investigación en violencia de género. Fundamentos y nuevas tendencias. Disponible en: https://www.researchgate.net/ profile/Esther_Arias/publication/296485748_ANALISIS_BIBLIOMETRICO_SOBRE_LA_INVESTIGACION_EN_VIOLENCIA_DE_GENERO_FUNDAMENTOS_Y_NUEVAS_TENDENCIAS_BIBLIOMETRIC_ANALYSIS_ON_INTIMATE_PARTNER_VIOLENCE_RESEARCH_BASIS_AND_NEW_TRENDS/ links/56d5dd7108aee1aa5f730caa.pdf

Arias, A. (2015). Nuevas aproximaciones metodológicas al estudio de la colaboración en la ciencia a través de las publicaciones científicas. [Tesis doctoral] Salamanca: Universidad de Salamanca. Disponible en: http://hdl.handle. net/10366/127969

Armfield, N., Edirippulige, S., Caffery, L., Bradford, N., Grey, J. \& Smith, A. (2014). Telemedicine - A bibliometric and content analysis of 17,932 publication records. International Journal of Medical Informatics, In Press, Corrected Proof.

Bailyn, L. (2003). Academic Careers and Gender Equity: Lessons Learned from MIT. Gender, Work and Organisation, 10(2): 137-153.

Benoit, M. (2015). Qui fait quoi? Analyse des libellés de contribution dans les articles savants [Tesis de Maestría]. Montreal: Université de Montreal. Disponible en: https://papyrus.bib. umontreal.ca/xmlui/handle/1866/12541

Bonilla,V., López de Méndez, A., Cintrón, M., Ramírez, S. \& Román, R. (2005). Feminización de la matrícula de Educación Superior en Puerto Rico. Disponible en: http://cie.uprrp.edu/ cuaderno/ediciones/20/pdf/c20art7.pdf

Bouyssou, D. \& Marchant, T. (2014). An axiomatic approach to bibliometric rankings and indices. Journal of Informetrics, 8(3): 449-477.

Brooks, C., Fenton, E. \& Walker, J. (2014). Gender and the evaluation of research. Research Policy, 43(6): 990-1001.

Brones, F., Monteiro de Carvalho, M. \& de Senzi Zancul, E. (2014). Ecodesign in project management: a missing link for the integration of sustainability in product development? Journal of Cleaner Production, 80(1): 106-118.

Brzezinski, M. (2014). Power Laws in Citation Distributions: Evidence from Scopus Disponible en: http://ssrn.com/abstract=2397685 or http://dx.doi.org/10.2139/ssrn.2397685

Bustos, O. \& Blázquez, N. (2003). Qué dicen las académicas acerca de la UNAM. México: UNAM.

Buquet, A., Cooper, J. \& Rodríguez, H. (2010). Sistema de indicadores para la equidad de género en instituciones de educación superior. México: UNAM. Disponible en: http:// www.pueg.unam.mx/images/stories/Equidad/Investigacion/ sist.\%20de\%20indicadores.pdf

Buquet, A., Cooper, J., Rodríguez, H. \& Botello, L. (2006). Presencia de mujeres y hombres en la UNAM: una radiografía. México: UNAM.

Buquet, A., Hernández, A. \& Jiménez, V. (2011). Diagnóstico de la situación de mujeres y hombres por dependencia. Instituto de Matemáticas de la UNAM. México D.F.: UNAM.

Caputo, C., Vargas, D. \& Requena, J. (2016). Desvanecimiento de la brecha de género en la universidad venezolana. Interciencia, 41(3): 154-161. 
Correa, M. (2003). Los géneros en la educación superior en Colombia. Santiago de Chile: Instituto Internacional para la Educación Superior en América Latina y el Caribe.

Costa, P. R. da. (2015). Inovação no ensino e aprendizagem em finanças: análise da literatura entre 2005 e 2015. [Tesis de maestría]. São Paulo: FECAP.

Daza, S. (2010). Las mujeres en el SNCTI. Balance de una década en condiciones diferentes. En OCyT, Indicadores de Ciencia y Tecnología (pp. 279-316). Bogotá: OCyT.

Daza, S. \& Pérez, T. (2008). Contando mujeres. Una reflexión sobre los indicadores de género y ciencia en Colombia. Revista de Antropología y sociología Virajes, 10: 29-51.

De Oliveira, M., Mazer, S., Guillaumon, M. \& Fernández, E. (2014). Análisis de la producción científica en Brasil sobre dificultades de aprendizaje: una revisión bibliométrica. Aula Abierta, 42(1): 31-38.

De Pablos, L. \& Gil, M. (2011). Las políticas de educación desde la perspectiva de género. Presupuesto y Gasto Público, 64: 179-208.

Delgado, E. (2016). ¿Evaluar la investigación con Google Scholar? Yes we can. Ponencia presentada en el V Seminario EC3, celebrado en Granada el 12 de junio de 2015. Disponible en: http://hdl.handle.net/10481/41069

Egghe, L. (2006). Theory and practise of the g-index. En: Scientometrics, 69(1): 131-152.

Eraso, L. (2016). La mujer en la medicina colombiana. Revista Medicina, 38(1): 73-81.

Escolano, E. (2006). Discriminación en un medio meritocrático: las profesoras en la Universidad española. Revista Mexicana de Sociología, 2, 231-263. Disponible en: http://www.revistas. unam.mx/index.php/rms/article/view/6055

Escolano, E. (2009). El poder como asignatura pendiente de las académicas en las universidades españolas. En: Chávez, M. A., Chávez, M.R, Ramírez, E., Cruz, M. \& Cervantes, G. Género y trabajo en las universidades (pp. 83-127). Guadalajara: Universidad de Guadalajara.

Estébañez, M. (2007). Género e investigación científica en las universidades latinoamericanas. Educación superior y sociedad, 1 (1): 1-26

Galvéz, J. (2009). La mujer a través del telescopio. Disponible en http://www.oei.es/cienciayuniversidad/spip.php?article109

García, P. (2009). Las académicas entre la materialidad política y la subjetividad. En: Chávez, M.A., Chávez, M.R, Ramírez, E., Cruz, M. \& Cervantes, G. Género y trabajo en las universidades (pp. 31-48). Guadalajara: Universidad de Guadalajara.

García, P. (2004). Mujeres académicas: el caso de una universidad estatal mexicana. México: Plaza y Valdés. Universidad de Guadalajara.

García, P. (1992). Notas sobre la participación de la mujer académica en la Universidad de Guadalajara. Revista Tiempo de Ciencia, 28: 33-36.

González, B., Guerrero, V. \& Moya, F. (2009). The SJR indicator: A new indicator of journals' scientific prestige. Tech. Rep. arxiv:abs/0912.4141 [cs.DL]. Consultado el 10 de junio de 2010 en http://arxiv.org/ftp/arxiv/papers/0912/0912.4141.pdf.

Gregorio, O., Méndez, C. \& Peralta, M. (2015). Acercamiento bibliométrico a las revistas científicas colombianas de ciencias sociales: comparación y nuevas miradas hacia la evaluación y categorización a partir de ISI WoS y Scielo Citation Index. IV Jornadas de Intercambio y Reflexión acerca de la Investigación en Bibliotecología. Disponible en: http://hdl.handle. net/10915/52479
Grupo Scimago (2007). "El índice h de Hirsch: su aplicación a algunos de los científicos españoles más destacados". El profesional de la información, 16(1): 47-49.

Filippo, D. \& Fernández, M. (2002). Bibliometría: importancia de los indicadores bibliométricos. El estado de la ciencia: principales indicadores deficiencia y tecnología iberoamericanos/interamericanos. Disponible em: http://www.ricyt.org/ component/docman/doc_view/113-bibliometria-importanciade-los-indicadores-bibliometricos?Itemid $=2$

Hagen, N. (2014). Reversing the byline hierarchy: the effect of equalizing bias on the accreditation of primary, secondary and senior authors. Journal of Informetrics, 8(3): 618-627.

Hirsch, J. (2005).An index to quantify an individual's scientific research output, Proceedings of the National Academy of Sciences, 102 (46): 16569-16572.

Jatobá, I. \& Gomes, J. (2012). Cartografia digital: o software philcarto no ensino da geocartografia. Revista Metáfora Educacional, 12: 49-65.

Jin, B., Liang L., Rousseau, R. \& Egghe, L. (2007). The R- and AR-indices: Complementing the h- index. Chinese Science Bulletin, 52(6): 855-863.

Joyce, C., Kelly, J. \& Sugrue, C. (2014). A bibliometric analysis of the 100 most influential papers in burns. Burns, 40(1): 30-37.

Kretschmer, H. \& Aguillo, I. (2005). New indicators for gender studies in Web networks. Information Processing \& Management, 41(6): 1481-1494.

Koc, E. \& Boz, H. (2014). Triangulation in tourism research: A bibliometric study of top three tourism journals. Tourism Management Perspectives, 12: 9-14.

Lemarchand, G. (ed.) (2010). Sistemas Nacionales de ciencia, tecnología e innovación en América Latina y el Caribe. Montevideo: Unesco.

Lis-Gutiérrez, J-P. (2012). Análisis de los grupos de investigación colombianos en ciencias económicas desde una perspectiva de género. Revista de la Facultad de Ciencias Económicas, XX (2): 143-164

López, M. \& de Pablos, J. (2013). El" índice h" en las estrategias de visibilidad, posicionamiento y medición de impacto de artículos y revistas de investigación. Investigar la Comunicación hoy. Revisión de políticas científicas y aportaciones metodológicas: Simposio Internacional sobre Política Científica en Comunicación, 133-150.

Lozano, I. \& Rodríguez, Y. (2012). Análisis de los índice H, G Y R en el sector agropecuario cubano a través de Scopus, 2005-2009. Anales de Documentación, 15(1): 1-17.

Lozano, I., Iglesias, M. \& Martínez, M. (2016). Un estudio cualitativo sobre los diferenciales de género en la educación superior: percepciones de las académicas en contextos masculinizados. La manzana de la discordia, 11 (1): 41-54.

López, J., Basora, J., Orozco, D. \& Bellón, J. (2014a). Mapa bibliométrico de la investigación realizada en atención primaria en España durante el periodo 2008-2012. Atención Primaria, In Press, Corrected Proof.

López, S., Svider, P. Misra, P., Bhagat, N., Langer, P. \& Eloy, J. (2014b). Gender differences in promotion and scholarly impact: an analysis of 1460 academic ophthalmologists. Journal of Surgical Education, In Press, Corrected Proof.

Lozano, I. \& Rodríguez, Y. (2012). Análisis de los índice H, G Y R en el sector agropecuario cubano a través de Scopus, 2005-2009. Anales de Documentación, 15(1): 1-17. 
Machado, C., Saraiva de Souza, M., dos Santos Parisotto, I. \& Palmisano, A. (2016). As Leis da Bibliometria em Diferentes Bases de Dados Científicos. Ciencias da Administraçao, 18(44): 111-123.

Martínez, J., Ríos, J., Meroño, A., Martínez, J. \& del-Baño, M. (2014). Caracterización de la base intelectual de la fisioterapia a través del análisis de cocitación de documentos. Fisioterapia, 36(4): 167-176.

Melo, H. (2013). Avaliação da Produção Acadêmica da Revista Gestão \& Regionalidade de 2005 a 2012 através de Bibliometria e Sociometria. Gestão e Sociedade, 7 (18). Doi: http:// dx.doi.org/10.21171/ges.v7i18.1899

Observatorio Colombiano de Ciencia y Tecnología OCyT (2009). Indicadores de Ciencia y Tecnología, 2008. Bogotá: Observatorio Colombiano de Ciencia y Tecnología. Disponible en: http://ocyt.org.co/es-es/InformeAnuallndicadores/ArtMID/542/ArticleID/17/Libro-de-Indicadores-de-Ciencia-yTecnolog237a-2008

Ortega, E., Valdivia, P., Olmedilla, A., Martínez, M. \& Villarejo, D. (2015). Estudio bibliométrico del papel de la mujer en las tesis doctorales de ciencias del deporte. Journal of Sport and Health Research, 7(2): 139-148.

Ortiz, E. \& Hidalgo, Y. (2016). Detección de comunidades a partir de redes de coautoría en grafos RDF. Revista Cubana de Información en Ciencias de la Salud, 27(1): 90-99.

Papadópulos, J. \& Radakovich, R. (2006). Educación superior y género en América Latina y el Caribe. En: Informe sobre la Educación Superior en América Latina y el Caribe 2000-2005. La metamorfosis de la educación superior. Caracas: UNESCO, IESALC.

Pérez, T. (2012). Miércoles de ciencia y tecnología. Un Radio. Podcast disponible en http://www.unradio.unal.edu.co/detalle/ cat/un-analisis/article/mujeres-cientificas.html

Portugal, M., Carvalho, J., Ribeiro de Almeida, M. \& Reis, N. (2014). Mergers \& acquisitions research: A bibliometric study of top strategy and international business journals, 1980-2010. Journal of Business Research, In Press.

Pritchard, A. (1969). Statistical bibliography or bibliometrics. Journal of documentation, 25: 348-349.

Ponomariov, B. \& Toivanen, H. (2014). Knowledge flows and bases in emerging economy innovation systems: Brazilian research 2005-2009. Research Policy, 43(3): 588-596.

Rehn, C., \& Kronman, U. (2008). Bibliometric handbook for Karolinska Institutet. Huddinge: Karolinska Institutet.

Requena, J., Vargas, D. \& Caputo, C. (2016). Género en la ciencia venezolana: desvanecimiento de la brecha. Interciencia, 41(3) , 162-170. Disponible en http://www.interciencia. org/v41_03/162.pdf

Restrepo, C. \& Urbizagástegui, R. (2016). Métrica de la literatura sobre los indígenas de México. Encontros Bibli: revista eletrônica de biblioteconomia e ciência da informação, 21(46): 104-120.

Rubio, M. (1999). Bibliometría y ciencias sociales. Clio, 7. Disponible en http://clio.rediris.es/numero007.html. Consultado el 20 de septiembre de 2010.

SCImago (2016). SJR - SCImago Journal \& Country Rank. Disponible en: http://www.scimagojr.com

Scopus (2016). Content overview. Disponible en: http://www. elsevier.com/online-tools/scopus/content-overview

Schreiber, M. (2014). Examples for counterintuitive behavior of the new citation-rank indicator P100 for bibliometric evaluations. Journal of Informetrics, 8(3): 738-748.
Si Niu, X. (2014). International scientific collaboration between Australia and China: A mixed-methodology for investigating the social processes and its implications for national innovation systems. Technological Forecasting and Social Change, 85: 58-68.

Silva Andrade, L., de Paiva, A., de Castro Alcântara, V. \& Brito, M. (2016). Desvelando o Campo da Estratégia como Prática e suas Relações, Iberoamerican Journal of Strategic Management, 15(1).

Sos Peña, R. (2015). La influencia de las primeras psicólogas norteamericanas en la historia de la psicología. Revista de Historia de la Psicología, 36(2): 31-46.

Tomei, K., Nahass, M., Husain, Q., Agarwal, N., Patel, S., Svider, P., Eloy, J. \& Liu, J. (2014). A gender-based comparison of academic rank and scholarly productivity in academic neurological surgery. Journal of Clinical Neuroscience, 21(7): 1102-1105.

Tovar, P. (2002). Género y ciencia en Colombia: Algunos indicadores. En: Colombia Ciencia y Tecnología, 20 (2). Bogotá: Colciencias.

Tovar, P. (2004). Indicadores nacionales de género, ciencia y tecnología. En: Memorias seminario: Las mujeres colombianas en el sistema de ciencia y tecnología: obstáculos y logros. Bogotá: ICANH. Abril 19-21 de 2006.

Tovar, P. (2005). La percepción que tienen los colombianos sobre la ciencia y la tecnología: la importancia de tener una perspectiva de género. En: Aguirre, J. (ed.). La percepción que tienen los colombianos sobre la ciencia y la tecnología. Bogotá: Colciencias.

Túñez, M. \& de Pablos, J. (2013). El "índice h" en las estrategias de visibilidad, posicionamiento y medición de impacto de artículos y revistas de investigación. En: Pacheco, M., Rueda, M., Mariño, V. \& González, T. (coords.). 2º Congreso Nacional sobre Metodología de la Investigación en Comunicación ( $p$. 133-150). Valladolid: Facultad de Ciencias Sociales, Jurídicas y de la Comunicación.

UNESCO (2009). S\&T World Data Fact Sheet. Montreal: Unesco. Valcárcel de Laiglesia, M., Alfonso, F., Miró, O., Casademont, J., Burbano Santos, P., Burillo, G., Fernández, C. \& Martín, F. (2014). Characteristics and Longevity of Electronic Citations in Four Leading Biomedical Journals in Spain. Revista Española de Cardiología (English Edition), In Press.

Veiga, D., Conforto, G., Malheiros, M., Carneiro, M., Cohen, M. \& da Silveira, C. (2014). Níveis de evidência da cirurgia de joelho em periódicos nacionais. Revista Brasileira de Ortopedia, 49(1): 13-16.

Vieira, E., Cabral, J. \& Gomes, J. (2014). How good is a model based on bibliometric indicators in predicting the final decisions made by peers? Journal of Informetrics, 8(2): 390-405.

Yu, C., Davis, C. \& Dijkema, G. (2014). Understanding the Evolution of Industrial Symbiosis Research (April 2014). Journal of Industrial Ecology, 18(2): 280-293.

Weiss, D., Kovshilovskaya, B. \& Breyer, B. (2012). Gender Trends of Urology Manuscript Authors in the United States: A 35Year Progression. The Journal of Urology, 187(1): 253-258.

Zapata, M. (2010). La equidad de género en las universidades alemanas. En: Mingo, A. (ed.) Desasosiegos. Relaciones de género en la educación (pp. 109-150). México D.F.: Instituto de Investigaciones sobre la Universidad y la Educación, UNAM. 


\section{ANEXOS}

Tabla 16. Citas recibidas por los documentos sobre desarrollo territorial (1975-2010)

\begin{tabular}{|c|c|c|c|c|c|c|c|}
\hline $\begin{array}{l}\text { Número } \\
\text { de citas }\end{array}$ & $\begin{array}{l}\text { N. de artículos } \\
\text { (frecuencia) } \\
\text { Ambas }\end{array}$ & $\begin{array}{c}\text { N. de artículos (frecuencia) } \\
\text { Business, Management and } \\
\text { Accounting }\end{array}$ & $\begin{array}{l}\text { N. de artículos (frecuen- } \\
\text { cia) Economics, Econo- } \\
\text { metrics and Finance }\end{array}$ & $\begin{array}{l}\text { N. de artículos } \\
\text { (frecuencia) } \\
\text { Total }\end{array}$ & $\begin{array}{c}\% \\
\text { documentos }\end{array}$ & $\begin{array}{l}\text { Total de } \\
\text { citas }\end{array}$ & $\%$ citas \\
\hline 1 & 25 & 56 & 90 & 171 & $13,02 \%$ & 171 & $4,2 \%$ \\
\hline 2 & 4 & 30 & 53 & 87 & $6,63 \%$ & 174 & $4,2 \%$ \\
\hline 3 & 5 & 24 & 30 & 59 & $4,49 \%$ & 177 & $4,3 \%$ \\
\hline 4 & 2 & 7 & 17 & 26 & $1,98 \%$ & 104 & $2,5 \%$ \\
\hline 5 & 2 & 10 & 14 & 26 & $1,98 \%$ & 130 & $3,2 \%$ \\
\hline 6 & 2 & 9 & 15 & 26 & $1,98 \%$ & 156 & $3,8 \%$ \\
\hline 7 & 2 & 4 & 11 & 17 & $1,29 \%$ & 119 & $2,9 \%$ \\
\hline 8 & & 4 & 8 & 12 & $0,91 \%$ & 96 & $2,3 \%$ \\
\hline 9 & & 2 & 4 & 6 & $0,46 \%$ & 54 & $1,3 \%$ \\
\hline 10 & 1 & 2 & 5 & 8 & $0,61 \%$ & 80 & $1,9 \%$ \\
\hline 11 & & 2 & 7 & 9 & $0,69 \%$ & 99 & $2,4 \%$ \\
\hline 12 & & 2 & 4 & 6 & $0,46 \%$ & 72 & $1,7 \%$ \\
\hline 13 & & 4 & 10 & 14 & $1,07 \%$ & 182 & $4,4 \%$ \\
\hline 14 & & & 3 & 3 & $0,23 \%$ & 42 & $1,0 \%$ \\
\hline 15 & 1 & 2 & & 3 & $0,23 \%$ & 45 & $1,1 \%$ \\
\hline 16 & & 3 & 2 & 5 & $0,38 \%$ & 80 & $1,9 \%$ \\
\hline 17 & & 2 & 2 & 4 & $0,30 \%$ & 68 & $1,7 \%$ \\
\hline 18 & 1 & 1 & 5 & 7 & $0,53 \%$ & 126 & $3,1 \%$ \\
\hline 19 & & 1 & 3 & 4 & $0,30 \%$ & 76 & $1,8 \%$ \\
\hline 20 & & 1 & 4 & 5 & $0,38 \%$ & 100 & $2,4 \%$ \\
\hline 21 & & & 2 & 2 & $0,15 \%$ & 42 & $1,0 \%$ \\
\hline 22 & 1 & & 2 & 3 & $0,23 \%$ & 66 & $1,6 \%$ \\
\hline 23 & & 1 & 2 & 3 & $0,23 \%$ & 69 & $1,7 \%$ \\
\hline 24 & & & 1 & 1 & $0,08 \%$ & 24 & $0,6 \%$ \\
\hline 25 & & & 2 & 2 & $0,15 \%$ & 50 & $1,2 \%$ \\
\hline 26 & & 1 & 1 & 2 & $0,15 \%$ & 52 & $1,3 \%$ \\
\hline 27 & & & 2 & 2 & $0,15 \%$ & 54 & $1,3 \%$ \\
\hline 29 & & 1 & & 1 & $0,08 \%$ & 29 & $0,7 \%$ \\
\hline
\end{tabular}




\begin{tabular}{|c|c|c|c|c|c|c|c|}
\hline $\begin{array}{l}\text { Número } \\
\text { de citas }\end{array}$ & $\begin{array}{l}\text { N. de artículos } \\
\text { (frecuencia) } \\
\text { Ambas }\end{array}$ & $\begin{array}{c}\text { N. de artículos (frecuencia) } \\
\text { Business, Management and } \\
\text { Accounting }\end{array}$ & $\begin{array}{l}\text { N. de artículos (frecuen- } \\
\text { cia) Economics, Econo- } \\
\text { metrics and Finance }\end{array}$ & $\begin{array}{l}\text { N. de artículos } \\
\text { (frecuencia) } \\
\text { Total }\end{array}$ & $\begin{array}{c}\% \\
\text { documentos }\end{array}$ & $\begin{array}{l}\text { Total de } \\
\text { citas }\end{array}$ & $\%$ citas \\
\hline 30 & & & 1 & 1 & $0,08 \%$ & 30 & $0,7 \%$ \\
\hline 31 & & & 1 & 1 & $0,08 \%$ & 31 & $0,8 \%$ \\
\hline 39 & 1 & & 1 & 2 & $0,15 \%$ & 78 & $1,9 \%$ \\
\hline 40 & & 1 & & 1 & $0,08 \%$ & 40 & $1,0 \%$ \\
\hline 41 & & & 2 & 2 & $0,15 \%$ & 82 & $2,0 \%$ \\
\hline 42 & & & 1 & 1 & $0,08 \%$ & 42 & $1,0 \%$ \\
\hline 43 & & & 1 & 1 & $0,08 \%$ & 43 & $1,0 \%$ \\
\hline 46 & & & 1 & 1 & $0,08 \%$ & 46 & $1,1 \%$ \\
\hline 48 & & & 1 & 1 & $0,08 \%$ & 48 & $1,2 \%$ \\
\hline 50 & & & 1 & 1 & $0,08 \%$ & 50 & $1,2 \%$ \\
\hline 52 & & & 2 & 2 & $0,15 \%$ & 104 & $2,5 \%$ \\
\hline 54 & & 1 & & 1 & $0,08 \%$ & 54 & $1,3 \%$ \\
\hline 59 & & & 1 & 1 & $0,08 \%$ & 59 & $1,4 \%$ \\
\hline 60 & & 1 & & 1 & $0,08 \%$ & 60 & $1,5 \%$ \\
\hline 61 & & 1 & & 1 & $0,08 \%$ & 61 & $1,5 \%$ \\
\hline 66 & & & 1 & 1 & $0,08 \%$ & 66 & $1,6 \%$ \\
\hline 69 & & 1 & & 1 & $0,08 \%$ & 69 & $1,7 \%$ \\
\hline 73 & & 1 & 1 & 2 & $0,15 \%$ & 146 & $3,5 \%$ \\
\hline 82 & & & 2 & 2 & $0,15 \%$ & 164 & $4,0 \%$ \\
\hline 87 & & & 1 & 1 & $0,08 \%$ & 87 & $2,1 \%$ \\
\hline 96 & & & 1 & 1 & $0,08 \%$ & 96 & $2,3 \%$ \\
\hline 122 & & & 1 & 1 & $0,08 \%$ & 122 & $3,0 \%$ \\
\hline 0 & 98 & 235 & 439 & 772 & $58,80 \%$ & 0 & $0,0 \%$ \\
\hline Total & 145 & 410 & 758 & 1313 & $100,00 \%$ & 4.115 & $100,0 \%$ \\
\hline
\end{tabular}

Fuente: elaboración propia a partir de los datos de Scopus. 
Tabla 17. Indicadores de gênero calculados

\begin{tabular}{|c|c|c|c|}
\hline Indicador & Explicación & Cálculo & Interpretación \\
\hline $\begin{array}{l}\text { Distribución } \\
\text { horizontal }\end{array}$ & $\begin{array}{l}\text { Participación relativa de mujeres y } \\
\text { hombres en un ambiente i determi- } \\
\text { nado. }\end{array}$ & $\begin{array}{l}\text { Dh }=\left[\left(\frac{X i j}{T i}\right)\right] * 100 \\
\text { Donde xij es la cantidad de personas en el ambiente } \\
\text { i del sexo j; y Ti es el total de personas en el am- } \\
\text { biente i. }\end{array}$ & $\begin{array}{l}\text { Porcentaje de personas del sexo j dentro } \\
\text { del total de la población en el ambiente i. }\end{array}$ \\
\hline $\begin{array}{l}\text { Distribución } \\
\text { vertical }\end{array}$ & $\begin{array}{l}\text { Concentración de los individuos de } \\
\text { un mismo sexo entre los distintos } \\
\text { nombramientos, actividades, carre- } \\
\text { ras o planteles. }\end{array}$ & $\begin{array}{l}\text { Dv }=[(\mathrm{Xij} / \mathrm{Tj})]^{\star 100} \\
\text { Siendo xij la cantidad de personas en el nombra- } \\
\text { miento, ocupación, carrera o plantel i del sexo j; y Tj } \\
\text { es el total de personas del sexo j. }\end{array}$ & $\begin{array}{l}\text { Porcentaje de personas del sexo j en el } \\
\text { nombramiento, actividad, carrera o plan- } \\
\text { tel i, dentro del total de la población del } \\
\text { sexo j. }\end{array}$ \\
\hline $\begin{array}{l}\text { Índice de } \\
\text { feminidad }\end{array}$ & $\begin{array}{l}\text { Número de mujeres por cada } 100 \\
\text { hombres dentro de una población } 0 \\
\text { conjunto en estudio. }\end{array}$ & $\begin{array}{l}\text { Es el cociente entre el número de mujeres y el nú- } \\
\text { mero de hombres en una población } \\
\text { IF }=\left[\left(\frac{\mathrm{Xm}}{\mathrm{Xh}}\right)\right] * 100 \\
\text { Donde xm es la cantidad de mujeres y xh es la canti- } \\
\text { dad de hombres dentro de una población o conjunto } \\
\text { en estudio }\end{array}$ & $\begin{array}{l}\text { Número de mujeres por cada } 100 \text { hom- } \\
\text { bres. }\end{array}$ \\
\hline $\begin{array}{l}\text { Índice de } \\
\text { masculini- } \\
\text { dad }\end{array}$ & $\begin{array}{l}\text { Número de hombres por cada } 100 \\
\text { mujeres dentro de una población } 0 \\
\text { conjunto en estudio. }\end{array}$ & $\begin{array}{l}\text { Es el cociente entre el número de hombres y el nú- } \\
\text { mero de mujeres en una población } \\
\text { IF }=\left[\left(\frac{\mathrm{Xh}}{\mathrm{Xm}}\right)\right] * 100 \\
\text { Donde xm es la cantidad de mujeres y xh es la canti- } \\
\text { dad de hombres dentro de una población o conjunto } \\
\text { en estudio. }\end{array}$ & $\begin{array}{l}\text { Número de hombres por cada } 100 \text { mu- } \\
\text { jeres. }\end{array}$ \\
\hline $\begin{array}{l}\text { Índice de } \\
\text { Duncan } \\
\text { (indicador } \\
\text { de } \\
\text { segrega- } \\
\text { ción) }\end{array}$ & $\begin{array}{l}\text { Porcentaje de mujeres y de hom- } \\
\text { bres que tendrían que cambiar de } \\
\text { nombramiento, de puesto o de ca- } \\
\text { rrera para que hombres y mujeres } \\
\text { estuvieran distribuidos de manera } \\
\text { equitativa. }\end{array}$ & $\begin{aligned} I D= & \frac{1}{2} \sum \underset{i=1}{\mathrm{i}=\mathrm{n}} \mid \frac{\text { Mujeres en la ocupación } \mathrm{i}}{\text { Empleo total femenino }}- \\
& \frac{\text { Hombres en la ocupación } \mathrm{i}}{\text { empleo total masculino }} \mid\end{aligned}$ & $\begin{array}{l}\text { Con este índice se calcula la diferencia } \\
\text { entre la proporción de individuos del gru- } \\
\text { po minoritario }(X) \text { y la proporción del res- } \\
\text { to de población. Este índice puede tomar } \\
\text { cualquier valor comprendido entre } 0 \text { y } 1 \text {, } \\
\text { y cuanto más alto sea el valor, expresa } \\
\text { mayor grado de segregación. Donde no } \\
\text { hay segregación, el índice de Duncan es } \\
\text { igual a cero. El valor } 1 \text { implica segrega- } \\
\text { ción completa; cada ocupación es com- } \\
\text { pletamente masculina o femenina. }\end{array}$ \\
\hline $\begin{array}{l}\text { Índice de } \\
\text { disimila- } \\
\text { ridad de } \\
\text { Duncan } \\
\text { (IDD) } \\
\text { por sexo }\end{array}$ & $\begin{array}{l}\text { Proporción de hombres (mujeres) } \\
\text { que deberían cambiar de ocupación } \\
\text { para mantener una proporción de } \\
\text { hombres y mujeres en la ocupación } \\
\text { igual a la que se registra a nivel del } \\
\text { total de ocupados }\end{array}$ & $\begin{array}{l}\mathrm{D}=\frac{1}{2} \sum_{\mathrm{j}=1}^{\mathrm{j}=\mathrm{n}}\left|\left(\frac{\mathrm{Fj}}{\mathrm{F}}\right)-\left(\frac{\mathrm{Mj}}{\mathrm{M}}\right)\right| * 100 \\
\text { Fj es el número de mujeres en la ocupación j, F es } \\
\text { el total de mujeres ocupadas, Mj es el número de } \\
\text { hombres en la ocupación j y M es el total de hom- } \\
\text { bres ocupados. }\end{array}$ & $\begin{array}{l}\text { Porcentaje del total de ocupados que de- } \\
\text { bería cambiar de ocupación para lograr } \\
\text { una correspondencia exacta entre la pro- } \\
\text { porción de mujeres en cada ocupación } \\
\text { y la proporción de mujeres en el total de } \\
\text { ocupados. } \\
\text { El índice de Duncan varía desde un valor } \\
\text { mínimo de } 0 \text { (cero), cuando no existe se- } \\
\text { gregación y la proporción de mujeres es } \\
\text { igual en todas las ocupaciones, hasta un } \\
\text { valor máximo de } 100 \text { cuando existen sólo } \\
\text { ocupaciones que son } 100 \% \text { masculinas } 0 \\
100 \% \text { femeninas. }\end{array}$ \\
\hline
\end{tabular}




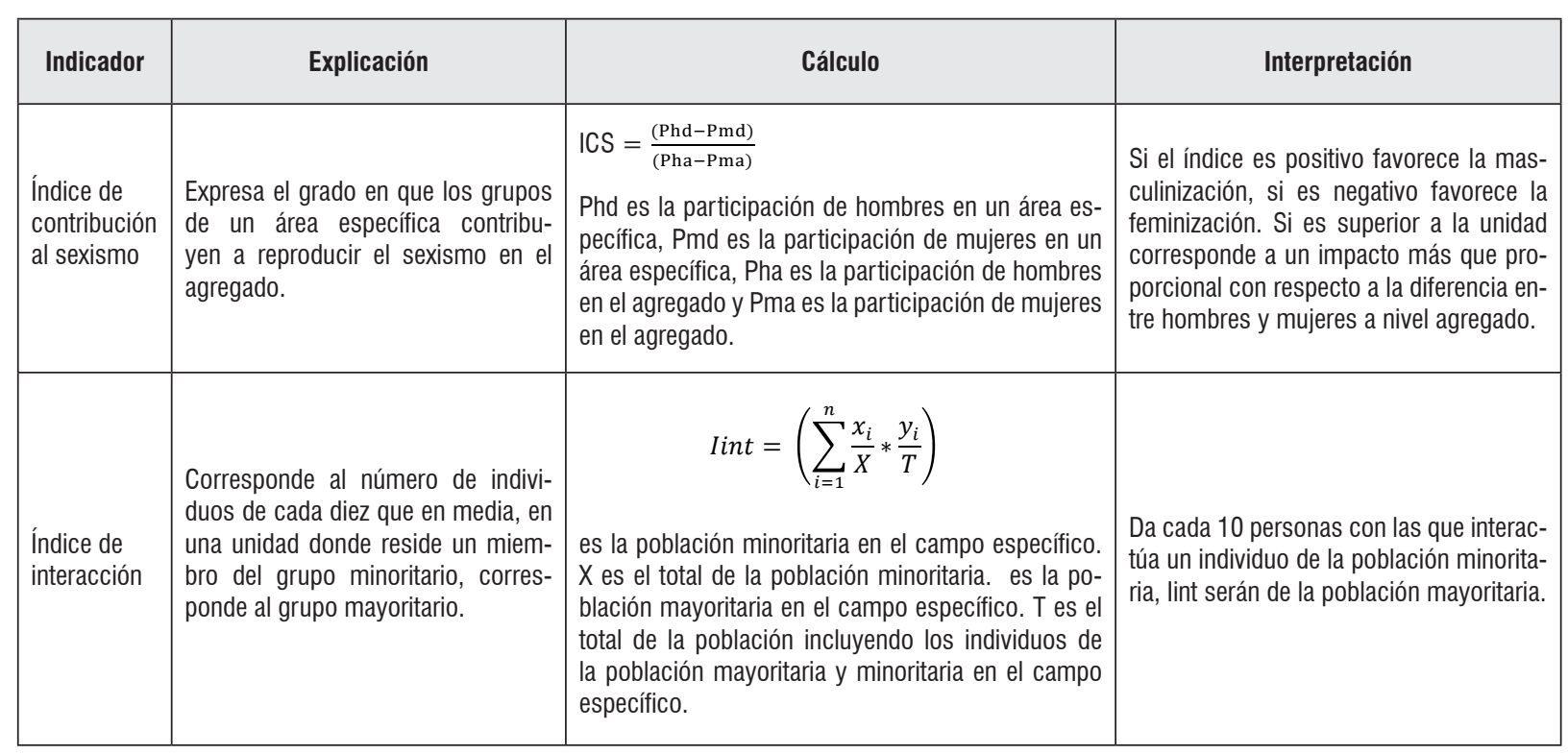

Fuente: Lis-Gutiérrez (2012). 


\section{NUESTRO NÚMERO ANTERIOR OUR LAST ISSUE NOSSA ÚLTIMA EDIÇÃO}

\section{VOL. XXIII (1)}

Miranda, S. \& Macri, M. (2015). Patrones de género en la práctica del trabajo infantil: el caso de las niñas jornaleras en la región florícola del Estado de México En: Revista de la Facultad de Ciencias Económicas de la Universidad Militar Nueva Granada. rev.fac.cienc.econ, XXIII (1), 7 - 21.

Restrepo, A., Sarmiento, J. \& Gómez, A. (2015). Participación laboral de las mujeres en el municipio de Popayán (Colombia). En: Revista de la Facultad de Ciencias Económicas de la Universidad Militar Nueva Granada. rev.fac.cienc.econ, XXIII (1), 23-51.

Muñoz, S., Ruíz, G. \& Sarmiento, H. (2015). Didácticas para la formación en investigación contable: una discusión crítica de las prácticas de enseñanza. En: Revista de la Facultad de Ciencias Económicas de la Universidad Militar Nueva Granada. rev.fac.cienc.econ, XXIII (1), 53-86.

Vásquez, N. \& Patiño, R. (2015). El subsistema de formación contable en Colombia y México. En: Revista de la Facultad de Ciencias Económicas de la Universidad Militar Nueva Granada. rev.fac. cienc.econ, XXIII (1), 87-102.

Correa, F. (2015). Una revisión analítica sobre el papel de la tierra en la teoría económica de David Ricardo. En: Revista de la Facultad de Ciencias Económicas de la Universidad Militar Nueva Granada. rev.fac.cienc.econ, XXIII (1), 103-114.

Burbano, E. (2015). Reestructuración sectorial en el Putumayo: una dinámica de "tres velocidades". En: Revista de la Facultad de Ciencias Económicas de la Universidad Militar Nueva Granada. rev.fac.cienc.econ, XXIII (1), 105-139.

Ramírez, A. (2015). Ajuste de una función de producción al sector financiero en Colombia. En: Revista de la Facultad de Ciencias Económicas de la Universidad Militar Nueva Granada. rev.fac. cienc.econ, XXIII (1), 141-156.

Pletsch, C., Reif, E. \& Da Silva, T. (2015). Análise da relação entre o valor econômico agregado (EVA) $e$ os indicadores do mercado de empresas brasileiras. En: Revista de la Facultad de Ciencias Económicas de la Universidad Militar Nueva Granada. rev.fac.cienc.econ, XXIII (1), 157-173.

Almeida, P., Carpes, N. \& Klann, R. (2014). Concentração de propriedade e o impairment loss sobre o goodwill: investigação empírica no contexto das companhias abertas brasileiras. En: Revista de la Facultad de Ciencias Económicas de la Universidad Militar Nueva Granada. rev.fac.cienc.econ, XXIII (1), 175-188.

Morales, M., Sanabria, P. \& Caballero, D. (2015). Características de la vinculación universidad entorno en la Universidad Nacional de Colombia. En: Revista de la Facultad de Ciencias Económicasde la Universidad Militar Nueva Granada. rev.fac. cienc.econ, XXIII (1), 189-208.

Sanabria, M., Saavedra, J. \& Smida, A. (2015). Los estudios críticos en administración: origen, evolución y posibilidades de aporte al desarrollo del campo de los estudios organizacionales en América Latina. En: En: Revista de la Facultad de Ciencias Económicas de la Universidad Militar Nueva Granada. rev. fac.cienc.econ, XXIII (1), 209-234.

Higuita, D. (2015). Hábitos y habitus en la transformación cultural: estudio de una organización del sector energético. En: Revista de la Facultad de Ciencias Económicas de la Universidad Militar Nueva Granada. rev.fac.cienc.econ, XXIII (1), 235-250.

Pedraza, N., Lavín, J., Delgado, G. \& Bernal, I. (2015) Prácticas de liderazgo en empresas comerciales en Tamaulipas (México). En: Revista de la Facultad de Ciencias Económicas de la Universidad Militar Nueva Granada. rev.fac.cienc.econ, XXIII (1), 251-265.

Millán, A., Montoya, I. \& Montoya, L. (2015). Análisis de las decisiones estratégicas: caso une EPM Telecomunicaciones. En: Revista de la Facultad de Ciencias Económicas de la Universidad Militar Nueva Granada. rev.fac.cienc.econ, XXIII (1), 267-287.

\section{VOL. XXIII (2)}

Ramírez, Y., Ávila, C. \& Arias. I. (2015) Factores que inciden en la probabilidad de permanecer en la informalidad en Colombia (2008-2012): un análisis de la medidas de política pública.. En: Revista de la Facultad de Ciencias Económicas de la Universidad Militar Nueva Granada. rev.fac.cienc.econ, XXIII (2).

Silva Filho, L., Silva, F. \& Queiroz, S. (2015) Jovens no mercado de trabalho formal brasileiro: uma análise quantitativa. En: Revista de la Facultad de Ciencias Económicas de la Universidad Militar Nueva Granada. rev.fac.cienc.econ, XXIII (2).

Zayas, P., Báez, R., Zayas, J. \& Hernández, M. (2015). Causas de la satisfacción laboral en una organización comercializadora mayorista. En: Revista de la Facultad de Ciencias Económicas de la Universidad Militar Nueva Granada. rev.fac.cienc. econ, XXIII (2).

Campos, L. (2016) Medición alternativa del bienestar: aplicación del índice abreviado del bienestar a la encuesta de presupuesto familiar en Venezuela. En: Revista de la Facultad de Ciencias Económicas de la Universidad Militar Nueva Granada. rev. fac.cienc.econ, XXIII (2)

Caridad, M., Castellanos, M. \& Hernandez, M. (2015). Marketing experiencial para la promoción del proceso educativo a nivel de pregrado: un estudio de dos universidades privadas En: Revista de la Facultad de Ciencias Económicas de la Universidad Militar Nueva Granada. rev.fac.cienc.econ, XXIII (2).

Parra, L. \& Argote, M. (2015). Factores asociados a las empresas con potencial de crecimiento en la Universidad EAN. En: Revista de la Facultad de Ciencias Económicas de la Universidad Militar Nueva Granada. rev.fac.cienc.econ, XXIII (2). 
Fagundes, J., Crespo, C., Ripoll, V. \& Ferreira, M. (2015). Indicadores para o gerenciamento de faculdades: um estudo de dois casos na Espanha. En: Revista de la Facultad de Ciencias Económicas de la Universidad Militar Nueva Granada. rev.fac. cienc.econ, XXIII(2).

Castillo, O., Kerguelen, M. \& Negrette, M. (2015). Microeconomía de la producción de ganado vacuno de carne en el valle medio del rio sinú (Montería - Colombia): un estudio de caso. En: Revista de la Facultad de Ciencias Económicas de la Universidad Militar Nueva Granada. rev.fac.cienc.econ, XXIII (2).

Hurtado, E. \& Escamilla, J. (2015). Modelo de gestión de la demanda energética integral. En: Revista de la Facultad de Ciencias Económicas de la Universidad Militar Nueva Granada. rev.fac.cienc.econ, XXIII (2).

Rodríguez, G. \& Tarazona, O. (2015). Unidades de emprendimiento bajo un estudio de eficiencia relativa. En: Revista de la Facultad de Ciencias Económicas de la Universidad Militar Nueva Granada. rev.fac.cienc.econ, XXIII (2).

Zepeda-Mercado, G. (2015). Sincronización cíclica del sector manufacturero de México y Estados Unidos desde una perspectiva no lineal autorregresiva con transición suave. En: Revista de la Facultad de Ciencias Económicas de la Universidad Militar Nueva Granada. rev.fac.cienc.econ, XXIII (2).

Moreno, J. (2015) Los orígenes contemporáneos del centralismo fiscal en las relaciones intergubernamentales en México (19701990). En: Revista de la Facultad de Ciencias Económicas de la Universidad Militar Nueva Granada. rev.fac.cienc.econ, XXIII (2).

Pinzón, J. (2015). Análisis del comportamiento del impuesto ICA en el presupuesto del Distrito Capital (1996 - 2005). En: Revista de la Facultad de Ciencias Económicas de la Universidad Militar Nueva Granada. rev.fac.cienc.econ, XXIII (2). 


\section{ÍNDICE DE AUTORES}

En esta sección se encuentran los diferentes autores que ha publicado en la Revista Facultad de Ciencias Económicas, en el segundo número de 2016. Estos son presentados en orden alfabético.

\begin{tabular}{|c|c|c|}
\hline & Vol. & Pág. \\
\hline \multicolumn{3}{|l|}{ A } \\
\hline (Arruda, D.) Daniel Arruda Coronel & XXIV (2) & 85 \\
\hline \multicolumn{3}{|l|}{ B } \\
\hline (Bahos-Olivera, C-A.) Clorith-Angélica Bahos-Olivera & XXIV (2) & 183 \\
\hline (Bender, R.) Reisoli Bender Filho & XXIV (2) & 85 \\
\hline \multicolumn{3}{|l|}{ C } \\
\hline (Campo, J.) Jacobo Campo Robledo & XXIV (2) & 29 \\
\hline (Chacón, G.) Galia Beatriz Chacón Parra & XXIV (2) & 111 \\
\hline \multicolumn{3}{|l|}{ D } \\
\hline (Da Silva, T.) Tarcísio Pedro Da Silva & XXIV (2) & 47 \\
\hline \multicolumn{3}{|l|}{ G } \\
\hline (González, D.) Diana Xóchitl González Gómez & XXIV (2) & 7 \\
\hline (Guse, J.) Jaqueline Carla Guse & XXIV (2) & 47 \\
\hline (Grigion, A.) Ani Caroline Grigion Potrich & XXIV (2) & 85 \\
\hline \multicolumn{3}{|l|}{$\mathbf{H}$} \\
\hline (Herrera, M.) Margarita Herrera Avilés & XXIV (2) & 133 \\
\hline \multicolumn{3}{|l|}{$\mathbf{L}$} \\
\hline (Leite, M.) Maurício Leite & XXIV (2) & 47 \\
\hline (Lis-Gutiérrez, J-P.) Jenny-Paola Lis-Gutiérrez & XXIV (2) & 183 \\
\hline \multicolumn{3}{|l|}{ M } \\
\hline (Mendes, K.) Kelmara Mendes Vieira & XXIV (2) & 85 \\
\hline (Mendoza, H.) Henry Antonio Mendoza Tolosa & XXIV (2) & 29 \\
\hline (Molina, O.) Olga Rosa Molina De Paredes & XXIV (2) & 111 \\
\hline \multicolumn{3}{|l|}{0} \\
\hline (Ortiz, D.) Diana Carolina Ortiz Motta & XXIV (2) & 161 \\
\hline \multicolumn{3}{|l|}{$\mathbf{P}$} \\
\hline (Pantoja, S.) Sebastián David Pantoja Barrios & XXIV (2) & 147 \\
\hline (Pantoja, F.) Freddy Hernán Pantoja Timarán & XXIV (2) & 147 \\
\hline
\end{tabular}




\begin{tabular}{|l|c|c|}
\hline $\mathbf{R}$ & & \\
\hline (Restrepo, A.) Amanda Lucía Restrepo Londoño & XXIV (2) & 63 \\
\hline (Rojas, E.) Eli Saul Rojas Ruiz & XXIV (2) & 111 \\
\hline S & & 133 \\
\hline (Sánchez, S.) Sandra Sánchez Peñaflor & XXIV (2) & 63 \\
\hline (Sepúlveda, C.) Claudia Inés Sepúlveda Rivillas & XXIV (2) & \\
\hline $\mathbf{V}$ & & 7 \\
\hline (Velázquez, D.) Daniel Velázquez Orihuela & XXIV (2) & 161 \\
\hline (Vergara, C.) Carlos Andrés Vergara Tamayo & XXIV (2) & \\
\hline
\end{tabular}




\section{PAUTAS PARA LOS AUTORES}

La Revista Facultad de Ciencias Económicas: Investigación y Reflexión de la Universidad Militar "Nueva Granada" es una publicación científica, semestral, dedicada a la difusión de temas relacionados con la Administración de Empresas, la Contaduría Pública y la Economía. La Revista es un medio de expresión para que las comunidades vinculadas a la Facultad de Ciencias Económicas, a la Universidad Militar y a otras instituciones (estatales, públicas no estatales, privadas, gremios y asociaciones), a quienes está dirigida, pongan a circular su conocimiento y los resultados de sus investigaciones. Su principal objetivo es convertirse en un espacio en el que las comunidades de investigadores reflexionen sobre la realidad de la economía y las organizaciones colombianas y por ese medio contribuyan a la construcción de un modelo de desarrollo adecuado con dicha realidad y con los retos que ella implica.

Las opiniones de los artículos son responsabilidad exclusiva de los autores y, si bien son avalados en términos del rigor conceptual y metodológico por el editor de la revista y su Comité Editorial, no comprometen a la Universidad Militar "Nueva Granada".

Las pautas que debe cumplir un texto para que sea considerado para su evaluación y publicación por el Comité Editorial de la Revista son las siguientes:

- El autor debe enviar su artículo por correo electrónico a: economia. neogranadina@unimilitar.edu.co,en dos archivos así:

- El primer archivo contendrá el texto en Word, un resumen analítico del artículo, en inglés y en castellano, y de 5 a 6 palabras clave, en los dos idiomas. Contendrá además los siguientes datos:

Los datos del artículo: Se señalará con un asterisco en el título la naturaleza del artículo. Se debe especificar si el artículo es producto de una investigación, tesis de grado, ensayo o reseña crítica. Si es producto de investigación, debe señalarse el título del proyecto, la entidad financiadora y la fecha de realización. Los datos del autor: Se señalarán con dos asteriscos en los nombres y apellidos completos, así:

Formación académica: títulos obtenidos e instituciones que los otorgaron

Cargo e institución actual.

Grupo de investigación al cual se encuentra vinculado, si es el caso.

- El segundo archivo contendrá los cuadros en Excel, los gráficos o diagramas en Word o Power Point. En caso de adjuntar imágenes jpg, se solicita una resolución no inferior a $300 \mathrm{dpi}$.

- El artículo debe presentarse en Word, letra Garamond 12, con texto justificado. Su extensión no debe superar las 40 páginas, tamaño carta, con espacio sencillo entre líneas y doble entre párrafos. Cuando el texto del artículo incluya ecuaciones matemáticas, éstas se deben realizar utilizando el editor de ecuaciones de Word.

- Las referencias bibliográficas deben figurar dentro del texto utilizando el sistema parentético (Apellido, año, página). Las notas a pie de página se utilizarán sólo para aportes sustantivos al texto.
- La citación de las referencias se hará al final del artículo, de la siguiente forma:

Libro. Apellido, Inicial del nombre (año). Título del libro. Ciudad: Editorial.

Artículo de revista. Apellido, Inicial del nombre (año) "Título del artículo". En: Nombre de la revista, Institución, volumen (número): páginas.

Capítulo de libro. Apellido, Inicial del nombre (año). "Título del capítulo". En: Apellido, Inicial del nombre (Eds.). Título del libro. Ciudad: Editorial.

Trabajo no publicado (mimeo). Apellido, Inicial del nombre (año). Título. Trabajo no publicado. Ciudad: Institución.

Tesis de grado no publicada. Apellido, Inicial del nombre (año). Título de la tesis. Tesis de grado no publicada. Ciudad: Institución, Facultad.

Ponencia presentada a un evento. Apellido, Inicial del nombre (año). Título de la ponencia. Nombre del evento. Ciudad y fecha (mes y días).

Documento electrónico. Apellido, Inicial del nombre (fecha de publicación o recuperación). "Título del documento". Nombre del documento completo. Disponible en: dirección electrónica.

- $\quad$ El texto debe acompañarse de una carta de remisión, dirigida al editor, en la que se postula el artículo para su evaluación y se afirma que es un producto original que no ha sido presentado a ninguna otra publicación.

- La edición de la revista acusará recibo de los artículos en un plazo no mayor a ocho días hábiles.

- La presentación de un artículo no constituye compromiso alguno para su publicación. Ésta se encuentra sujeta a la revisión por parte de evaluadores anónimos, quienes conceptuarán sobre cada artículo y formularán observaciones que deberán ser tenidas en cuenta por los autores.

- $\quad$ En caso de ser aprobado por los evaluadores, al autor del artículo suscribirá una comunicación en la que autoriza su publicación en las versiones impresa y electrónica de la Revista de la Facultad de Ciencias Económicas.

- La Revista de la Facultad de Ciencias Económicas privilegiará la publicación de artículos producto de investigación así como reflexiones teóricas y críticas sólidas sobre temas relacionados con las ciencias económicas (economía, administración de empresas y contaduría pública). A este respecto, serán privilegiados los artículos que clasifiquen dentro de las categorías 1, 2 y 3 propuestas por Colciencias.

- La Revista de la Facultad de Ciencias Económicas supone la originalidad del artículo conforme a las normas vigentes sobre derechos de autor, así como su carácter inédito. Supone además, que en caso de aceptación, no será publicado por otro medio, salvo autorización expresa del Comité Editorial. 


\section{AUTHORS' GUIDELINES}

The Revista Facultad de Ciencias Económicas: Investigación y Reflexión of Nueva Granada Military University is a biannual scientific publication whose aim is to convey issues dealing with Business Management, Public Accounting and Economics. The Review is a mean of expression so that the communities part of the Faculty of Economic Sciences, Military University, and other institutions (government, public non-government, private, and associations), to whom it is aimed, make known their knowledge and the result of their research. Its main purpose is to become a means in which the research community reflects on the reality of the Colombian economy and organizations, and through this they contribute to the construction of an adequate development model within the set reality and taking into consideration the challenges implied.

The opinions expressed in the articles are the sole responsibility of the authors and, although they are accepted taking into consideration their conceptual and methodological rigor by the editor of the review and the editorial committee, they do not compromise the University.

The parameters a text must meet to be considered for its evaluation and publication by its editorial committee are as follows:

- The author must send the article by e-mail to economia.neogranadina@unimilitar.edu.co in two files thus:

- The first file will have the text in Word, an analytical abstract of the article, in English and in Spanish, and with five or six keywords in both languages. It will also have the following information:

Information on the article: with an asterisk in the title the nature of the article will be given it must be specified whether the article is the result of research, graduation project, essay or review. If it is the result of research the title of the project must be indicated as well as the financing entity and the date it was carried out.

Information on the author: with two asterisks the full names and last names will be indicated thus:

Academic education: titles and institutions granting them.

Present position and institution

Research group to which the author is part of if such is the case.

- The second file will have graphs in Excel, graphs or diagrams in Word or Power Point. In case jpg images are enclosed a resolution not lower than $300 \mathrm{dpi}$ is requested.

- The article must be submitted in word, Garamond 12, justified. It must not be longer than 40 pages, letter size, single space between lines and double between paragraphs. When the text includes mathematical equations, they must be done using Word's equations editor.
- Bibliographic references must be within the text using the last name, year, page system. Footnotes will be used only to provide meaningful support to the text.

- References will come at the end of the article thus:

- Book. Last name, first name initials, year, Title of Book. City, Publisher.

- Magazine article. Last name, first name initials, year. "Title of article" In: Name of the magazine, institution, volume, number, pages.

Book chapter. Last name, first name initials, "Title of chapter". In: Last name, first name initials (Eds). Book title. City. Publisher. Not Published work (mimeograph). Last name, first name initials, year. Title. Not published work. City. Institution.

Not Published Graduation Project. Last name, first name initials, year. Graduation Project Title. Not Publisher graduation Project. City. Institution. Faculty.

Lecture in an event. Last name, first name initials, year. Title of lecture. Name of event. City and date (month and days).

Electronic Document. Last name, first name initials (Publication or recovery date). "Title of document". Name of full document. Available in: e-mail address.

- Text must be sent with an introduction setter to the editor in which the article is submitted for its evaluation and where it is stated that it is an original work that has not been submitted to any other publication.

- The review will inform receipt of articles no later than eight working days.

- The submittal of an article doesn't imply the obligation to publish it. To do so, it is subject to review by anonymous evaluators who will provide their opinion on each article and will provide observations that must be taken into account by the authors.

- Should the article be approved by evaluators, the author will send written communication authorizing its publication in the printed and electronic versions of the Revista de la Facultad de Ciencias Económicas.

- The Revista de la Facultad de Ciencias Económicas will select articles result of research as well as solid theoretical and critical reflections on issues dealing with economic sciences (Economics, Business Management and Public Accounting). Regarding this, articles classifying within the 1,2 and 3 categories proposed by Colciencias will be considered first.

- The Revista de la Facultad de Ciencias Económicas assumes the article is an original in agreement with the copyright norms in force as well as its unpublished character. In addition, it assumes that should it be accepted it will not be published by any other means except with express authorization by the editorial committee. 


\section{PAUTAS PARA OS AUTORES}

A Revista Facultad de Ciencias Económicas: Investigación y Reflexión de la Universidad Militar "Nueva Granada" é uma publicação científica, semestral, dedicada à difusão de temas relacionados com a Administração de Empresas, com a Contabilidade Pública e com a Economia. A Revista é um meio de expressão para que as comunidades vinculadas à Faculdade de Ciências Econômicas, à Universidade Militar e a outras instituições (estatais, públicas não estatais, privadas, grêmios e associações), a quem está dirigida, ponham a circular seu conhecimento e os resultados de suas pesquisas. Seu principal objetivo é tornar-se um espaço no qual as comunidades de pesquisadores reflitam sobre a realidade da economia e das organizações colombianas e por esse meio contribuam à construção de um modelo de desenvolvimento adequado com esta realidade e com os desafios que ela apresenta.

As opiniões dos artigos são responsabilidade exclusiva dos autores e por isso são avalizados nos termos do rigor conceitual e metodológico pelo editor da revista e seu Comitê Editorial e não comprometem a Universidade Militar "Nueva Granada".

As pautas que deve cumprir um texto para que seja considerado para sua avaliação e publicação pelo Comitê Editorial da Revista são as seguintes:

- O autor deve enviar seu artigo por correio eletrônico a: economia. neogranadina@unimilitar.edu.co, em dois arquivos da seguinte maneira:

- O primeiro arquivo conterá o texto em Word, um resumo analítico do artigo em inglês e em castelhano, e entre 5 e 6 palavras chave, nos dois idiomas. Além disto, conterá os seguintes dados: Os dados do artigo: Indicar-se-á com um asterisco no título a natureza do artigo. Deve-se especificar se o artigo é produto de uma pesquisa, trabalho final de conclusão de curso, ensaio ou resumo crítico. Se o texto é produto de pesquisa, deve-se indicar o título do projeto, a entidade financiadora e a data da realização. Os dados do autor: Indicar-se-ão com dois asteriscos os nomes e sobrenomes completos, da seguinte forma: Formação acadêmica: títulos obtidos e instituições que os outorgaram. Cargo e instituição atual. Grupo de investigação ao qual se encontra vinculado, se for o caso.

O segundo arquivo conterá os quadros em Excel, os gráficos ou diagramas em Word ou Power Point. Caso tenha imagens em.jpg, solicita-se uma resolução não inferior a 300 dpi. 0 artigo deve apresentar-se em Word, letra Garamond 12, com texto justificado. Sua extensão não deve superar as 40 páginas, tamanho carta, com espaço simples entre linhas e duplo entre parágrafos. Quando o texto do artigo inclua equações matemáticas, estas devem se realizar utilizando o editor de equações de Word.

- As referências bibliográficas devem aparecer dentro do texto, utilizando o sistema parentético (Sobrenome, ano, página). As notas de pé de página serão utilizadas somente para contribuições substanciais ao texto. A citação das referências se fará ao final do artigo, da seguinte forma:

Livro: Sobrenome, Inicial do nome (ano). Título do livro. Cidade: Editorial.

Artigo de revista:Sobrenome, Inicial do nome (ano) "Título do artigo". Em: Nome da revista, Instituição, volume (número): páginas. Capítulo de livro: Sobrenome, Inicial do nome (ano). "Título do capítulo". Em: Sobrenome, Inicial do nome (Eds.). Título do livro. Cidade: Editorial.

Trabalho não publicado (mimeo): Sobrenome, Inicial do nome (ano). Título. Trabalho não publicado. Cidade: Instituição.

Trabalhos de conclusões de cursos (TCC, monografias, dissertação de mestrado, tese de doutorado): Sobrenome, Inicial do nome (ano). Título do trabalho. Tese (ou dissertação...) não publicada. Cidade: Instituição, Faculdade.

Conferência apresentada a um evento: Sobrenome, Inicial do nome (ano). Título da conferência. Nome do evento. Cidade e data (mês e dias).

Documento eletrônico: Sobrenome, Inicial do nome (data de publicação ou recuperação). "Título do documento". Nome do documento completo. Disponível em: direção eletrônica.

- O texto deve estar acompanhado de uma carta dirigida ao editor, na qual se propõe o artigo para sua avaliação e se afirma que é um produto original que não foi apresentado a nenhuma outra publicação.

- A edição da revista acusará o recebimento dos artigos num prazo não superior a oito dias úteis.

- A apresentação de um artigo não constitui compromisso algum com sua publicação. Esta se encontra sujeita à revisão por parte de avaliadores anônimos, que conceituarão sobre cada artigo e formularão observações que deverão ser tidas em conta pelos autores.

- Caso seja aprovado pelos avaliadores, o autor do artigo assinará uma comunicação na que autoriza sua publicação nas versões impressa e eletrônica da Revista da Faculdade de Ciências Econômicas.

- A Revista da Faculdade de Ciências Econômicas privilegiará a publicação de artigos produto de pesquisa bem como reflexões teóricas e críticas sólidas sobre temas relacionados com as ciências econômicas (economia, administração de empresas e contabilidade pública). Neste sentido serão privilegiados os artigos que se classifiquem dentro das categorias 1, 2 e 3, propostas por Colciencias.

- A Revista da Faculdade de Ciências Econômicas supõe a originalidade do artigo conforme as normas vigentes sobre direitos autorais, bem como seu caráter inédito. Além disto, supõe que em caso de aceitação, não será publicado por outro meio, salvo com autorização expressa do Comitê Editorial. 


\section{Revista Facultad de Ciencias Económicas: Investigación y Reflexión}

ISSN 0121-6805 / ISSN ON LINE: 1909-7719

Universidad Militar Nueva Granada

Facultad de Ciencias Económicas - Centro de Investigaciones Económicas Carrera II No. I0 I-80, bloque C primer piso Bogotá, Colombia - Teléfono 6500000 Ext. I 306

Correo electrónico: economia.neogranadina@unimilitar.edu.co

Suscripción personal / Personal suscription / assinatura pessoal

\begin{tabular}{|l|l|l|l|}
\hline $\begin{array}{l}\text { Nombres } \\
\text { y apellidos: }\end{array}$ & Name: & Nome: & \\
\hline D.l.: & D.I.: & D.l.: & \\
\hline Dirección: & Address: & Endereço: & \\
\hline Ciudad: & City: & Cidade: & \\
\hline Teléfono: & Phone: & Telefone: & \\
\hline Fax: & Fax: & Fax: & \\
\hline $\begin{array}{l}\text { Correo } \\
\text { electrónico: }\end{array}$ & Email: & Email: & \\
\hline Profesión: & Profession: & Profissão: & \\
\hline Ocupación: & Occupation: & Profissão: & \\
\hline
\end{tabular}

Suscripción institucional / institutional subscription / assinatura institucional

\begin{tabular}{|l|l|l|l|}
\hline Institución & Institution & Instituição & \\
\hline Responsable & Responsible & Responsável & \\
\hline Dirección: & Address: & Endereço: & \\
\hline Ciudad: & City: & Cidade: & \\
\hline Teléfono: & Phone: & Telefone: & \\
\hline Fax: & Fax: & Fax: & \\
\hline $\begin{array}{l}\text { Correo } \\
\text { electrónico: }\end{array}$ & Email: & Email: & \\
\hline
\end{tabular}




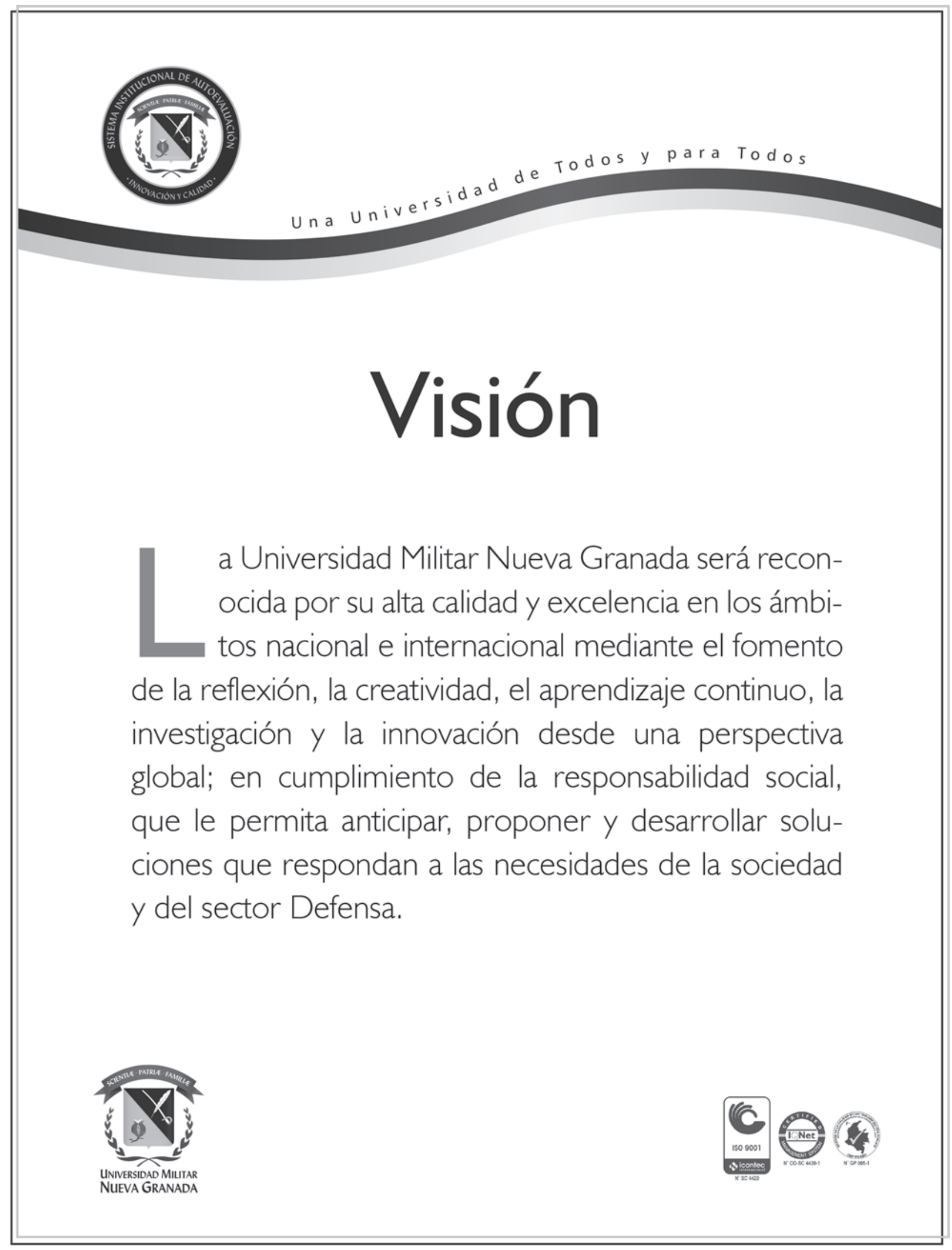




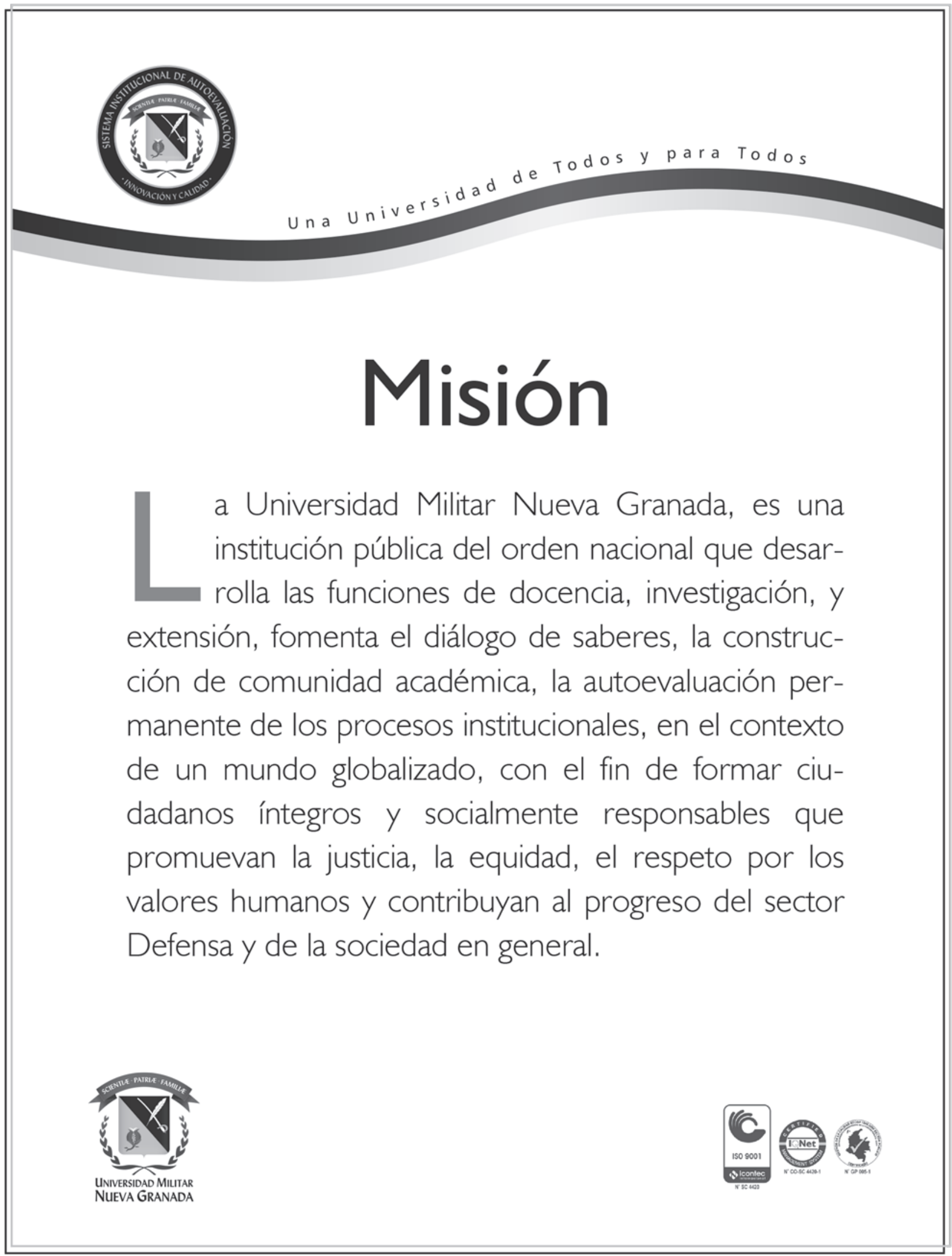




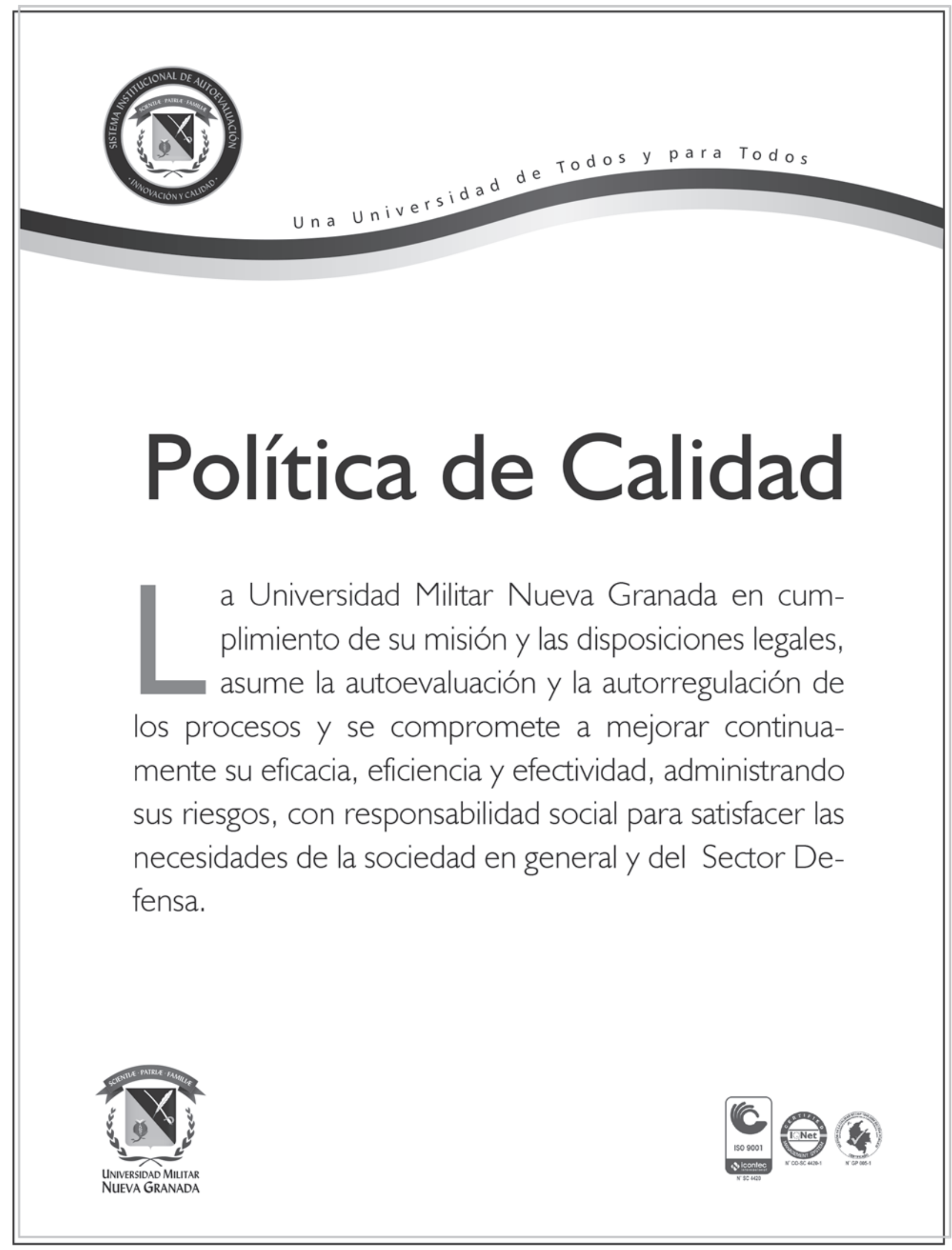




\section{wWw.umng.edu.co}

(571) $6343200-6500000$

Línea gratuita

018000111019



Conócela, la U para todos

Sede principal

Calle 100 con carrera 11
Sede Facultad de Medicina y Ciencias de la Salud Transversal 3, junto al Hospital Militar Central
Sede Campus Nueva Granada $\mathrm{Km} 2$ de la vía Cajicá-Zipaquirá 
Conócela, la U para todos

Sede principal

Calle 100 con carrera 11
Sede Facultad de Medicina y Ciencias de la Salud Transversal 3, junto al Hospital Militar Central

\section{wWw.umng.edu.co}

(571) 6343200 - 6500000

Línea gratuita

018000111019



\section{Giencias Económicas}

Con una Tecnología en Contabilidad y Tributaria; tres programas de pregrado en Economía, Contaduría Pública y Administración de Empresas; ocho especializaciones, y una maestría, la Facultad de Ciencias Económicas de la UMNG forma a los profesionales con mayor proyección en el país.

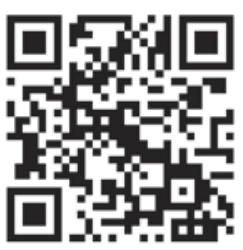

a 710 19. 둔



UNIVERSIDAD MILITAR

NuEVA GRANADA

LaU para todos

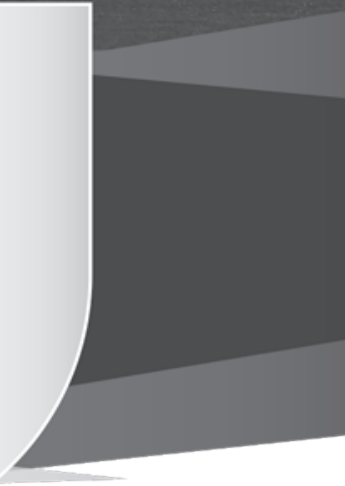

Sede Campus Nueva Granada $\mathrm{Km} 2$ de la vía Cajicá-Zipaquirá 